\title{
Nondestructive Methods to Characterize Rock Mechanical Properties at Low-Temperature: Applications for Asteroid Capture Technologies
}

\author{
Kara A. Savage
}

Follow this and additional works at: https://researchrepository.wvu.edu/etd

\section{Recommended Citation}

Savage, Kara A., "Nondestructive Methods to Characterize Rock Mechanical Properties at LowTemperature: Applications for Asteroid Capture Technologies" (2016). Graduate Theses, Dissertations, and Problem Reports. 6573.

https://researchrepository.wvu.edu/etd/6573

This Thesis is protected by copyright and/or related rights. It has been brought to you by the The Research Repository @ WVU with permission from the rights-holder(s). You are free to use this Thesis in any way that is permitted by the copyright and related rights legislation that applies to your use. For other uses you must obtain permission from the rights-holder(s) directly, unless additional rights are indicated by a Creative Commons license in the record and/ or on the work itself. This Thesis has been accepted for inclusion in WVU Graduate Theses, Dissertations, and Problem Reports collection by an authorized administrator of The Research Repository @ WVU. For more information, please contact researchrepository@mail.wvu.edu. 


\title{
Nondestructive Methods to Characterize Rock Mechanical Properties at Low-Temperature: Applications for Asteroid Capture Technologies
}

\author{
Kara A. Savage \\ Thesis Submitted \\ to the Statler College of Engineering \\ at West Virginia University \\ in partial fulfillment of the requirements for the degree of \\ Master of Science in \\ Mining Engineering
}

Aaron Noble, Ph.D., Chair

Brijes Mishra, Ph.D.

Thomas Evans, Ph.D.

Department of Mining Engineering

Morgantown, West Virginia

2016

Keywords: Nondestructive Tests, Low-Temperature Rock Mechanics, Schmidt Rebound Hammer, Ultrasonic Pulse Velocity, Asteroid Capture Copyright 2016 Kara A. Savage 


\begin{abstract}
Nondestructive Methods to Characterize Rock Mechanical Properties at Low-Temperature: Applications for Asteroid Capture Technologies
\end{abstract}

\author{
Kara A. Savage
}

Recent government initiatives and commercial activities have targeted asteroids for in situ material characterization, manipulation, and possible resource extraction. Most of these activities and missions have proposed significant robotic components, given the risks and costs associated with manned missions. To successfully execute these robotic activities, detailed mechanical characteristics of the target space bodies must be known prior to contact, in order to appropriately plan and direct the autonomous robotic protocols. Unfortunately, current estimates of asteroid mechanical properties are based on limited direct information, and significant uncertainty remains specifically concerning internal structures, strengths, and elastic properties of asteroids. One proposed method to elucidate this information is through in situ, nondestructive testing of asteroid material immediately after contact, but prior to any manipulation or resource extraction activities. While numerous nondestructive rock characterization techniques have been widely deployed for terrestrial applications, these methods must be adapted to account for unique properties of asteroid material and environmental conditions of space. For example, asteroid surface temperatures may range from $-100^{\circ} \mathrm{C}$ to $-30^{\circ} \mathrm{C}$ due to diurnal cycling, and these low-temperatures are especially noteworthy due to their deleterious influence on non-destructive testing.

As a result, this thesis investigates the effect of low-temperature on the mechanical characteristics and nondestructive technique responses of rock material. Initially, a novel method to produce low-temperature rock samples was developed. Dry ice and methanol cooling baths of specific formulations were used to decrease rock to temperatures ranging from $-60^{\circ} \mathrm{C}$ to $0^{\circ} \mathrm{C}$. At these temperatures, shale, chalk, and limestone rock samples were exposed to several nondestructive and conventional mechanical tests, including Schmidt hammer, ultrasonic pulse velocity, point load, and uniaxial compression. Experimental results show that rock mechanical properties (i.e. uniaxial compressive strength and Young's modulus) and nondestructive test responses (i.e. P-wave velocity and Schmidt rebound) are both influenced by low-temperature, and the nature of the response depends on the rock type. Chalk and limestone show increased Young's moduli and decreased Schmidt rebounds and P-wave velocities with decreased temperature, while shale shows decreased Young's modulus and increased $\mathrm{P}$-wave velocity. A significant increase in uniaxial compressive strength is observed for limestone samples with decreased temperature, though the inconsistent strength of chalk and shale samples at room temperature impaired the significance of correlations between decreased temperature and strength change for these samples. Altogether, these results indicate that ultrasonic pulse velocity and impact hammer methods may be suitable for in situ characterization of asteroid material; however, these methods will require temperature correction factors. 


\section{Acknowledgements}

I would like to express my sincerest appreciation to my committee chair and research advisor, Dr. Aaron Noble, Assistant Professor of Mining Engineering at West Virginia University. His persistent commitment, assistance, guidance, and encouragement throughout my studies have contributed greatly to the completion of this thesis and my work. Dr. Noble's relentless dedication to his students drives them to perform beyond their own expectations. With his profound brilliance, Dr. Noble poses thought-provoking challenges to make students think about the underlying causes of their research results. I feel very privileged to have worked under Dr. Aaron Noble, and the quality of my research, writing, and intellect have improved greatly as a result.

I would also like to thank my committee members, Dr. Brijes Mishra, professor of Mining Engineering at West Virginia University, and Dr. Thomas Evans, Assistant Professor in Mechanical and Aerospace Engineering and Research Program Manager of the WV Robotic Technology Center. Their continual support and concern with my research helped guide the results of this thesis.

In addition, thank you to the other Mining Engineering faculty at West Virginia University who provided me assistance and reassurance throughout my graduate studies. Thanks as well to the students I met at West Virginia University that inspired me to always strive for improvement.

I would like to acknowledge the NASA Space Technology Research Grants Program for funding the efforts of this thesis. This work was supported by an Early Stage Innovations grant from NASA's Space Technology Research Grants Program. 


\section{Table of Contents}

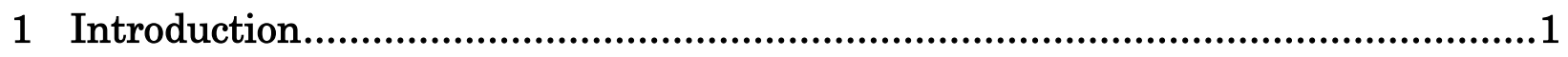

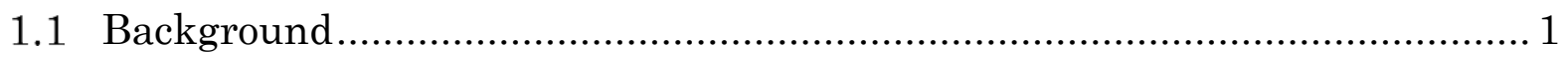

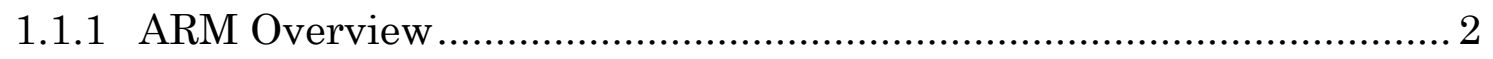

1.1.2 Asteroid Capture and Rendezvous..................................................... 4

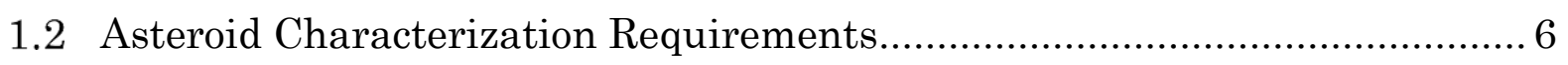

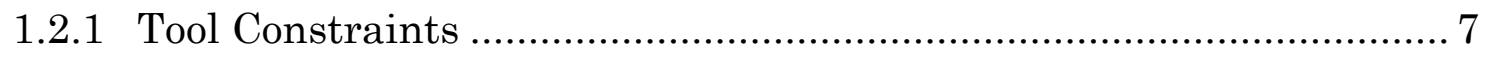

1.2.2 Estimating Mechanical Properties from NDTs ……........................... 7

1.2.3 Uncertainities in Mechanical Properties of Asteroids ......................... 8

1.2.4 Low-Temperature Rock Mechanics..................................................... 9

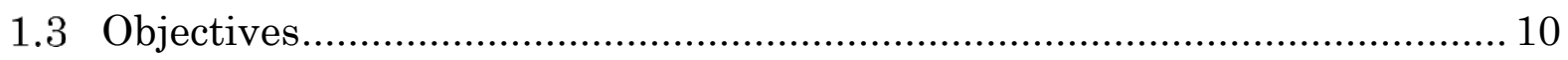

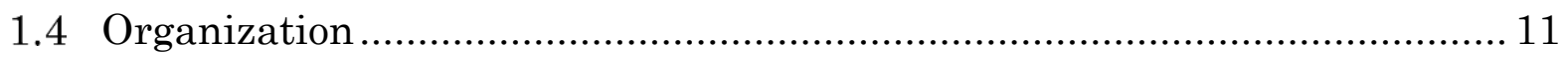

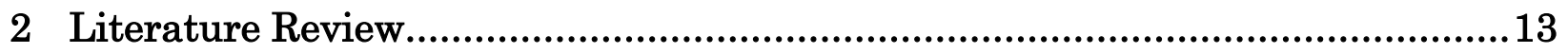

2.1 Test Methods for Strength Characterization ............................................. 13

2.1.1 Destructive Methods....................................................................... 14

2.1.2 Nondestructive Methods .................................................................. 19

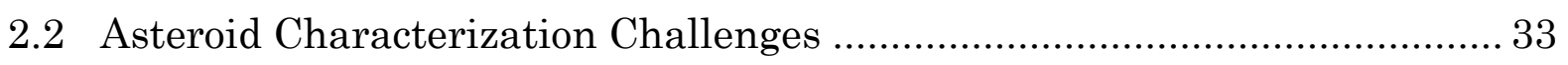

2.2.1 Target Near-Earth Asteroids ........................................................... 34

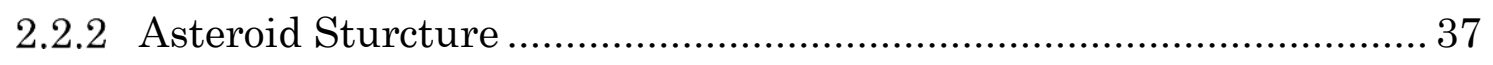

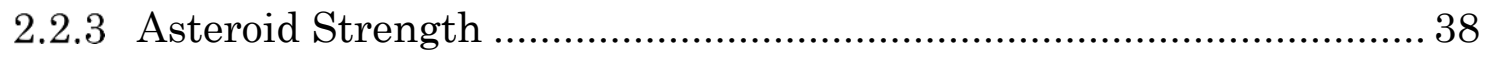




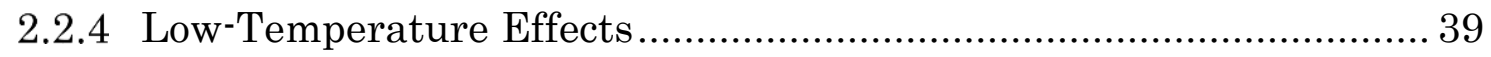

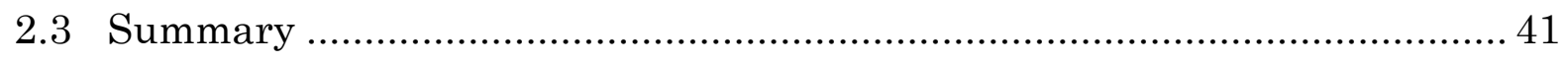

3 Novel Method to Test Rock Samples at Low-Temperature .................................44

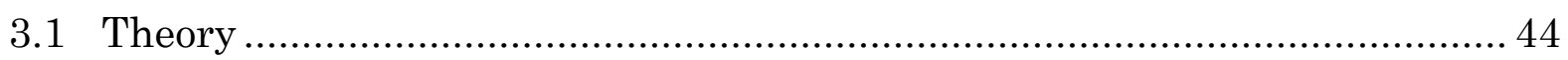

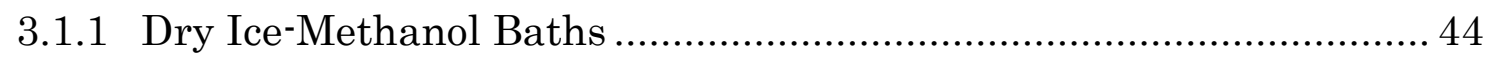

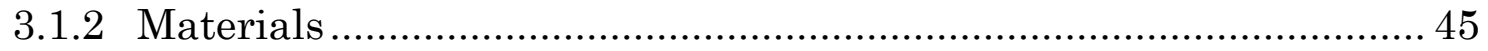

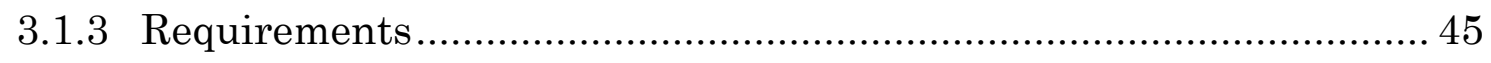

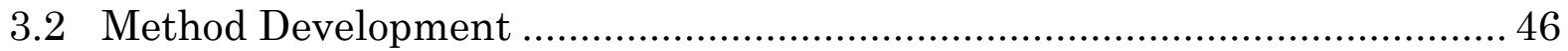

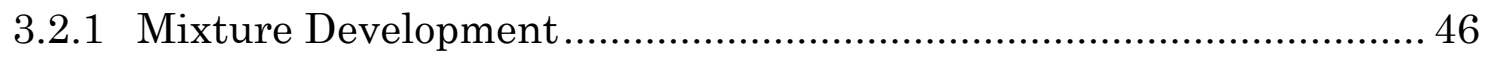

3.2.2 Determination of Cooling and Warming Time ................................. 49

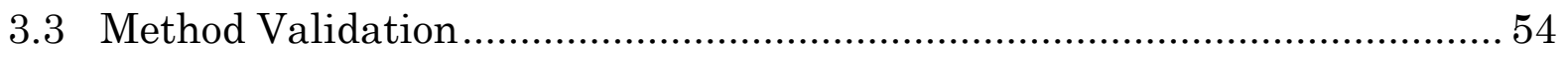

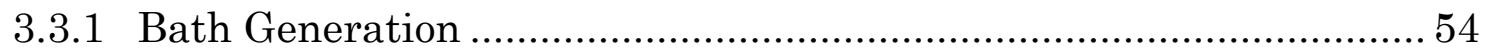

3.3.2 Sample Temperature Models ………….......................................... 55

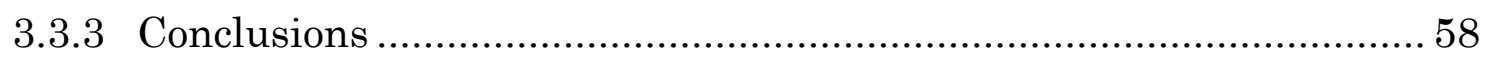

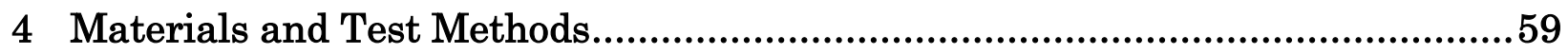

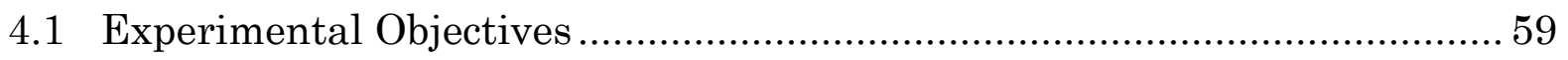

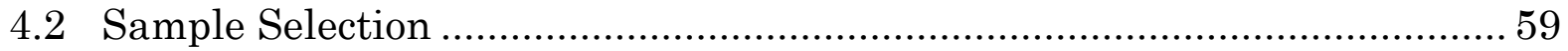

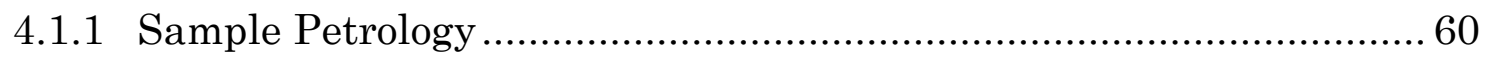

4.1.2 Sample Preparation............................................................................ 63

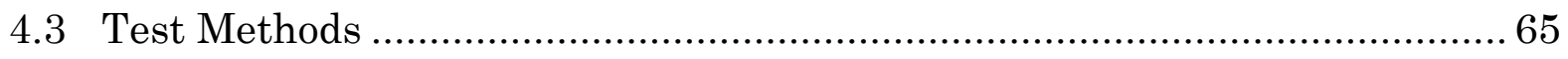

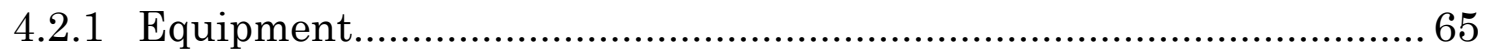

4.2.2 Destructive Test Procedures ............................................................. 65

4.2.3 Nondestructive Test Procedures ...................................................... 68

4.2.4 Detailed Low-Temperature Tests ..................................................... 70

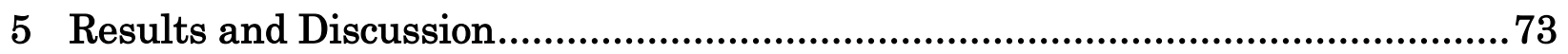

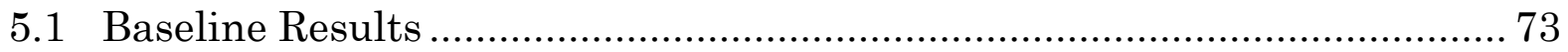

5.2 Low-Temperature Results and Discussion................................................. 74 


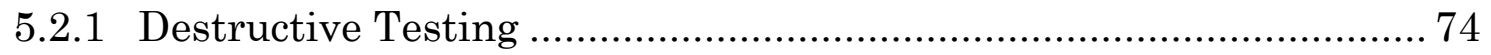

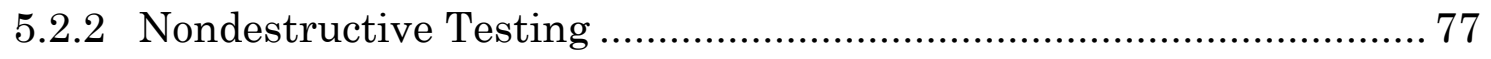

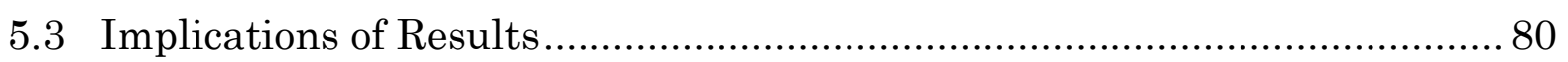

5.3.1 Relationship between Test Results.................................................. 80

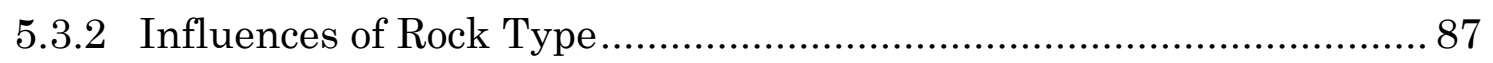

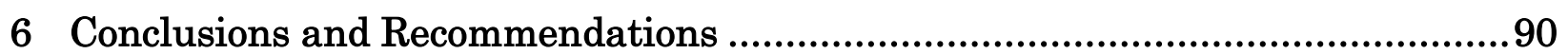




\section{List of Figures}

1.1 Anticipated Timeline of Events for NASA's Asteroid Redirect Mission...... 2

1.2 Drawing of Propsed ARV Rendezvous with Asteroid Boulder for ARRM

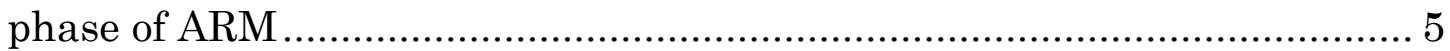

2.1 (a) Example Load-displacement Plot and (b) its Correspond Stress-Strain Plot, Derived from UCS Testing ................... Error! Bookmark not defined.

2.2 (a) UCS Test Device and (b) Load Configurations and Specimen Shape Requirements for UCS Test ................................................................... 16

2.3 (a) PL Test Device and (b) Truncated Conical Platen Specifications ........ 18

2.4 Load Configurations and Specimen Shape Requirements for (a) Diametral

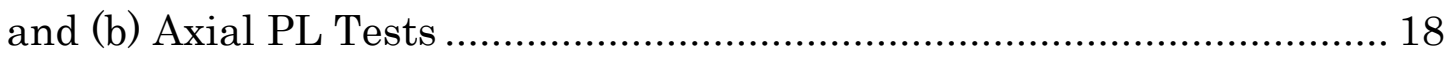

2.5 SH Cutaway Schematic for Operation.................................................... 20

2.6 Correlations of R to UCS for L-type SH Grouped by Rock Type ............... 29

2.7 Correlations of R to UCS for N-type SH Grouped by Rock Type............... 29

2.8 Bounding Limits by Rock Type for Correlations of R to UCS for L-type $\mathrm{SH}$

2.9 Bounding Limits by Rock Type for Correlations of R to UCS for N-type $\mathrm{SH}$

2.10 UPV Direct Transmission Schematic ....................................................... 33

3.1 Example Cooling Bath (a) after Dry Ice and Methanol Solution Addition 
and (b) after Completion of Dry Ice and Methanol Reaction 47

3.2 Method to Determine Methanol and Dry Ice Concentrations for a Desired Bath Temperature Based on Experimental Data with Example Steps for Use

3.3 Internal and External Temperature Differentials of Rocks Approximated by Finite Element Analysis (FEA) of 2D Heat Transfer Model for (a) Cooling and (b) Warming ...... 51

3.4 Example (a) Cooling Model to Determine Required Time to Cool Pre-Frozen Rock Sample to $-60^{\circ} \mathrm{C}$ in a $-65^{\circ} \mathrm{C}$ Bath and (b) Warming Model to Asses Temperature Change Over Time for Cooled Sample After Removal to Room Temperature $\left(22^{\circ} \mathrm{C}\right)$

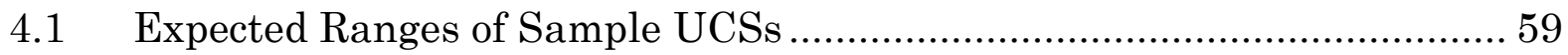

4.2 Prepared 2 in diameter, 4.5 in core samples of (a) Austin Chalk, (b) Elbrook and Conococheague Limestone, and (c) Barnett Shale .............................. 64

4.3 Machined Steel SH V-Notch Core Cradle................................................. 66

4.4 (a) PL Test Device to Estimate UCS and (b) Diametrically Loaded

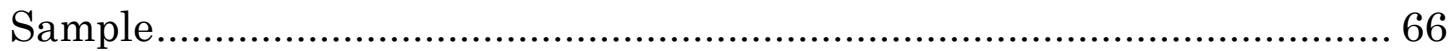

4.5 (a) MTS Machine for UCS Testing and (b) Sample after Failure.............. 67

4.6 (a) L-Type SH Test Device and (b) SH Testing of Sample ......................... 68

4.7 (a) UPV Test Device Display Screen and (b) UPV Testing of Sample....... 69

4.8 Detailed Steps with Images for Low-Temperature Testing....................... 71

5.1 PL Estimated UCS as a Function of Temperature for Limestone............. 74

5.2 UCS as a Function of Temperature for (a) Chalk, (b) Limestone, and (c)

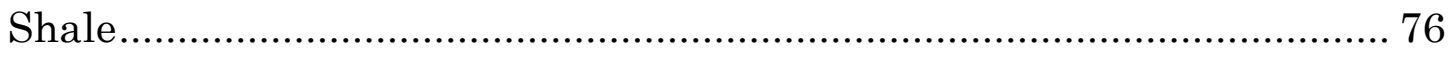

5.3 E/UCS as a Function of Temperature for (a) Chalk, (b) Limestone, and (c)

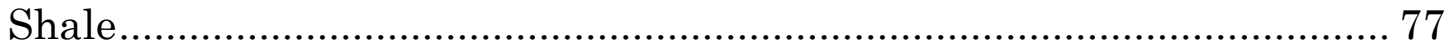

5.4 $V_{P}$ Change as a Function of Temperature for (a) Chalk, (b) Limestone, and

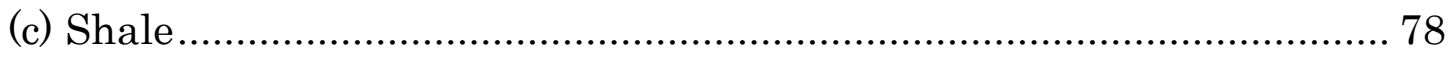


5.5 $\mathrm{R}$ as a Function of Temperature for (a) Chalk, and (b) Limestone............ 79

5.6 $\mathrm{V}_{\mathrm{P}} / \mathrm{R}$ as a Function of Temperature for (a) Chalk, and (b) Limestone....... 81

5.7 Correlation of Final VP to UCS for (a) Chalk, (b) Limestone, and (c)

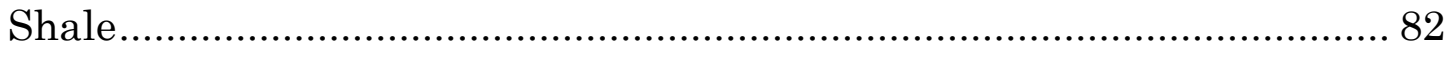

$5.8 \mathrm{~V}_{\mathrm{P}} / \mathrm{E}$ as a Function of Temperature for (a) Chalk, (b) Limestone, and (c)

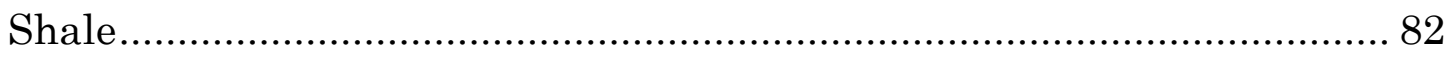

$5.9 \quad \mathrm{~V}_{\mathrm{P}} / \mathrm{UCS}$ as a Function of Temperature for (a) Chalk, (b) Limestone, and (c)

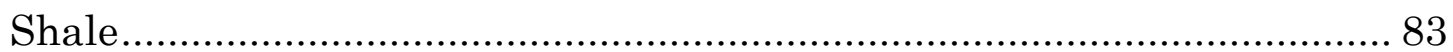

5.10 Correlation of R to UCS for (a) Chalk and (b) Limestone ......................... 84

5.11 R/UCS as a function of Temperature for (a) Chalk and (b) Limestone ..... 85

$5.12 \mathrm{R} / \mathrm{E}$ as a function of Temperature for (a) Chalk and (b) Limestone .......... 86

5.13 Correlation of Initial VP to UCS for Chalk, Limestone, and Shale ........... 87

5.14 Correlation of R to UCS for Chalk and Limestone.................................... 88 


\section{List of Tables}

2.1 Empirical Correlations of R to UCS for L-type SH ................................ 27

2.2 Empirical Correlations R to UCS for N-type SH.................................... 28

2.3 Parameter Table for ARM Candidate Parent Asteroids ............................ 36

2.4 Collection of Inferred Asteroid Strengths................................................ 39

2.5 Low-Temperature Rock Mechanics in Literature ..................................... 41

3.1 Validation of Cooling Bath Generation Curves ........................................ 54

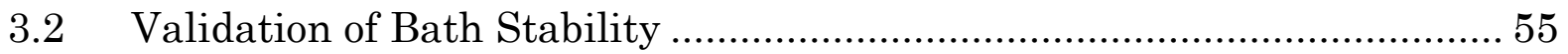

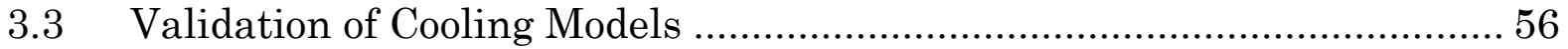

3.4 Validation of Warming Models .................................................................. 57

3.5 Insulation Influence on Warming of Samples .......................................... 57

4.1 Standards for L-Type SH Testing of Rock Core Samples …….................. 69

5.1 Baseline Sample Properties at Room Temperature ................................... 73

5.2 Property Effects for Rocks at Low-Temperature...................................... 80

5.3 Significance for Property Changes due to Low-Temperatures .................. 86 


\section{Chapter 1}

\section{Introduction}

\subsection{Background}

The exploration and characterization of Near-Earth Asteroid (NEA) is a longstanding scientific endeavor that has become increasingly important for various governmental and private enterprises. Various asteroidal studies have been proposed and developed under the auspices of planetary defense, commercial resource extraction, and scientific advancement. While much of the prior work has focused on observation from a distance (i.e. telescopic work), the most recent studies have proposed rendezvous and direct contact to elicit more direct measurement of various asteroid characteristics. One such study is NASA's Asteroid Redirect Mission (ARM), a $\$ 1.25$ billion project that proposes to autonomously capture a multi-ton boulder from the surface of an NEA and redirect the boulder into controlled lunar orbit (Hand, 2015). If successful, this project will provide novel scientific understanding on the fundamental composition and structure of asteroids and demonstrate mankind's ability to manipulate extraterrestrial bodies for the purpose of planetary defense.

ARM and similar missions will require substantial autonomy in the handling and manipulation of extraterrestrial rock bodies. Robotic handling may benefit from the prior assessment and estimation of the in situ mechanical properties of the body in question to ensure safety and success in manipulation. Prior studies and past missions have provided little insight into the mechanical behaviors of asteroidal bodies, and strength expectations of asteroids are currently unverified. The lack of 
certainty in the mechanical nature of asteroid materials poses an issue for the eventual handling of an asteroid body as proposed for ARM. Prior to handling an asteroid boulder, the anticipated mechanical properties of the body should be verified.

To aid in these measurements, various tools traditional to terrestrial rock mechanics studies can provide insight on the mechanical properties of rock bodies. Nondestructive tests (NDTs), often used in rock mechanics and civil engineering applications, provide mechanical property estimates without harming the in situ properties of the rock. Similar devices may be used to deliver mechanical property approximations to assist in robotic signaling for asteroid manipulation. While numerous NDTs are extensively used on Earth to provide insight into mechanical properties of rock, the unique constraints imposed by the extraterrestrial environment and the robotic implementation make the selection of possible NDTs for characterization of asteroid strength a non-trivial task. Furthermore, the terrestrial uses of these tools are dictated by the correlations from NDT responses to mechanical rock properties. These correlations are most often site-specific, as they rely on structural mechanisms that differ between rock and sample types. Investigations into how material and environmental properties influence NDT responses will allow for the adaptation and implementation of these tools to be suited specifically for use on asteroid materials in a space environment.

\subsubsection{ARM Overview}

NASA's ARM aims to retrieve an asteroid body from a near-Earth orbit and return it to lunar orbit. Once in controlled orbit, the asteroid boulder will serve as a

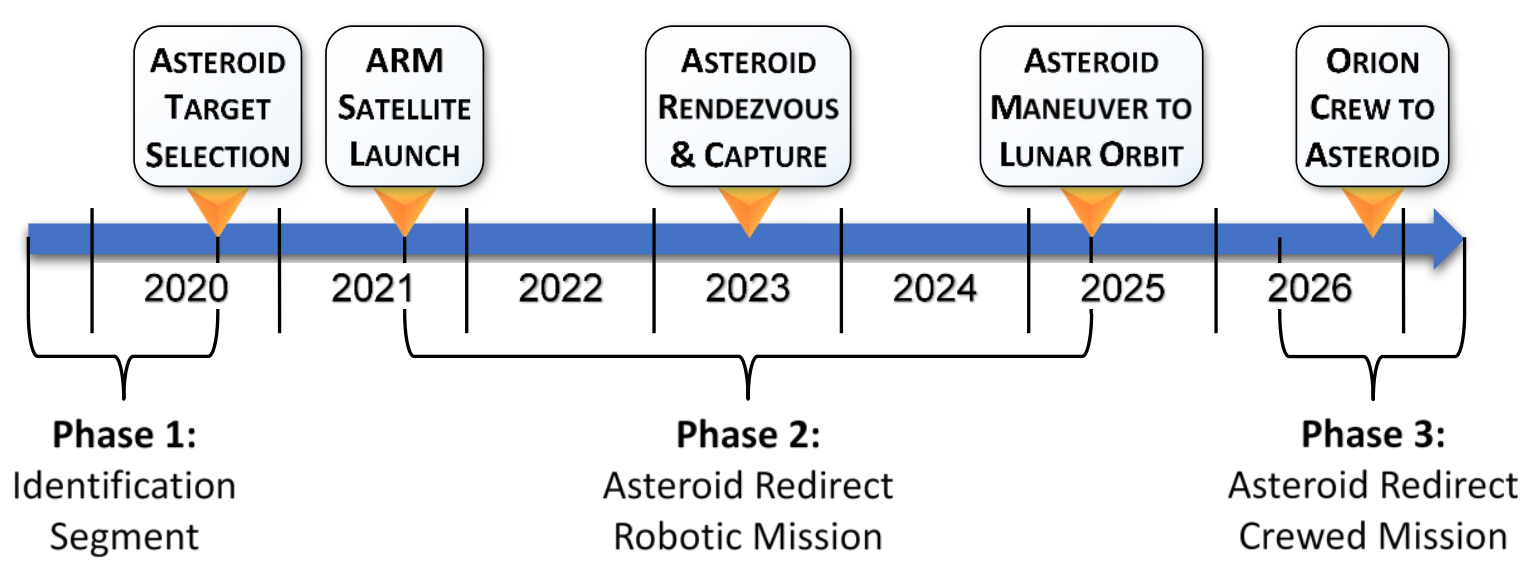

Figure 1.1: Anticipated Timeline of Events for NASA's Asteroid Redirect Mission 
vehicle for the manned testing of tools and techniques to develop their use in future space exploration endeavors. The anticipated timeline of events for ARM as of March, 2016 is displayed in Figure 1.1 (Gebhardt, 2016), though the timeline is fluid and has been pushed back significantly since the originally proposed start date in 2016 . The mission is broken into three major phases and include: (1) the candidate parent asteroid identification segment; (2) the robotic mission segment; and finally, (3) the crewed mission segment. ARM program intentions are detailed for the three main phases.

The first phase of the mission began in 2014 and includes space-based and ground-based telescope scanning to identify Near-Earth Objects (NEOs) that could be suitable NEA targets for capture. The asteroid target selection for ARM is expected to be finalized by the end of 2020 , though four candidate parent asteroids for ARM have already been identified and include Itokawa, Bennu, 2008 EV5, and Ryugu. While all four candidate parent asteroids are viable targets, NASA's main interest at the moment is 2008 EV5 (Gebhardt, 2016). The candidate parent asteroids will be discussed in greater detail in the literature review portion of this thesis in Chapter 2.

In the second phase of ARM, denoted as Asteroid Redirect Robotic Mission (ARRM), a NASA spacecraft will be tasked with flying to, rendezvousing with, and characterizing an NEA. During this phase, the spacecraft will retrieve a boulder from the asteroid surface, taxi back to the Moon, and place that boulder into a Distant Retrograde Orbit (DRO) of the Moon. The ARM spacecraft, called the Asteroid Redirect Vehicle (ARV), is proposed to launch from Earth in the year 2021. The ARV will be in transit for about two years until it reaches the target parent asteroid. Upon arrival to the parent asteroid, the ARV will rendezvous with and capture a 5-m boulder from the parent asteroid surface. After successful boulder capture, the ARV will then orbit the parent asteroid for up to 400 days to test the idea of subtly altering the asteroid's orbit using the spacecraft's gravitational field, as a potential method to defend Earth from a catastrophic asteroid impact (Hand, 2015). The ARV spacecraft will transit back towards the vicinity of the Moon, and release the boulder into a controlled lunar DRO at $71,000 \mathrm{~km}$, completing the ARRM portion of the mission (Gebhardt, 2016).

The third portion of ARM, designated as the Asteroid Redirect Crewed Mission (ARCM), will involve manned testing of the asteroid in lunar DRO. ARCM officially 
began with the first test flight of the Orion spacecraft, the planned vehicle for this mission, in December 2014. In the proposed plan for ARCM, the Orion shuttle will be launched for its first un-crewed test beyond the Moon sometime between 2018 and 2019. Crewed Orion missions are projected to launch between 2021 and 2023, with a planned rate of one flight per year. The targeted flight for ARCM will be the EM- 5 assignment (fifth exploration mission of the Orion) and is scheduled to take place in 2026. The EM-5 mission will be a 24.3 day, two-person crewed mission launched from an Orion vehicle improved with an ARCM mission kit. The mission kit will equip the Orion with specific tools for ARM including Autonomous Rendezvous and Docking (AR\&D) sensors, and Extravehicular Activity (EVA) tools and equipment for crew members to use outside the spacecraft. The launch and transit will stretch over approximately 12 days, until the mission rendezvous and docks with the ARV in a 71,000 lunar DRO. Once arrived at the ARV, the Orion and its two-person crew will spend the next five days performing DRO operations and documenting and collecting samples from the asteroid boulder. Following the planned operations and testing, Orion will then begin inbound transit back to Earth for an ocean landing (Gebhardt, 2016).

If the proposed plan for ARM is a success, the mission will assist in the preparation for future extraterrestrial investigations. The crewed testing of AR\&D and EVA tools will demonstrate technologies for eventual crewed missions to the surface of Mars. Successful completion of ARM will also demonstrate NASA's ability to redirect an asteroid in a case of necessity for planetary defense (Gebhardt, 2016).

\subsubsection{Asteroid Capture and Rendezvous}

A major challenge of ARRM is the design of a capture system for the ARV that will be used to retrieve a surface boulder from an asteroid. ARV rendezvous will include the characterization of the parent asteroid and/or target boulder as well as manipulation of the boulder for capture (Gebhardt, 2016). Figure 1.2 shows the proposed plans for the ARV capture system and rendezvous with the asteroid boulder.

To prepare for capture, the ARV will position and secure itself above the boulder. For the current prototype design, the ARV will use a three-pronged securing structure. Robotic arms, specifically designed as gripping mechanisms, will be used to apply pressure to and grasp the boulder. Lifting mechanisms of the robotic arms will then engage to separate the boulder from the asteroid surface. Securing 


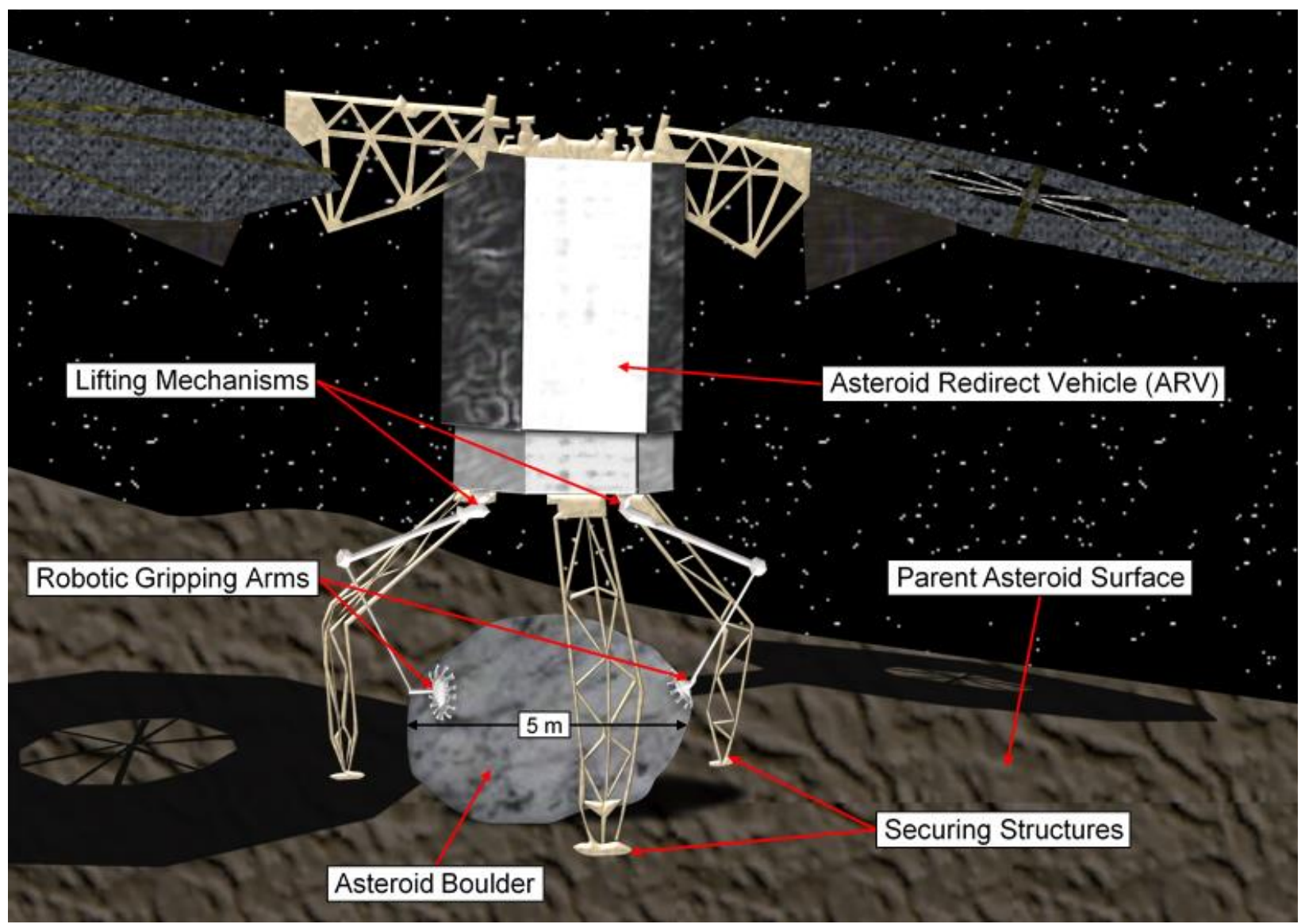

Figure 1.2: $\quad$ Drawing of Propsed ARV Rendezvous with Asteroid Boulder for ARRM phase of ARM

structures of the ARV will then eject the vehicle from the asteroid surface and wrap around and secure the lifted boulder.

In order to capture of an asteroid boulder, characterization of the parent asteroid and asteroid boulder must be complete before attempting to grip into, lift, and secure the target boulder. By characterizing the asteroid material, the feasibility of boulder capture can be assessed. Estimations of the apparent cohesion, strength, and elastic properties of the target boulder will be used to deliver signals to the robotic controls of the ARV used in boulder capture.

Surface hardness and compressibility of the boulder material will allow for the control of gripping mechanisms so that the boulder will be grasped without causing failure. To separate the boulder from the parent asteroid surface without disassociating the main boulder structure, internal strength and stiffness 
approximations will be used to control lifting mechanisms of the gripping arms. Estimations of the internal strength and cohesion will be used to ensure closure of securing structures around the lifted boulder will not cause boulder failure during transit.

In order to perform safe and successful boulder capture, the ARV must be equip with tools that can provide some indication of the surface and internal mechanical properties of the asteroid material. The development of characterization and understanding of asteroid material is crucial to the rendezvous and capture portion of ARRM. Terrestrial rock characterization will be used as a basis for the characterization of asteroid material.

\subsection{Asteroid Characterization Requirements}

Rock mechanic techniques can derive rock mechanical properties that are used in mining engineering design practices. To approach ARV boulder characterization from a mining engineering perspective, terrestrial methods to derive mechanical characteristics of rock are considered.

The most commonly utilized characterization tests for mine design purposes are destructive in nature and require sample extraction. For the capture portion of ARRM, the retrieved boulder will ideally be unharmed. Therefore, the ARV will be limited in its ability to perform traditional destructive tests used in rock mechanics. To overcome this challenge, nondestructive rock mechanics tests that do not require sample extraction are considered for ARV implementation.

While NDTs may have the potential to satisfy the ARM rock characterization requirements, the direct implementation of these tools is constrained by several limiting factors, including: (1) the estimation procedures inherent to NDT evaluation; (2) the uncertainties regarding asteroid properties; and (3) the influence of low-temperatures in the space environment. These items are explained in more detail later in this section, but the overall goal of this study is to address each challenge in a rigorous and scientific manner. 


\subsubsection{Tool Constraints}

Potential NDTs for ARV boulder characterization must be nondestructive when used on asteroid material. Devices must be able to quickly determine if a target asteroid boulder is cohesive so that time and power are not wasted in an attempt to lift a boulder that is not monolithic in structure. The chosen tool(s) must also provide general strength properties so that gripping and lifting controls can be administered without causing failure to the asteroid boulder. Lastly, tools should be lightweight, cost effective, and require little computation for ease of implementation onto the ARM spacecraft.

Based on the problem constraints, two common terrestrial NDTs were chosen for this study: (1) Schmidt hammer (SH) and (2) ultrasonic pulse velocity (UPV). Responses from the SH method are indicative of surface properties, while UPV responses are indicative of internal structure. Both of these qualities are required for ARV boulder characterization to ensure successful boulder capture for ARRM.

\subsubsection{Estimating Mechanical Properties from NDTs}

For the current problem of NDT evaluation of an asteroid boulder, the SH and UPV methods have been proposed as potential tools. The quality of SH and UPV tests will be assessed on their ability to correlate the NDT responses to mechanical properties derived from traditional destructive tests.

While destructive tests are often the preferred method of obtaining accurate rock mechanical properties, some situations do not permit damage to the rock body in question. For example, destructive testing is not an option in the rehabilitation and repair of existing masonry structures. In such cases, characterization of elastic and strength properties generally must be carried out through in situ test methods that can be performed at the required positions, without causing further damage to the structures (Vasconcelos et al., 2007).

As a result, NDTs have been developed to estimate some of these mechanical properties without causing harm to test specimens. Unfortunately, NDTs do not always accurately correlate to true mechanical properties, and they often require attention to specific sample properties. The specific operation of NDTS can directly influence the accuracy of the strength and elastic property correlations, and different 
sample mineralogy may influence the NDT responses.

To address the issue of material properties influences on NDT responses, this report will examine the influence of rock type in empirically-developed SH response correlations to UCS. Rock properties dictating the differing responses for different rock types will be investigated so that the mineralogical influences on NDT responses may be used to predict how NDTs will respond to the anticipated mineralogy of asteroid material. The investigations into these tests methods will contain a more direct focus on the $\mathrm{SH}$ apparatus.

\subsubsection{Uncertainities in Mechanical Properties of Asteroids}

The mechanical properties of asteroids are not comprehensively understood. Potential SH and UPV characterization of asteroid bodies requires a thorough analysis of the anticipated mechanical properties of asteroids.

The Earth is constantly undergoing dynamic, geomorphic processes such as erosion, mantle convection, subduction and collision of tectonic plates, volcanic eruptions, and other mechanisms that reshape and define its geologic structure. Asteroid bodies experience some reshaping incidents similar to those that take place on Earth; however, these processes occur under different formative environments. Specific processes and environments have driven the mineralogy, internal structure, strength, grain size, porosity, density, and rotational period of asteroids.

Mechanical properties of asteroids are not well understood due to lack of direct data, as well as differing considerations of what constitutes strength for asteroid bodies. Many asteroid strength models exist and are defined by the various yielding and failure elements (Holsapple, 2009).

While some traditional destructive tests have been performed on meteorite samples (e.g. Buddhue, 1942; Petrovic, 2001; Popova et al., 2011), the mechanical behaviors of these samples have likely been altered from their original asteroidal properties during descent to Earth as the meteorites have broken Earth's atmosphere. Other estimations of asteroid strength have been derived from observations of fragmentations upon initial break up of a meteorite while entering Earth's atmosphere (e.g. Petrovic, 2001, Popova et al., 2011). Modeling of thermal stress, impact eject, and regolith (e.g. Dombard and Freed, 2002; Michikami et al., 
2007; and Sanchez and Scheeres, 2013, respectively) are other examples of methods that have been used to estimate compressive, tensile, and cohesive properties of asteroids. Literature on the speculated strength of asteroids provides a wide range of strength values derived from various test and estimation methods.

In this report, the issue of uncertainty in expected asteroid mechanical properties will be addressed through analysis of past asteroid strength derivations. The validities of these derivations will be assessed so that terrestrial samples may be chosen to sufficiently cover an expected range of asteroid strengths.

\subsubsection{Low-Temperature Rock Mechanics}

Temperatures of asteroid bodies in the solar system are much colder than the temperatures of Earth. The low-temperature environments of space may contribute to differences in the mechanical behavior of some extraterrestrial bodies when compared to these behaviors in terrestrial rocks. Furthermore, low temperatures may influence responses of NDTs and how they correlate to true strength values.

While terrestrial rock mechanics at heightened temperatures are well-studied and understood (e.g. Paterson, 1970; Tullis, 1979; Egydio-Silva et al., 2002; Tian et al., 2016), few investigations of rock material at low-temperatures (i.e. $<0^{\circ} \mathrm{C}$ ) have been performed.

The majority of low-temperature investigations have involved the testing concrete materials (reviewed in Dahmani et al., 2006) as opposed to naturally occurring rocks. From review of these studies, the general consensus is that concrete gains strength when subject to low-temperatures; however, Monfore \& Lentz (1962) (as cited in Heins \& Friz, 1967) has shown a decrease in concrete strength with decreasing temperatures. Low-temperature rock mechanics studies (e.g. Heins \& Friz, 1967; Mellor, 1971; and Podnieks, 1969 (as cited in Mellor, 1971)) have also shown increases in rock strength with decreasing temperature; however, changes to rock elastic properties as a result of low-temperature differed between studies. Examinations of low-temperature rock mechanics are scarcely available, and results from studies have presented opposing influences of low-temperature on mechanical properties; however, the majority of studies indicate that rock and concrete material gain strength as their temperatures are reduced below-freezing. 
To address the issue of uncertainty in the influence of low-temperature on rock mechanical properties, this report will examine past studied on low-temperature mechanics of concrete and rock. Given the divergent conclusions from literature, experimental tests have been performed to determine how low-temperature influences rock mechanical properties and NDT responses. Results from these tests will be used to assess the feasibility of asteroid characterization, accounting for low-temperature influences on the mechanical properties and NDT responses for terrestrial samples.

\subsection{Objectives}

For ARM asteroid boulder characterization, NDTs have been considered for ARV implementation. Differences in NDT correlations for specific materials pose challenges for the development tool response correlations to true mechanical properties. Mechanical properties of asteroid material are currently not well understood or agreed upon. Low-temperature rock mechanics studies have indicated that below-freezing temperatures have an influence on rock mechanical properties. These properties in asteroids may also be affected due to the cold temperatures of space environments.

Given the aforementioned challenges associated with asteroid boulder characterization for ARM, the ultimate goal of this research is to determine the validity of using SH and UPV to accurately predict the mechanical properties of rock material at low-temperatures, commensurate with an extraterrestrial environment. This determination will address the feasibility of using methods similar to $\mathrm{SH}$ and UPV to characterize an asteroid boulder for ARM.

In summary, the itemized objectives of this study are to:

- Establish a protocol to assess rock samples at low-temperature that is low-cost and inherently safe for replication in a laboratory setting.

- Determine the influence of low-temperature on the mechanical behavior of rocks determined from standard destructive tests. 
- Determine and quantify the influence of low-temperatures on the accuracy and validity of NDT estimates of true mechanical properties.

- Assess the implications of these findings on the mechanical behavior of asteroids and other extraterrestrial bodies at low-temperature, while providing guidance for implementation and design of a characterization system for ARV based on SH and UPV.

\subsection{Organization}

This thesis is ordered into 6 chapters, with major works including a thorough literature review, development of a novel method to prepare rock samples for low-temperature testing, experimental investigations, and results of experimental work. References used for this thesis will be summarized at the end of the report.

Chapter 1 includes a description of the problem statement, the problem challenges motivating the investigative and experimental work, and an overview of the objectives this study aims to answer.

Chapter 2 provides a comprehensive review of the destructive and nondestructive test used in the experimental work, focusing on their methods of operation and associated issues, as well as their correlation to mechanical properties of terrestrial rocks. This chapter includes a description of the essential asteroid properties for successful capture, as well as speculated mineralogical and mechanical properties of asteroids targeted for this study. The potential effects of low-temperatures on asteroids are noted, and a review of studies into low-temperature rock mechanics is presented. The review in this chapter addresses the shortcomings of NDTs for the characterization of asteroid material. These obstacles include: material influences on NDT correlations to true mechanical properties, scarcity in the understanding of asteroid mechanical behaviors, and insufficient comprehension of terrestrial rock behavior at cold temperatures.

Chapter 3 describes the development and verification of a novel protocol to reduce rock samples to low-temperatures. The method uses cooling baths generated from mixtures of dry ice and methanol. This chapter discusses the theory and 
experimental work behind the generation of cooling baths and details the materials and requirements for bath preparation. This chapter also includes theoretically-developed cooling and warming models for samples used in this study, along with validation experiments for the theoretical models.

Chapter 4 details the materials and methods used for the experimental portion of this study. The specific geology and preparation of terrestrial rock samples chosen to simulate a broad range of strengths to cover the potential range of speculated asteroid strengths are provided, and equipment used to conduct experimental tests are detailed. This chapter includes a discussion of the methods used in this study for destructive and nondestructive operational procedures based on implications ascertained from the preceding review.

Chapter 5 presents the results from experimental tests discussed in the previous chapter, including consequences of low-temperature on destructive and nondestructive test responses as well as the correlations between nondestructive tests and true mechanical properties. The influence of rock type is offered as a possible explanation for the observed modifications in mechanical properties and nondestructive tool responses for rocks at low-temperature.

Chapter 6 summarizes the key findings of this work, addressing the objectives set out Chapter 1, and introduces suggestions for supplemental research and development. 


\section{Chapter 2}

\section{Literature Review}

\subsection{Test Methods for Strength Characterization}

Naturally-occurring rock mass is a complex structure comprised of intact rock and planes of weakness such as joints, bedding, faults and other discontinuities (Wittke, 2014). Such discontinuities create variable stresses and loading concentrations within the rock mass. Intact rock is the aggregate of minerals of which a rock is basically composed, and the basic structure of an intact rock is a result of its crystalline and amorphous aggregate minerals. Mineral grains and crystals are cemented together by the fine-grained mineral portion of the intact rock, called the rock matrix. Structures in intact rocks are differentiated by the appearance, size, size distribution, and shape of individual grains and mineral particle aggregates (Wittke, 2014). Discontinuities in rock masses and structural variations of intact rocks influence their mechanical behaviors.

In standard practice, rock mechanical properties can be determined through analysis of the deformation and failure of extracted rock samples under applied loads through destructive tests. Loading mechanisms and force distributions in relation to rock samples dictate the types of mechanical properties that can be derived.

As an alternative to destructive testing, NDTs have been developed so that mechanical properties of rocks may be estimated for a rock mass without sample excavation or rock mass destruction. Empirical equations are used to relate the NDT 
responses to strength and elastic properties of rocks. However, NDT correlations are often unique to specific sample properties and therefore cannot be used for a broad range of sample types.

Destructive tests discussed in this section include: (1) uniaxial compressive strength (UCS) and (2) point load (PL) strength index. UCS was chosen due to its common use in rock mass classification, and PL was chosen as a crude strength estimation to provide relative strength changes with temperature, while allowing for many samples to be tested quickly and easily.

NDTs discussed in this section include: (1) SH and (2) UPV tests. SH and UPV tests were chosen based on their capabilities to acquire information on a material's surface hardness and internal structure, respectively. Characterization of these properties is required for ARRM boulder capture as described in Section 1.2.

Applications of these test methods will focus on the use of cylindrical rock samples, as this is the most commonly used sample type in laboratory testing of rock mechanics and was the sample type used in the following study.

\subsubsection{Destructive Methods}

For rock mass characterization, stress-strain behavior is of considerable importance for the design of tunnels and structures from rock masses (Wittke, 2014). Mechanical testing of rocks was possibly developed thousands of years ago, and in the $16^{\text {th }}$ and $17^{\text {th }}$ centuries, simple apparatuses were used to measure the elastic strength of rocks. The first experimental studies in rock mechanics were performed around 1770 by Gauthey (as cited in Ulusay, 2015), who developed a device to measure compressive strength for the design of structural pillars for a building. During this time, scientists first discovered a simple, linear relationship between applied load and elastic deformation. Over the years, laboratory destructive tests improved and standard methods for testing were developed. Some destructive tests for intact rock include UCS tests, PL strength index tests, triaxial tests, Brazilian tests, creep tests, and shear tests. Altogether, these methods can be administered to determine a variety of mechanical properties for rock samples based. Mechanical properties are determined from direct measurement or conversions from index results of tests. The two methods of focus in this section include: (1) UCS, a direct strength measurement, and (2) PL, an index test that provides indirect strength estimations. 


\section{Uniaxial Compressive Strength}

The most commonly utilized destructive test for laboratory rock samples is the UCS test. For this test, rock samples are subject to uniform compressional loads until sample failure. Unlike other strength tests, UCS tests do not include the addition or analysis of confining pressures. The UCS determined from this test is often used as a design criterion; however, properties measured in a laboratory setting may not accurately reflect in situ properties of large rock masses due to the influence of joint, faults, weakness planes, and other factors on the in situ mechanical properties of the rock mass. UCS tests also tend to underestimate strength that would be calculated from confined compressive tests, where force is applied along three axes (ASTM Standard D7012, 2014).

The ASTM standard for UCS testing of rock cores (D7012) prescribes strict sample and operation requirements. For UCS testing of cylindrical core samples, lengths of specimen should be two to three times sample diameters. Samples should be right circular cylinders with flat, smooth ends, and sides of specimens should be free of any visible or abrupt irregularities. The apparatus used for a UCS tests should be sufficiently capable of applying and recording a uniaxial load (Wittke, 2014). To prepare for uniaxial loading, core specimens are placed vertically between the steel patents of the loading machine (Figure 2.1a), and the platens are moved until the sample is held in place by a minimum force. With a core specimen in place, axial loading is initiated by compressional movement of the steel platens at a constant strain rate. Figure $2.1 \mathrm{~b}$ shows how force is applied during uniaxial compression. The applied force versus platen displacement is recorded during testing, and load application should cease once the sample has failed (failure is indicated by a sharp and sudden drop in the applied load versus displacement).

The maximum load on the load-displacement graph (Figure 2.2a) before failure represents the peak load of the sample and is used to calculate the sample's maximum UCS:

$$
\sigma_{U C S}=\frac{P}{A}
$$

where $\sigma_{\mathrm{UCS}}$ is the UCS, $\mathrm{P}$ is the peak load before failure, and $\mathrm{A}$ is the cross-sectional area of the specimen. 


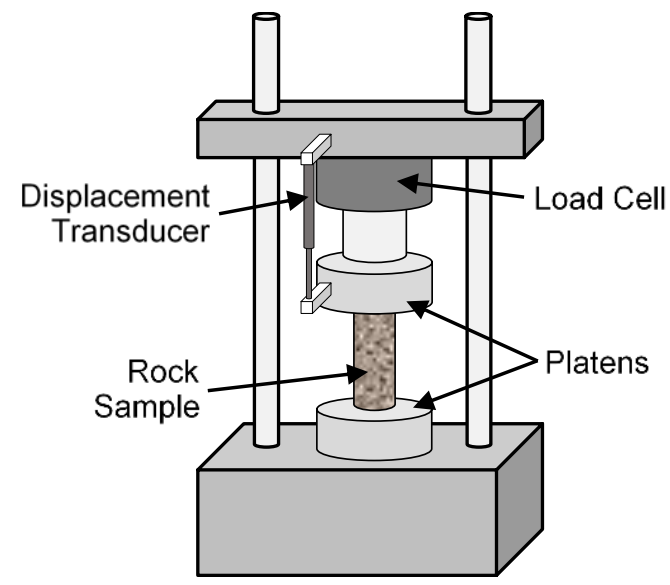

(a)

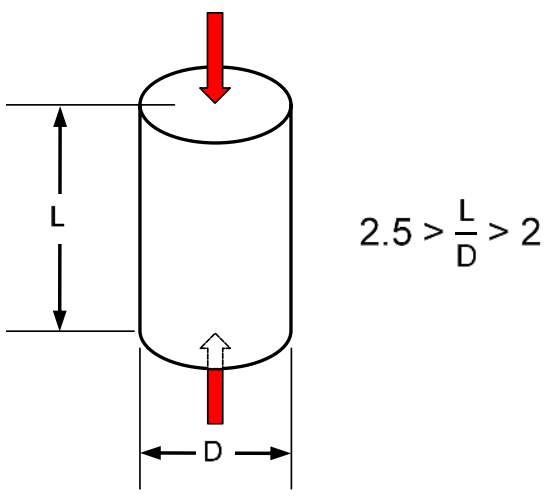

(b)

Figure 2.2: (a) UCS Test Device and (b) Load Configurations and Specimen Shape Requirements for UCS Test

The load-displacement plot can be translated to a stress-strain curve so that elastic properties can be assessed (Figure 2.2b). Stress is calculated in the same way as UCS shown above, by dividing each force recording by the specimen cross-sectional area. Strain is calculated by dividing each displacement recording by the sample

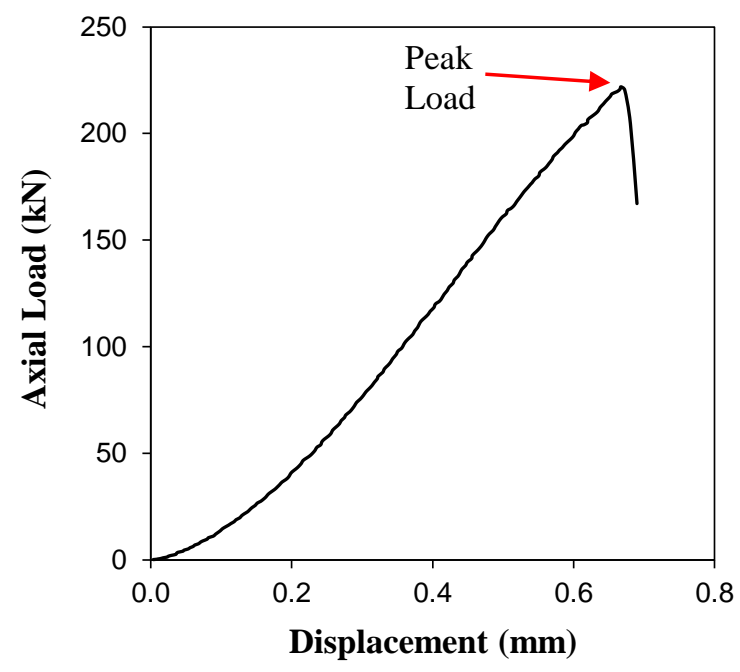

(a)

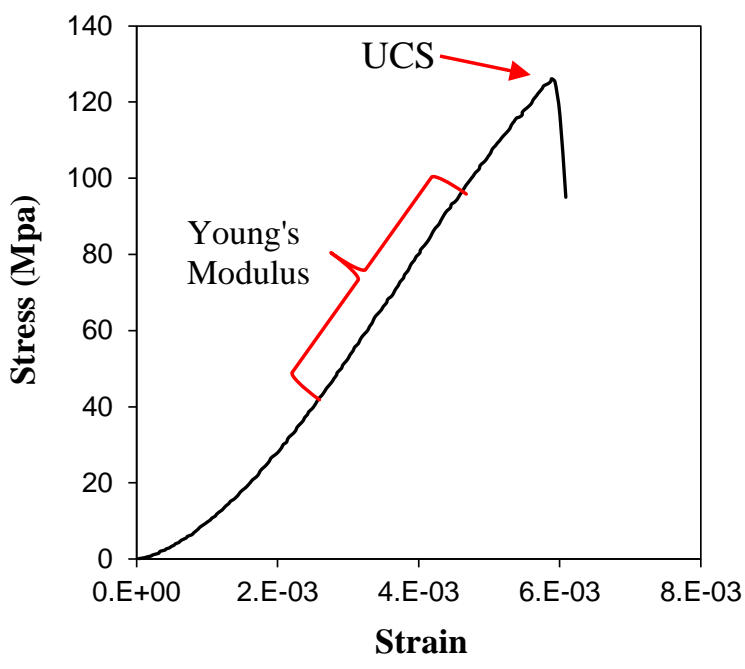

(b)

LEGEND- D: core diameter; L: core length

Figure 2.1: (a) UCS Test Device and (b) Load Configurations and Specimen Shape Requirements for UCS Test 
length, and is therefore unitless. For most rock types, the stress-strain curve from uniaxial compression exhibits approximate linearity before failure (Wittke, 2014). For the simple analysis of the stress-strain relationship considering only uniaxial stress and strain, strain increases linearly with stress and is represented by the equation:

$$
\sigma=E \varepsilon
$$

where $\sigma$ is the stress, $\mathrm{E}$ is the Young's modulus or elastic modulus, and $\varepsilon$ is the dimensionless strain. On the stress-strain curve from a UCS test, E is represented by the linear portion of the curve before sample failure. $\mathrm{E}$ is a material property of rocks that defines a material's elasticity. Stress-strain curves that have large slopes leading up to failure will correspond to high $\mathrm{E}$ values and indicate high stiffness and strength of a material. Materials whose stress-strain curves do not start to descend after peak failure are described as ductile, or elastic. A material having a stressstrain curve that approaches peak failure at a slight incline but decreases slowly after failure has a low E value, and is therefore lower in stiffness and strength, but still brittle based on the stress-strain relationship after peak load .

\section{Point Load Strength Index}

The PL strength index test is performed by subjecting rock specimen to increasingly concentrated loads through compression of conical platens. The uncorrected point load strength index $\left(I_{s}\right)$ is calculated using the load at failure, and is commonly used as an indirect measurement to estimate compressive or tensile strength. While the UCS test method is time-consuming and requires significant sample preparation, the PL test requires considerably less time and preparation and is therefore often used as an alternative method to quickly deliver crude estimates of rock properties when UCS testing is impractical (ASTM Standard D5731, 2008).

Like the UCS test, ASTM prescribes specific sample and operational requirements for PL testing of rock samples (D5731). Approved apparatuses (Figure 2.3a) for PL testing consist of a loading system comprised of a loading frame, platens, and a system capable of measuring the load at failure, P. For PL tests, truncated, steel platens consist of $60^{\circ}$ cones tangent to $5 \mathrm{~mm}$ radius, spherical tips (Figure $2.3 \mathrm{~b}$ ).

For PL testing of core specimens, two loading options exist: (1) diametral and 


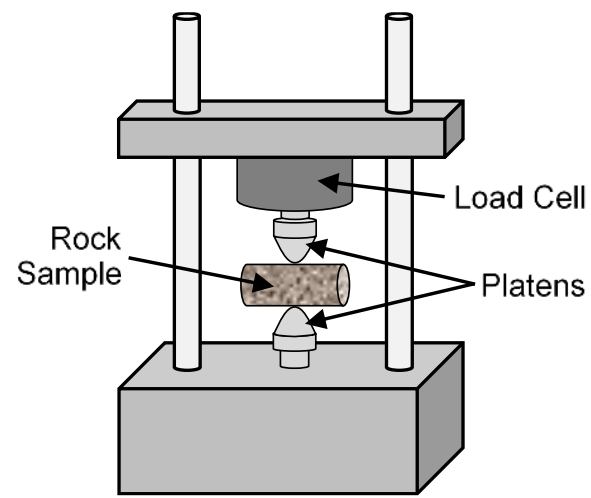

(a)

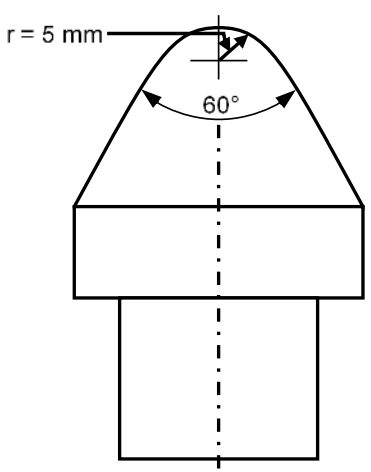

(b)

Figure 2.3: (a) PL Test Device and (b) Truncated Conical Platen Specifications

(2) axial (Figure 2.4). Shape guidelines and requirements for PL core tests are illustrated in Figure 2.4. For PL testing a specimen is inserted into the loading frame and the platens are closed along the specimen diameter (diametral) or the line perpendicular to core end faces (axial) just until the rock sample is held in place. Once a sample is properly loaded, a steadily-increasing load is applied to the rock specimen such that failure occurs between 10 and 60 seconds, and the failure load, P, is recorded. Tests in which the fracture surface does not pass through both platen loading points must be discarded.

Once the failure load, $\mathrm{P}$, is obtained through testing, the uncorrected point load strength index, $\mathrm{I}_{\mathrm{s}}$, may be calculated:

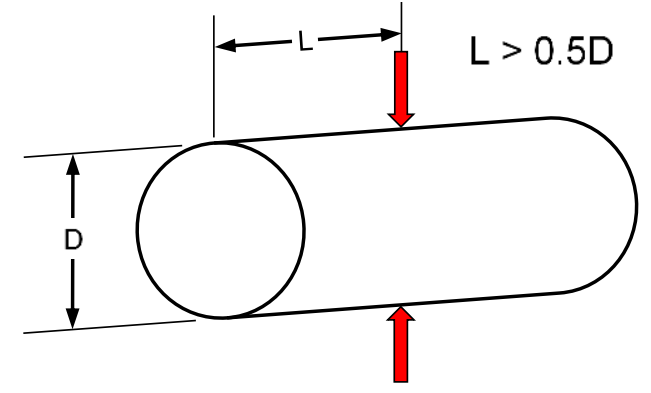

(a)

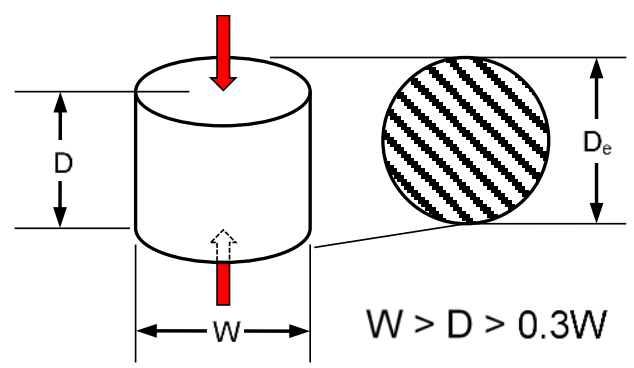

(b)

LEGEND- D: distance between contact points; L: distance between contact points and nearest free face; W: specimen width; De: equivalent core diameter

Figure 2.4: Load Configurations and Specimen Shape Requirements for (a) Diametral and (b) Axial PL Tests 


$$
I_{s}=\frac{P}{D_{e}{ }^{2}}
$$

where $I_{s}$ is the uncorrected point load strength index, $P$ is the failure load, and $D_{e}$ is the equivalent core diameter.

The squared equivalent core diameter, $\mathrm{D}_{\mathrm{e}}^{2}$, may be calculated as follows for diametral tests:

$$
D_{e}{ }^{2}=D^{2}
$$

and axial tests:

$$
D_{e}{ }^{2}=\frac{4 W D}{\pi}
$$

where $\mathrm{D}_{\mathrm{e}}^{2}$ is the squared equivalent diameter, $\mathrm{D}$ is the distance between platens, and $\mathrm{W}$ is the sample width.

$\mathrm{I}_{\mathrm{S}}$ is often used to indirectly estimate UCS. ISRM (1985), (as cited in Kahraman \& Gunaydin, 2009) specifies that the ratio between UCS and $\mathrm{I}_{\mathrm{s}}$ varies between 20 and 25, though numerous studies presneted in Kahraman \& Gunaydin (2009) have found exponential relationships between UCS and $I_{s}$. Through investigation of emirically-developed relationships between UCS and $\mathrm{I}_{\mathrm{s}}$ in literature, Kahraman \& Gunaydin concluded that simple ratio correlations are not valid or applicable to all samples and tests, but stronger correlations are found when analyzing values from the same rock type.

\subsubsection{Nondestructive Methods}

While destructive tests like UCS and PL may provide good estimates of rock mechanical properties, sample preparation for weak and soft rocks required for such tests is difficult. Additionally, some applications may not warrant the use of sample extraction for laboratory tests. As a result, NDTs have been gaining popularity for determination of mechanical properties where laboratory destructive tests are not favorable (Ulusay, 2015). While numerous nondestructive techniques (e.g. electromagnetic testing, infrared thermal testing, profilometry, radiography, etc.) have been developed, two will be discussed in this section: (1) SH and (2) UPV. Both 
methods have empirically-demonstrated correlations to UCS, though SH uses surface hardness and UPV uses sonic velocity to determine these correlations.

\section{Schmidt Rebound Hammer}

The Schmidt hammer consists of a steel hammer that is spring-loaded with a predetermined amount of energy. When released, the hammer strikes a metal plunger in contact with the rock surface, and the loss of energy due to plastic deformation of the rock defines the Schmidt rebound or hardness value, (R). The fraction of energy not absorbed by the test surface is representative of the material hardness, or impact penetration resistance. An empirical measure of rock hardness is given by the rebound distance of the hammer from the top of the plunger (ASTM Standard D5873, 2014). A cutout schematic showing the steps and processes for operation is shown in Figure 2.5

Commercial Schmidt hammers are available in two designs, differentiated by their impact energies: the L-type hammer (impact energy $=0.735 \mathrm{Nm}$ ) and the $\mathrm{N}$ type hammer (impact energy $=2.207 \mathrm{Nm}$ ). Earlier versions of ISRM standards endorsed the sole use of the L-type hammer for rock testing, and current ASTM standards also discount the use of the $\mathrm{N}$-type hammer for testing rock materials.

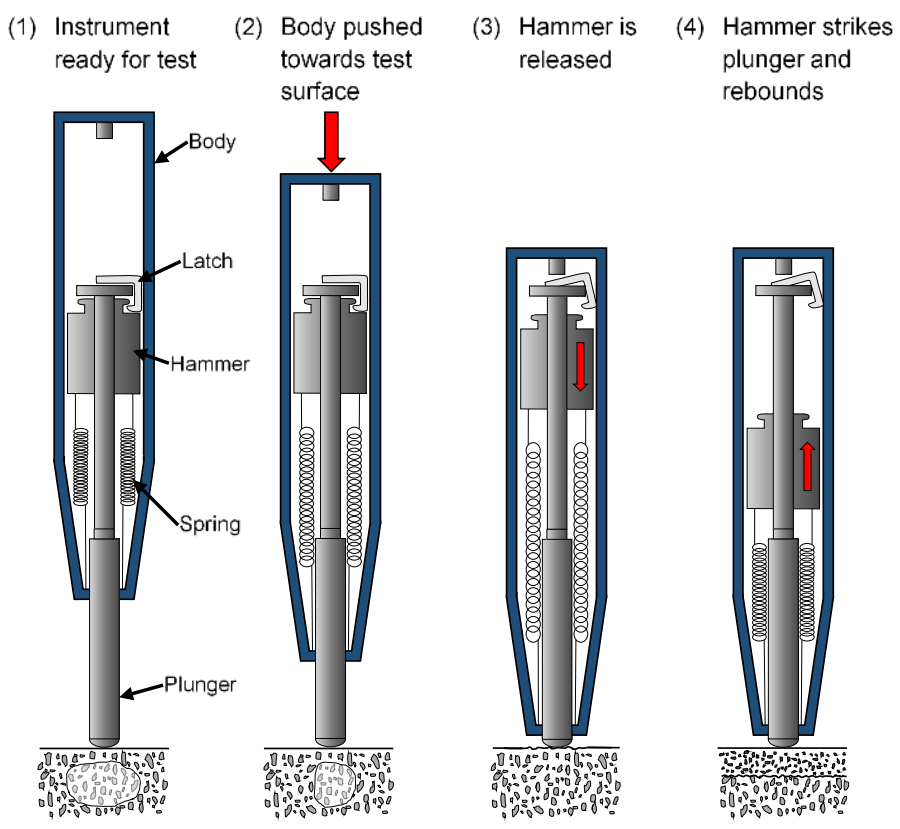

Figure 2.5: SH Cutaway Schematic for Operation 
However, recent methods from ISRM note that the choice of impact energy determines the hammer's range of applicability, so that an $\mathrm{N}$-type hammer may be used when test conditions allow. In fact, ISRM's suggested methods state that results from tests done with an $\mathrm{N}$-type hammer are likely to express less scatter when compared to data from tests done with an L-type hammer, provided that the sample is competent enough to withstand the $\mathrm{N}$-type impact. This reproducibility is due to the larger impacting volume of the $\mathrm{N}$-type hammer, which makes it less sensitive to surface irregularities. It is important to note that while the operation principles of the L-type and N-type SHs are the same, test results from different hammer types may not be readily correlated (Aydin, 2013). However, the ratios of $\mathrm{R}$ values taken on two different points of a homogeneous surface measured at two different energy levels (i.e. N-type and L-type) should be constant (Aydin \& Basu, 2005).

Both ISRM and ASTM stress the importance of competent rock samples for testing, designating that samples be representative of the rock to be studied while avoiding use of samples affected by weathering, discontinuities, or damage. The standards also specify the need for smooth test surfaces, whether they are naturally occurring or ground smooth with an abrasive stone. ASTM states that the rebound hammer method (using an L-type hammer) is best suited for rock material having UCS ranging from $1 \mathrm{MPa}$ to100 MPa. Conversely, ISRM states that the SH should be used with caution on materials outside the range of $20 \mathrm{MPa}$ to $150 \mathrm{MPa}$, although test methods, materials, and hammer type may allow otherwise. Additionally, ISRM states that the $\mathrm{SH}$ test is generally nondestructive for rocks $\geq 80 \mathrm{MPa}$.

A major contributing factor to proper Schmidt hammer operation is the type and size of samples tested. There are three possible classes of specimen that may be tested with the Schmidt hammer: cores of rock, block samples, and in situ rock faces. The sample type dictates the choice of hammer type (i.e. L-type vs. N-type), as well as methods of data collection and reduction. For core and block samples, size restrictions are suggested to preserve the integrity of samples and ensure the test remains nondestructive. Local sample destruction is negligible for testing of in situ rock faces. Both ISRM and ASTM standards state that cores should be of at least NX size $(\geq 54.7 \mathrm{~mm})$ for testing with an L-type hammer. For an N-type hammer, ISRM recommends a core size of T2 $(\geq 84 \mathrm{~mm})$. For block samples, ISRM proposes that thicknesses at impact points should be no less than $100 \mathrm{~mm}$. ASTM designates that all edges of a block sample be at least $15 \mathrm{~cm}$, core lengths be at least $15 \mathrm{~cm}$, and areas 
for field testing be flat areas of at least $15 \mathrm{~cm}$ in diameter. Contrary to ASTM, ISRM suggests minimum specimen lengths for both core and block samples to accommodate their suggested testing procedures and impact locations.

When performing the $\mathrm{SH}$ test, the impact directions should be made perpendicular to the test surface to minimize frictional sliding of the plunger tip, material removal by chipping, and partial energy transfer to and from the hammer. Both ISRM and ASTM standards stress the necessity for the hammer to impact test specimens perpendicular to specimen surfaces within $\pm 5^{\circ}$. To further emphasize this requirement, the standards suggest the use of a guided tube that fixes the hammer impact orientation to right angels. ISRM's suggested methods include an approach to normalize $R$ values that were taken at angles deviating from perpendicularity and is particularly useful for in situ testing, where right angle impacts may not be possible. Analytical functions are provided for both L-type and N-type SHs to normalize of $\mathrm{R}$ values for impacts taken at angles greater than $5^{\circ}$ from perpendicular. Newer hammers on the market, like the Proceq RockSchmidt, have built-in normalization functions to provide $R$ values that are angle independent.

ISRM- and ASTM-suggested methods advocate for laboratory tests to be performed in such a way as to minimize and prevent specimen movement and vibration during testing. For specimens that are not securely fastened to the ground surface during testing, loss of impact energy to other surfaces may result in a reduced and non-representative energy transfer from the material to the hammer. To minimize this risk, ISRM endorses the use of steel bases for block and core samples, to which samples should be securely clamped. The steel base should be placed on firm, flat ground and have minimum weights of $20 \mathrm{~kg}$ and $40 \mathrm{~kg}$ for use with L-type and N-type hammers, respectively. ASTM standards require core samples to be secured to a steel holder, although a minimum weight is not specified, block samples may alternatively be placed directly on a firm, flat surface. According to ASTM and ISRM standards, steel bases for core specimens include V-notch cradles and cradles with semicircular machined slots having the same radius as the core to be tested. The ASTM standard provides a note on the evaluation of three different holders for hammer testing on rock cores. It states that between steel angle, V-block, and semicircular core holders, differences in $\mathrm{R}$ values are small, but the $\mathrm{V}$-block gives consistently higher $\mathrm{R}$ values. However, since the $\mathrm{V}$-block design is the most economical to machine, the study indicates that the V-block holder is the most 
conventional, and the best selection as a core holder for SH testing of rock cores. ISRM discourages the use of V-notch cradles, particularly in weak rocks, since the unsupported section of the core is directly below the impact point, effectively changing the loading configuration. If a V-notch design must be used, ISRM suggests that the V-slot be angled to specify identical seating positions for different diameter specimens, where a $60^{\circ} \mathrm{V}$-shaped slot is the preferred angle for $\mathrm{NX}(54.7 \mathrm{~mm})$ cores.

Gunsallus et al. (1984) addressed the lack of an ASTM standard for SH testing of rocks in the laboratory at the time. This technical note is often cited in the most recent test standards. While the procedures at the time (ISRM and U.S. Army Corps of Engineers) suggested rigid support for the core to be tested, a specific support design for rock cores had not been specified. Gunsallus et al. evaluated the performance and results of three different core sample supports for SH testing: (1) a steel angle of $90^{\circ}$, welded to a steel sheet at three points along its length; (2) a steel block in which a $90^{\circ} \mathrm{V}$-notch had been machined; and (3) a steel block in which a semicircular groove had been machined. This study showed that the V-block gave consistently higher $\mathrm{R}$ values than the other supports, though the testing program was limited and only conducted on one type of sandstone and two types of dolostone. Additional errors in impacting methods and inclusion of material properties contributed to deficiencies in the findings.

A more rigorous study on the influence of rock cradle geometry on $R$ was published by Yilmaz et al. (2015) to address the lack of fundamental reasoning and agreement on the proper methods for supporting rock cores during laboratory $\mathrm{SH}$ testing. This study included 20 different rock varieties, and incorporated parameters like density, strength, and porosity. For the lower grouping of densities, $R$ values from testing with the arc shaped cradle were much higher than samples in the same density class, tested with the V-block. While the same trend was observed for samples in the upper density class, the difference between values from arc and V-block supports is less significant. In other words, reduced $\mathrm{R}$ values were witnessed for samples tested in the V-notch, with values being especially reduced for rock samples in lower density classes. The conclusions of this study are inconsistent with those presented in Gunsallus et al. (1984).

When samples were differentiated by strength, $R$ values from tests with the V-block were lower than those from tests with the semicircular block, with the weak class of rocks experiencing the most reduction, and the strongest class of rocks 
experiencing the least amount of reduction. For two classes of porosity, the more porous rock samples resulted in a greater reduction of $R$ values for the V-block when compared to the semicircular block. Strength tests also showed that a better correlation between UCS and R was achieved when using the semicircular holder, as opposed to the V-block. The authors conclude this study by stating that the choice of core cradle geometry may influence $R$. The arc-shaped cradle yields the best correlation to UCS, less sensitive to rock strength, density, porosity, and is the preferred choice for $\mathrm{SH}$ testing. The study also concludes that comparing results from tests performed on different core holder geometries should be avoided. $\mathrm{R}$ values from samples having been tested using a V-block may be reduced compared to expected values had an arc-shaped support been used, with increased reduction expected for particularly weak, low-density, and porous materials (Yilmaz et al., 2015).

The data collection and analysis protocols for $\mathrm{SH}$ vary between standards. The most recent ISRM-suggested methods state that $20 \mathrm{R}$ values should be taken with impacts being separated by at least one plunger diameter. If at any point during data gathering 10 subsequent readings differ by only four $R$ values, data collection may be stopped. In comparison, the first version of ISRM-suggested methods (1978) required only 10 readings. Original and current ASTM standards also suggest 10 readings to be taken per sample, with testing locations being separated by at least one plunger diameter. ISRM standards designate that for core samples, all points of impact should be one radius away from the nearest edge, and half of the thickness away from boundaries of block samples. ASTM standards specify that impact positions should be no less than one diameter from the sample edge for laboratory tests (using core and block samples).

Data reduction and calculation of a final characteristic SH value for a sample has also differed among published standards. The most recent ISRM-suggested methods state that no values should be discarded, and all values taken should be averaged to arrive at a final $\mathrm{R}$ for a sample. Earlier versions of ISRM's standards suggest that after a total of 20 readings are taken, the average of the highest 10 values should be taken as the sample average. ASTM standards suggest that after averaging 10 readings, any samples differing from the average by seven or more units should be discarded, and the remaining values should be averaged again to arrive at a final $R$ value.

Numerous averaging procedures for $\mathrm{SH}$ tests performed over the years are 
presented by Karaman \& Kesimal (2015). The number of impacts per sample in the studies investigated by Karaman \& Kesimal range from 3 to 40. Averaging methods differ by number and placement of impacts, inclusion of all readings, and discarding high versus low values. To investigate the influence of the different averaging methods to determine $\mathrm{R}$ of a sample, tests were conducted on 47 different rock samples using accepted methods from literature (including ASTM and ISRM), as well as three trial methods. The three trial methods for calculation of $\mathrm{R}$ included: (1) calculating the mean of six single impacts; (2) discarding the highest and lowest of eight single impacts and calculating the mean of the remaining values; and (3) discarding the two highest and two lowest of ten single impacts and calculating the mean of the reaming values.

Results of this study showed that the ASTM method provided slightly stronger correlations to UCS than the ISRM method referenced. Additionally, of the three trial methods, the first, where no values were discarded, provided the strongest correlation to UCS. In terms of the usefulness in discarding readings to calculate $\mathrm{R}$ averages, results of this study are inconclusive. Values to be discarded (whether they be extreme outliers, or just values on the high or low end) may be resultant of improper or carless operational procedures, and the extent of having to discard values, regardless of the method chosen, should be reduced by meticulous attention to experimental instructions. The most recent ISRM standard discourages discarding any values, as peculiar values might be representative of sample heterogeneity and the change of mechanical properties along a sample.

For samples having coarse grains throughout a matrix, the scatter of $\mathrm{R}$ values is expected to increase, especially when grain sizes are comparable to the plunger diameter and the relative strengths of grains and matrix differ greatly (Aydin, 2008). ASTM standards state that rocks having vesicular textures may be beyond the scope of SH tests since a solid contact surface may be impossible to produce. Weathering of crystalline rocks that induce microstructural changes results in significantly different $R$ values. This differential wearing of rock material introduces heterogeneity relative to grain size. Therefore, ISRM standards recommend that samples have the same degree of weathering if meaningful comparisons are to be made.

Moisture content can have a considerable effect on $R$ values depending on the sample microstructure. Sample moisture leads to softening of grains, weakening of 
bonds holding the matrix together, and can lead to sliding of inter-connected grains. The influence of moisture is enhanced for weathered, porous, loosely cemented, and muddy rocks, or newly crystalline rocks, with ample microcracks between grains. ISRM recommends that when using $R$ values to estimate UCS, tests should be conducted on samples that have the same moisture content. The method also suggests that rocks having low permeability be tested in a dry state due to difficulties in achieving uniform degrees of saturation for those samples.

SH tests have been extensively used to correlate R to UCS and other mechanical properties. Numerous studies advocate the use of correlation equations to convert SR to UCS. Often these equations are developed on the basis of rock type, though some equations have been developed with the purpose of wide applicability among different samples. Exponential and power law forms for correlations are common, but some early studies use linear functions for small ranges of $\mathrm{R}$ values (Aydin, 2008).

Tables 2.1 and 2.2 contain empirically-developed correlations between $\mathrm{R}$ and UCS (for L-type and N-type hammers, respectively) from various studies in which the SH method was used to estimate UCS. SH studies in literature were extensively researched to determine the types of samples used in development of the correlations

These equations were plotted to establish trends in the correlations based on rock type. Figure 2.6 and Figure 2.7 display the equations from Table 2.1 and Table 2.2 differentiated by rock types for L-type and N-type correlations, respectively. Several factors influence Schmidt hammer response and data scatter, so existing correlations may not be useful for some data sets. Even for similar rock types, differences in testing procedures, data reduction, and microstructures of tested samples may lead to substantial differences in derived correlations.

The plots in Figure 2.6 and 2.7 were analyzed on the basis of rock types, and general groupings of correlations were observed for similar rock types. For studies including data tables of values for UCS and R, some equations were manually developed and constructed for specific rock classes. Once differentiated in greater detail, the grouping of correlations for sedimentary rocks became more defined. Areas encompassing the equations for each rock type were drawn to showcase trends (Figure 2.8 and Figure 2.9 for L-type and N-type hammers, respectively). Several equations originally classified as "various" for the $\mathrm{N}$-type hammer had significantly 
Table 2.1: $\quad$ Empirical Correlations of R to UCS for L-type SH

\begin{tabular}{|c|c|c|c|c|c|}
\hline Source & Correlations & Rock Types & бUCS & $\mathbf{R}_{\mathbf{L}}$ & $\mathbf{r}$ \\
\hline Abu Bakar M.Z. et al. (2013) & $\sigma_{U C S}=5.24 \cdot R_{L}-29.12$ & Sandstone, Siltstone, Limestone & $24-112$ & $10-27$ & 0.82 \\
\hline \multirow[t]{8}{*}{ Aggistalis et al. (1996) } & $\sigma_{U C S}=2.14 \cdot R_{L}-15.44$ & Limestone, Sandstone, Marl, Dolomite & $9-48$ & $10-30$ & 0.71 \\
\hline & $\sigma_{U C S}=2.22 R_{L}-47.67$ & Basalt & $17-92$ & $21-55$ & 0.79 \\
\hline & $\sigma_{U C S}=4.235 \cdot e^{0.545 \cdot R_{L}}$ & & $17-92$ & $21-55$ & 0.84 \\
\hline & $\sigma_{U C S}=e^{\left(1.44+0.545 \cdot R_{L}\right)}$ & & $17-92$ & $21-55$ & 0.84 \\
\hline & $\sigma_{U C S}=4.235 \cdot 1.056^{R_{L}}$ & & $17-92$ & $21-55$ & 0.84 \\
\hline & $\sigma_{U C S}=1.52 \cdot R_{L}-5.94$ & Gabbro & $6-108$ & $19-58$ & 0.54 \\
\hline & $\sigma_{U C S}=1.31 \cdot R_{L}-2.52$ & Gabbro and Basalt & $6-108$ & $19-58$ & 0.55 \\
\hline & $\sigma_{U C S}=0.0396 \cdot R_{L}{ }^{2}-1.43 \cdot R_{L}+42.48$ & & 6-108 & $19-58$ & 0.59 \\
\hline $\begin{array}{l}\text { Aufmuth (1973: in Aydin \& } \\
\text { Basu, 2005) }\end{array}$ & $\sigma_{U C S}=0.33 \cdot\left(R_{L} \cdot \rho\right)^{1.35}$ & 25 different lithologies & $12-362$ & $10-54$ & 0.80 \\
\hline Aydin \& Basu (2005) & $\sigma_{U C S}=1.4459 \cdot e^{\left(0.0706 \cdot R_{L}\right)}$ & Granite & $6-197$ & $20-66$ & 0.92 \\
\hline $\begin{array}{l}\text { Beverly et al. (1979: in } \\
\text { Haramy \& DeMarco, 1985) }\end{array}$ & $\sigma_{U C S}=12.74 \cdot e^{\left(0.0185 \cdot R_{L} \cdot \rho\right)}$ & 20 different lithologies & $38-218$ & -- & -- \\
\hline \multirow[t]{2}{*}{ Cargill \& Shakoor (1990) } & $\sigma_{U C S}=3.32 \cdot e^{\left(0.043 \cdot R_{L} \cdot \rho\right)}$ & Sandstone & $35-271$ & $27-42$ & 0.93 \\
\hline & $\sigma_{U C S}=18.17 \cdot e^{\left(0.018 \cdot R_{L} \cdot \rho\right)}$ & $\begin{array}{l}\text { Carbonates: Limestone, dolomite, } \\
\text { marble, synthetic gneiss }\end{array}$ & $56-289$ & $31-49$ & 0.98 \\
\hline Çobanoğlu \& Çelik (2008) & $\sigma_{U C S}=6.59 \cdot R_{L}-212.63$ & $\begin{array}{l}\text { Saturated Limestone, sandstone, and } \\
\text { cement mortar }\end{array}$ & $35-106$ & $38-48$ & 0.65 \\
\hline $\begin{array}{l}\text { Dearman \& Irfan (1978: in } \\
\text { Aydin and Basu, 2005) }\end{array}$ & $\sigma_{U C S}=0.00016 \cdot R_{L}^{3.47}$ & Granite & $11-266$ & $23-62$ & -- \\
\hline Deere \& Miller (1966) & $\sigma_{U C S}=9.97 \cdot e^{\left(0.043 \cdot R_{L} \cdot \rho\right)}$ & $\begin{array}{l}\text { Basalt, diabase, dolomite, gneiss, } \\
\text { limestone, marble, quartzite, rock salt, } \\
\text { sandstone, schist, siltstone, tuff }\end{array}$ & $22-358$ & $23-59$ & 0.94 \\
\hline \multirow[t]{3}{*}{ Dinçer et al. (2004) } & $\sigma_{U C S}=3.32 \cdot e^{\left(0.043 \cdot R_{L} \cdot \rho\right)}$ & Basalt, andesite, tuff & $32-113$ & $26-54$ & 0.95 \\
\hline & $\sigma_{U C S}=104.3 \cdot \ln \left(R_{L}\right)-308.6$ & & & & 0.94 \\
\hline & $\sigma_{U C S}=13.02 \cdot e^{\left(0.0414 \cdot R_{L}\right)}$ & & & & 0.92 \\
\hline $\begin{array}{l}\text { Gokceoglu (1996: in Aydin \& } \\
\text { Basu, 2005) }\end{array}$ & $\sigma_{U C S}=0.0001 \cdot R_{L}^{3.27}$ & Marl & -- & -- & 0.84 \\
\hline Haramy \& DeMarco (1985) & $\sigma_{U C S}=0.994 \cdot R_{L}-0.383$ & Coal & $7-46$ & $12-44$ & 0.84 \\
\hline \multirow[t]{4}{*}{ Minaeian \& Ahangari (2013) } & $\sigma_{U C S}=0.678 \cdot R_{L}$ & Argillaceous-calcareous conglomerates & $3-33$ & $5-61$ & 0.94 \\
\hline & $\sigma_{U C S}=6.038 \cdot \ln \left(R_{L}\right)$ & with tuff, limestone, and marl & & & 0.88 \\
\hline & $\sigma_{U C S}=R_{L}^{0.885}$ & & & & 0.87 \\
\hline & $\sigma_{U C S}=e^{\left(0.092 \cdot R_{L}\right)}$ & & & & 0.87 \\
\hline Nazir et al. (2013) & $\sigma_{U C S}=12.83 \cdot e^{\left(0.0487 \cdot R_{L}\right)}$ & Limestone & $52-86$ & $28-39$ & 0.91 \\
\hline O’Rourke (1989) & $\sigma_{U C S}=4.85 \cdot R_{L}-76.18$ & $\begin{array}{l}\text { Sandstone, siltstone, limestone, } \\
\text { anhydrite }\end{array}$ & $14-215$ & $19-52$ & 0.77 \\
\hline Sachpazis (1990) & $\sigma_{U C S}=\frac{\left(R_{L}-15.7244\right)}{0.2329}$ & $\begin{array}{l}\text { Limestone, marble, dolomite, } \\
\text { metamorphosed limestone }\end{array}$ & $22-311$ & $17-60$ & 0.92 \\
\hline Shalabi et al. (2007) & $\sigma_{U C S}=3.201 \cdot R_{L}-46.59$ & $\begin{array}{l}\text { Low density dolomite, dolomitic } \\
\text { limestone }\end{array}$ & $21-110$ & $23-45$ & 0.76 \\
\hline Singh et al. (1983) & $\sigma_{U C S}=2 \cdot R_{L}$ & $\begin{array}{l}\text { Mudstone, sandstone, coal, seatearth, } \\
\text { siltstone }\end{array}$ & $11-102$ & $11-46$ & 0.72 \\
\hline Torabi et al. (2011) & $\sigma_{U C S}=0.0465 \cdot R_{L}^{2}-0.1756 \cdot R_{L}+27.682$ & Siltstone, sandstone, shale, argyle & $25-224$ & $16-67$ & 0.86 \\
\hline Tuğrul \& Zarif (1999) & $\sigma_{U C S}=8.36 \cdot R_{L}-416$ & Granite & $98-252$ & $61-72$ & 0.87 \\
\hline \multirow[t]{5}{*}{ Xu et al. (1990) } & $\sigma_{U C S}=e^{\left(0.0556 \cdot R_{L}+1.091\right)}$ & Mica-schist & $9-56$ & $17-53$ & 0.95 \\
\hline & $\sigma_{U C S}=e^{\left(0.0565 \cdot R_{L}+1.095\right)}$ & Prasinite & $8-145$ & $21-64$ & 0.91 \\
\hline & $\sigma_{U C S}=e^{\left(0.0272 \cdot R_{L}+2.0175\right)}$ & Serpentinite & -- & -- & 0.94 \\
\hline & $\sigma_{U C S}=e^{\left(0.0504 \cdot R_{L}+1.3286\right)}$ & Gabbro & -- & -- & 0.93 \\
\hline & $\sigma_{U C S}=e^{\left(0.5227 \cdot R_{L}+0.2304\right)}$ & Mudstone & -- & -- & 0.92 \\
\hline Yaşar \& Erdoğan (2004) & $\sigma_{U C S}=0.000004 \cdot R_{L}^{4.2917}$ & Limestone, marble, basalt, sandstone & $32-127$ & $41-58$ & 0.80 \\
\hline Yilmaz \& Sendir (2002) & $\sigma_{U C S}=2.27 \cdot e^{\left(0.06 \cdot R_{L}\right)}$ & Gypsum & $15-30$ & $30-44$ & 0.95 \\
\hline Yurdakul et al. (2011) & $\sigma_{U C S}=\frac{\left(R_{L}-57.973\right)}{0.082}$ & Marble, limestone, travertine & $24-193$ & $54-71$ & 0.39 \\
\hline
\end{tabular}

LEGEND- $\sigma_{U C S}$ : UCS $(\mathrm{MPa}) ; \mathrm{R}_{\mathrm{L}}$ : L-type Schmidt rebound; $\rho$ : density $\left(\mathrm{g} / \mathrm{cm}^{3}\right)$; $\mathrm{r}$ : regression coefficient 
Table 2.2: $\quad$ Empirical Correlations R to UCS for N-type SH

\begin{tabular}{|c|c|c|c|c|c|}
\hline Source & Correlations & Rock Types & $\sigma_{\text {UCS }}$ & $\mathbf{R}_{\mathbf{N}}$ & $\mathbf{r}$ \\
\hline$\overline{\text { Aydin \& Basu (2005) }}$ & $\sigma_{U C S}=0.9165 \cdot e^{\left(0.0669 \cdot R_{N}\right)}$ & Granite & $6-197$ & $23-76$ & 0.94 \\
\hline Fener et al. (2005) & $\sigma_{U C S}=4.24 \cdot e^{\left(0.059 \cdot R_{N}\right)}$ & $\begin{array}{l}\text { Basalt, granite, andesite, metagabro, } \\
\text { granodiorite, quartzite, marble, } \\
\text { limestone, travertine }\end{array}$ & $50-213$ & $46-65$ & 0.81 \\
\hline Ghose \& Chakraborti (1986) & $\sigma_{U C S}=0.88 \cdot R_{N}-12.11$ & Coal & $9-55$ & $25-61$ & 0.87 \\
\hline $\begin{array}{l}\text { Kahraman (1996: in Aydin \& } \\
\text { Basu, 2005) }\end{array}$ & $\sigma_{U C S}=0.00045 \cdot\left(R_{N} \cdot \rho\right)^{2.46}$ & 10 different litholoogies & -- & -- & 0.96 \\
\hline Kahraman (2001) & $\sigma_{U C S}=6.97 \cdot e^{\left(0.014 \cdot R_{N} \cdot \rho\right)}$ & $\begin{array}{l}\text { Dolomite, sandstone, limestone, marl, } \\
\text { diabase, serpentine, hematite }\end{array}$ & $4-153$ & $15-70$ & 0.78 \\
\hline Katz et al. (2000) & $\sigma_{U C S}=2.208 \cdot e^{\left(0.067 \cdot R_{N}\right)}$ & $\begin{array}{l}\text { Chalk, limestone, sandstone, marble, } \\
\text { syenite, granite }\end{array}$ & $11-259$ & $23-74$ & 0.96 \\
\hline $\begin{array}{l}\text { Kidybiniski (1980: in } \\
\text { Kahraman, 2001) }\end{array}$ & $\sigma_{U C S}=0.447 \cdot e^{(0.045 \cdot R+\rho)}$ & $\begin{array}{l}\text { Coal, shale, mudstone, siltstone, } \\
\text { sandstone }\end{array}$ & -- & -- & -- \\
\hline Kiliç \& Teyman (2008) & $\sigma_{U C S}=0.0137 \cdot R_{N}^{2.2721}$ & $\begin{array}{l}\text { Diorite, quartzite, limestone, } \\
\text { sandstone, granodiorite, basalt, marble, } \\
\text { trachyte, travertine, andesite, tuff }\end{array}$ & $6-240$ & $17-63$ & 0.94 \\
\hline Shorey et al. (1984) & $\begin{aligned} \sigma_{U C S} & =0.337 \cdot R_{N}-4.9 \\
\sigma_{U C S} & =1.20 \cdot e^{\left(0.052 \cdot R_{N}\right)}\end{aligned}$ & Coal & $2-14$ & $19-59$ & $\begin{array}{l}0.94 \\
0.94\end{array}$ \\
\hline Vasconcelos et al. (2007) & $\sigma_{U C S}=12.24 \cdot R_{N}-739.94$ & Granite & $26-149$ & $62-72$ & 0.83 \\
\hline Yagiz (2009) & $\sigma_{U C S}=0.0028 \cdot R_{N}^{1.5545}$ & $\begin{array}{l}\text { Travertine, limestone, schist, dolomitic } \\
\text { limestone }\end{array}$ & $20-137$ & $31-61$ & 0.92 \\
\hline
\end{tabular}

LEGEND- $\sigma_{U C S}$ : UCS $(\mathrm{MPa}) ; \mathrm{R}_{\mathrm{N}}$ : N-type Schmidt rebound; $\rho$ : density $\left(\mathrm{g} / \mathrm{cm}^{3}\right)$; $\mathrm{r}$ : regression coefficient

lower curves in Figure 2.7 than for the L-type hammer plotted in Figure 2.6. Upon further investigation, all of the samples in N-type "various" tests were low-density sedimentary, igneous, metamorphic, or coal. For both L-type and N-type hammers, less steeply-sloping correlations between R and UCS are associated with coal, low-density sedimentary, and metamorphic rocks. A combination of these rock types can be differentiated from the other "various" groups that include strongly-sloping correlating rock types (e.g. dolomite and sandstone). Several plots showing the bounding limits for correlation equations of certain rock types are shown in in Figures 2.8 and 2.9, for the L-type and N-type Schmidt hammers, respectively.

The plots illustrate the distinct trends in empirically-developed correlation equations between $R$ and UCS. R values for high-density sedimentary samples show correlations with greater slopes and increased curvature, whereas correlations from coal, low-density sedimentary rocks, and metamorphic rocks tend to have less steep slopes and curvature. Igneous rock trends fall somewhere in the middle of the other trends, while greater slopes are observed from L-type correlations versus $\mathrm{N}$-type correlations. 


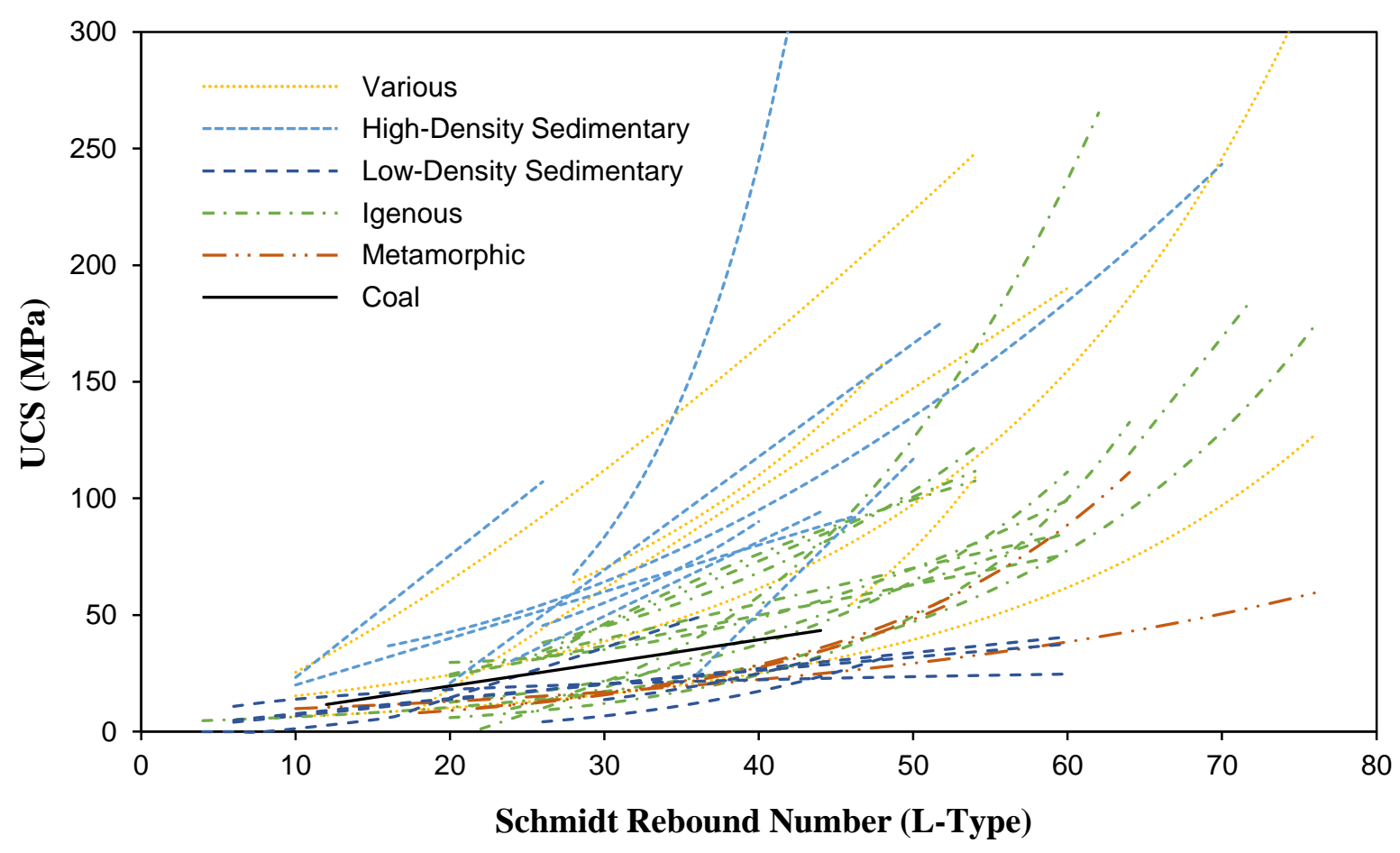

Figure 2.6: Correlations of R to UCS for L-type SH Grouped by Rock Type

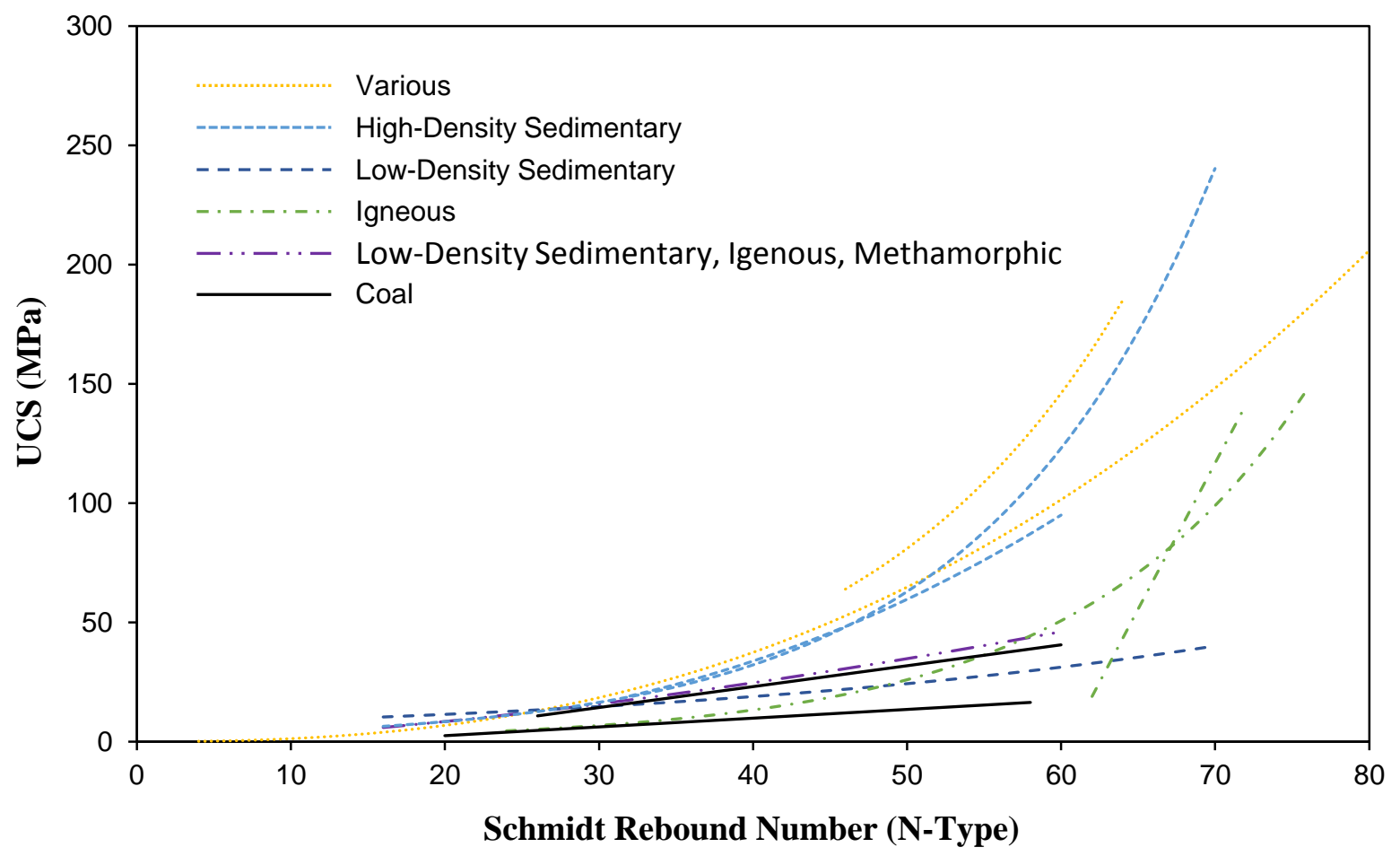

Figure 2.7: Correlations of R to UCS for N-type SH Grouped by Rock Type 

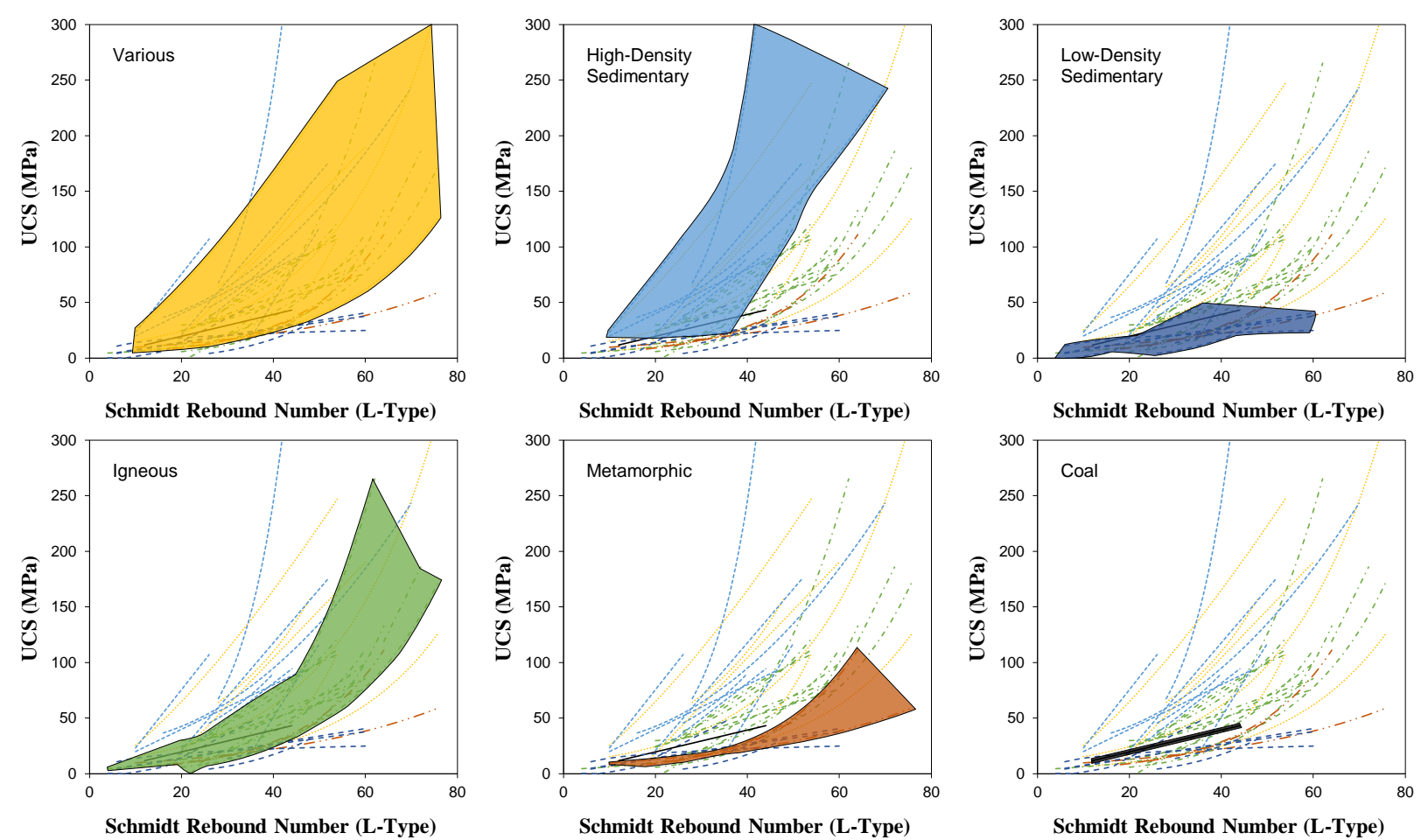

Figure 2.8: Bounding Limits by Rock Type for Correlations of R to UCS for L-type SH
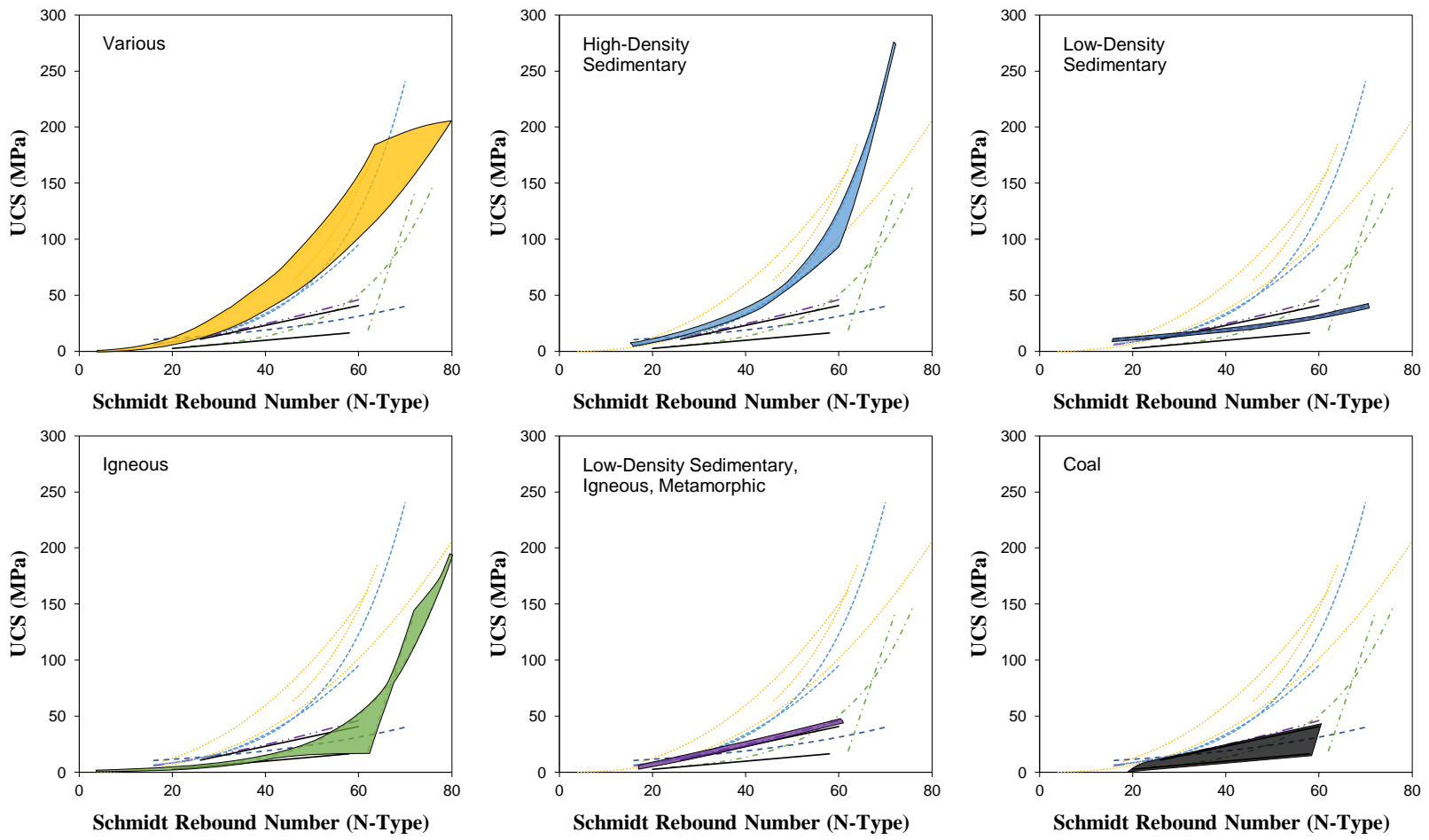

Figure 2.9: Bounding Limits by Rock Type for Correlations of R to UCS for N-type SH 
Based on this meta-analysis of SH correlations to UCS, it is concluded that rock types influence the correlations of $\mathrm{R}$ values from $\mathrm{SH}$ tests to true UCS values. This result agrees with standard instructions for the development of SH correlations.

According to ISRM-suggested methods, correlations should be developed on a case-by-case basis to increase estimation accuracy of UCS and E from R. Test specimens should be anisotropic and representative of the entire sample set. Correlations from R to UCS and E should be established using a data set including all of several hammer impacts to reflect the nature of heterogeneity in sample surfaces (Aydin, 2008).

While numerous correlation equations are available in literature, it is important to realize that each equation from a study provides a correlation that is specific to the material tested and may be dependent on the methods of operation and deduction of R. Users of any single empirical equation to estimate UCS based on SH tests of rocks should be wary of choosing an equation based solely on the correlation coefficient, as similar values may not be expected for rock types, testing procedures, or other rock properties that differ from those of the original samples used in the study.

Although several studies use linear models for correlations, the reasoning for this trend might have been due to the simplicity of the method. According to ISRM's revised standards, linear correlations may be expected for rocks with relatively uniform microstructures. The linear model has been successfully used to estimate coal strength (e.g. Haramy \& DeMarco, 1985; Ghose \& Chakraborti, 1986) likely due to the consistent microstructure and surface smoothness of coal material. For samples with similar microstructural arrangements, $\mathrm{R}$ results from hammer tests are likely to be linearly correlated to UCS.

Aydin \& Basu (2005) investigated the influence of various weathering grades of granites and found that the resultant exponential form of correlation curves was a consequence of microstructural changes during the course of weathering. For the granites in the first two weathering classes (mostly crystalline structures with the least amount of weathering), variation in UCS was the greatest. The large rate of change in UCS for the least weathered samples is explained by the greater sensitivity to deformation and failure in fresh crystalline igneous rocks. Failure for crystalline rocks occurs by the merging of pre-existing and load-induced microcracks. For 
granites that had progressive amounts of weathering, the rate of change in deformation and strength decreased. Therefore, the rate of change for $\mathrm{R}$ values of highly weathered granites decreased in a similar fashion. For weathered igneous rocks, failure occurs as grain and intra-granular contacts weaken.

This study presented a possible explanation to the tendency for certain $R$ values to correlate exponentially to UCS. As failure mechanisms transitioned from intra-microcrack (caused by failure and merging of the connections between crystalline structures) to intra-granular (caused by failure along grain boundaries as grain-to-grain space is increased with the breakdown of crystal structure), the shape of the curve transitioned from a steeply-sloping linear trend to a less steeply-sloping linear trend. The combination of a less steeply-sloping trend for highly weathered material and a steeply-sloping trend for crystalline material resulted in a curve that mimicked an exponential function. The exponential shape observed in many of the correlations of R to UCS in literature may be explained by a transition of rock failure mechanisms, as was observed by Aydin \& Basu (2005) for weathered granites.

\section{Ultrasonic Pulse Velocity}

UPV is a method of rock characterization based on the generation, transmission, and reception of a low frequency (commonly $54 \mathrm{kHz}$ ) waveform through a sample. The sonic velocity of a material is calculated by dividing the sample length between the transducers by the travel time for the signal wave propagation through the medium. The movement of the wave is the transfer of strain energy through a medium; therefore, the sonic velocity is dependent on small-scale material properties (such as mineralogy, grain size, porosity, and structural arrangement) that influence the rate of energy dissipation as well as the mechanical and elastic properties of the medium. Material properties influencing energy dissipation in a generated waveform define a unique sonic velocity for a medium (Aydin, 2013).

The general circuit layout for a UPV system testing a rock core is shown in Figure 2.10. Systems for ultrasonic testing of rock samples typically include the following as designated by their lettered positions in Figure 2.1: (a) a signal timer that marks the beginning of each pulse interval being generated; (b) amplifiers and filters to enhance the signal; (c) an arrival timer often in the form of an oscilloscope that measures the time of the arrival for the received signal; and (d) a data acquisition 
(a)

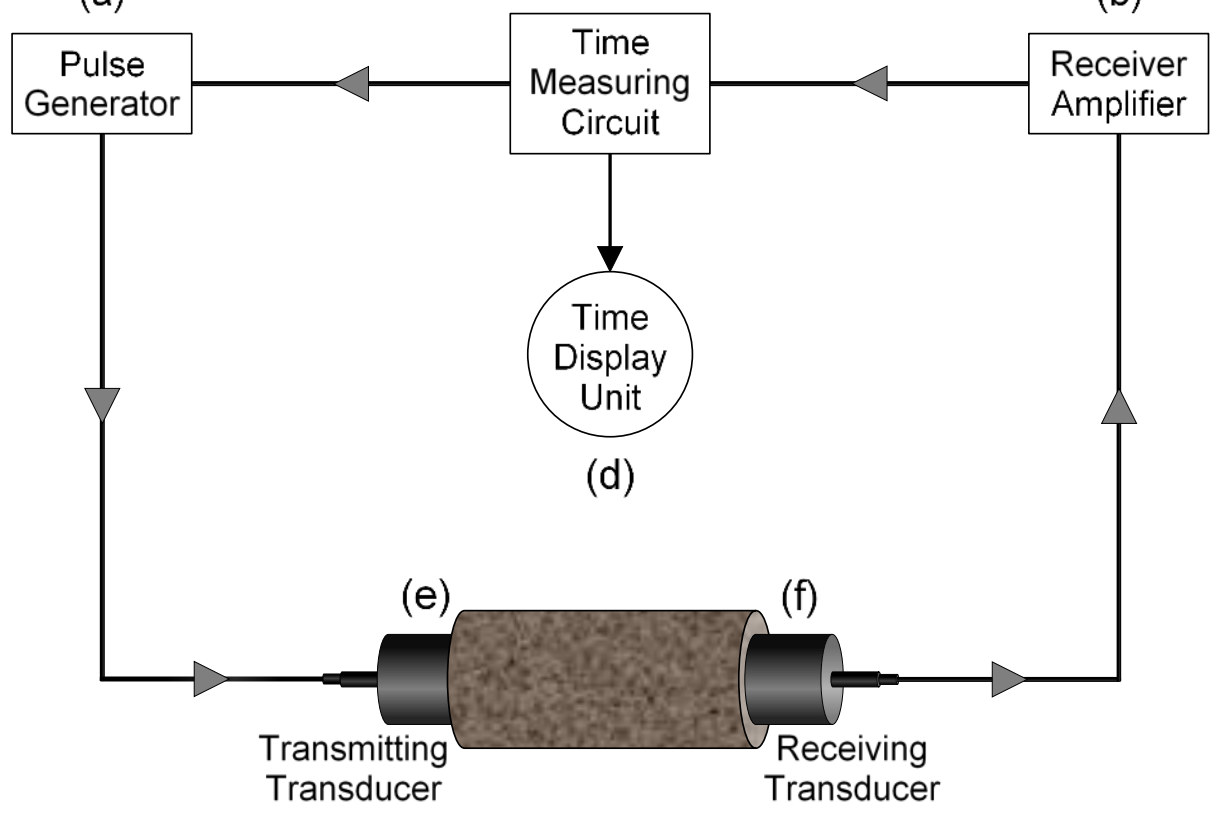

Figure 2.10: UPV Direct Transmission Schematic

unit that allows for signal display. Additionally, a transmitting-receiving pair of transducers is required to actually generate and receive signals. The transmitting (e) and receiving (f) transducers in Figure 2.10 show the placement of transducers on a rock core specimen for the direct mode of transmission, in which signal propagation occurs on a $0^{\circ}$ axis between the transducers.

UPV is a widely-used NDT method that allows for characterization of rock material from the calculated material sound velocity (Aydin, 2013). Several studies are presented by Karakul and Ulusay (2013) that show several instances where close correlations exist between primary sonic velocity, $\left(\mathrm{V}_{\mathrm{P}}\right)$, and mechanical properties of rocks, like UCS. Like the Schmidt hammer, empirical equations for $V_{P}$ differ for different rock types and material properties.

\subsection{Asteroid Characterization Challenges}

During asteroid capture operation, mechanical characterization of the rock material is necessary to provide information to the robotic controllers governing the lifting mechanisms. In order to predict mechanical behaviors of asteroids using 
NDTs, the expected mineralogy, structure, and strength of asteroid material must be considered to strengthen these predictions based on the NDT response from similarly formatted terrestrial samples.

NEA's targeted for ARM will be discussed in detail with specific focuses on their classifications and mineral constituents. Anticipated structural arrangements of asteroids and associated challenges with nondestructive characterization will be presented. Additionally, a history of strength derivations for asteroid bodies will be offered and verified for quality.

The additional factor of the low-temperature environments encountered by asteroids and its implications on an asteroid's mechanical properties must be considered. Influences of a low-temperature environment on the response of NDTs must be realized for the use of such tools in the autonomous characterization of asteroid mechanical properties. The low temperature anticipated for asteroid bodies will be presented, and the implications of low-temperature on the mechanical properties of terrestrial rock materials from past studies will be discussed.

\subsubsection{Target Near-Earth Asteroids}

An NEA is classified as an asteroid of the solar system that is between 0.983 and 1.3 Astronautical Units (1 AU is equal to 149.6 million $\mathrm{km}$, the mean distance from the center of the Earth to the center of the Sun) away from the sun at the closest distance along its orbit, making it within close proximity to Earth's orbit. Numerous NEAs in our solar system have been extensively studied up close and from afar, contributing to a collection of likely and predicted physical parameters for many of these asteroids. This section will detail available information on the four potential target asteroids for ARM: (1) Itokawa (25143); (2) Bennu (101955); (3) 2008 EV5 (341843); and (4) Ryugu (162173), and will include a discussion of the corresponding spectral classifications for these asteroids.

Asteroids may be classified by their spectral type (thought to correspond to the surface constituents of the asteroid), color, and albedo. The Tholen classification, the most widely used asteroid taxonomy, divides asteroids into three main groups: the C-group- dark carbonaceous bodies; the S-group- siliceous "stony" bodies; and the X-group- metallic bodies (Schelte, 2002). For the proposed ARM, C-group and S-group type NEA's are being targeted and will be discussed. Itokawa is classified as 
an S(IV) asteroid, within the S-group. The three others fall under the classification of C-group asteroids; Bennu is a B-type asteroid, while 2008 EV5 and Ryugu are both C-type asteroids (NASA Jet Propulsion Laboratory).

The S-group classification includes asteroids with spectral absorptions around $1 \mu \mathrm{m}$, indicating surfaces comprised of siliceous and stony material. The composition of S-type asteroids is thought to be metallic iron mixed with iron and magnesium silicates. These asteroids are moderately bright with albedos between 0.10 and 0.22 The S-group asteroids are broken down by compositional subtypes S(I)-S(VII), varied by the mineralogy of their surfaces, ranging from pure olivine, to olivine-pyroxene mixtures, to pure pyroxene, and pyroxene-feldspar (basalt) mixtures. The surface silica components of S(IV) asteroids are composed of olivine-orthopyroxene mixtures that are poor in calcium. The S(IV) subgroup has been directly linked to ordinary chondrite meteorites (Gaffey, 1993).

C-group asteroids are named for their carbonaceous surface constituents. Within the C-group classification, B-type asteroids are thought to be primitive remnants from the early solar system, rich in volatiles. Spectral data suggests the majority of the surface of B-type asteroids is covered by anhydrous silicates, hydrated clay minerals, organic polymers, magnetite, and sulfides. The closest meteoritic matches to B-type asteroids have been obtained by gently heating carbonaceous chondrites (CM type) in a laboratory (Clark, 2010).

C-type asteroids are the most common and standard among the C-group classification. C-type asteroids are extremely dark with average albedos ranging from 0.02 to 0.12 (Tedesco, 2002). Spectral data indicates the presence of water content in minerals on the surface of C-type asteroids. Surface compositions of Ctype asteroids are largely carbonaceous and have been linked to CI and CM carbonaceous chondrite meteorites.

The four candidate parent asteroids for ARM are discussed in greater detail below, and Table 2.3 lists available parameter estimates for these asteroids.

\section{Itokawa (25143)}

Itokawa was first discovered in 1998, and photometric and radar observations from Earth provided an initial shape model of the asteroid. In 2005, the Hayabusa 
Table 2.3: $\quad$ Parameter Table for ARM Candidate Parent Asteroids

\begin{tabular}{|c|c|c|c|c|c|}
\hline Parameter & Itokawa & Benuu & $2008 \mathrm{EV} 5$ & Ryugu & Source \\
\hline Spectral type & $\mathrm{S}(\mathrm{IV})$ & $\mathrm{B}$ & $\mathrm{C}$ & $\mathrm{C}$ & $\begin{array}{l}\text { Itokawa: NASA Jet Propulsion Laboratory } \\
\text { Bennu: Müller, 2012 } \\
\text { 2008 EV5: Busch, } 2011 \\
\text { Ryugu: Hasegawa, } 2008\end{array}$ \\
\hline Geometric albedo & $0.19_{-0.03}^{+0.11}$ & $\begin{array}{c}0.046 \pm 0.005 \\
0.045_{-0.012}^{+0.015}\end{array}$ & $\begin{array}{c}0.13 \pm 0.05 \\
0.12 \pm 0.04 \\
0.125 \pm 0.075\end{array}$ & $\begin{array}{c}0.07 \pm 0.006 \\
0.063_{-0.015}^{+0.020}\end{array}$ & $\begin{array}{l}\text { Itokawa: Müller, 2015 } \\
\text { Bennu: Emery, 2014; Müller, } 2012 \\
\text { 2008 EV5: Alí-Logoa, 2013; Busch 2013; Reddy, } 2012 \\
\text { Ryugu: Müller, 2011; Hasegawa, } 2008\end{array}$ \\
\hline Dimensions (m) & $\begin{array}{c}535 \times 294 \times 209 \\
520 \times 270 \times 230 \\
\pm 50 \times 30 \times 20\end{array}$ & -- & 0 & -- & $\begin{array}{l}\text { Itokawa: Fujiwara, 2006; Müller, } 2005 \\
\text { Bennu: N/A } \\
\text { 2008 EV5: N/A } \\
\text { Ryugu: N/A }\end{array}$ \\
\hline Effective diameter (m) & $\begin{array}{c}330 \\
320 \pm 30\end{array}$ & $\begin{array}{l}492 \pm 20 \\
492 \pm 15\end{array}$ & $\begin{array}{c}370 \pm 6 \\
400 \pm 50\end{array}$ & $\begin{array}{c}870 \pm 30 \\
920 \pm 120\end{array}$ & $\begin{array}{l}\text { Itokawa: NASA Jet Propulsion Laboratory; Müller, } 2005 \\
\text { Bennu: Nolan, 2013; Müller, } 2012 \\
\text { 2008 EV5: Alí-Logoa, 2013; Busch, } 2011 \\
\text { Ryugu: Müller, 2011; Hasegawa, } 2008\end{array}$ \\
\hline Volume $\left(\mathrm{x} 10^{7} \mathrm{~m}^{3}\right)$ & $1.84 \pm 0.092$ & $6.23 \pm 0.6$ & $3.5 \pm 1.4$ & -- & $\begin{array}{l}\text { Ittokawa: Fujiwara, } 2006 \\
\text { Bennu: Nolan, 2013 } \\
\text { 2008 EV5: Busch, } 2011 \\
\text { Ryugu: N/A }\end{array}$ \\
\hline Bulk density $\left(\mathrm{g} / \mathrm{cm}^{3}\right)$ & $\begin{array}{l}1.9 \pm 0.13 \\
2.6\end{array}$ & $\begin{array}{l}1.26 \pm 0.07 \\
1.65\end{array}$ & $\begin{array}{c}3.11 \\
3.0 \pm 1.0\end{array}$ & -- & $\begin{array}{l}\text { Itokawa: Fujiwara, 2006; Müller, 2005 } \\
\text { Bennu: Chesley, 2014, Nolan, 2013 } \\
\text { 2008 EV5: Alí-Logoa, 2013; Busch, } 2011 \\
\text { Ryugu: N/A }\end{array}$ \\
\hline $\operatorname{Mass}\left(\mathrm{x} 10^{10} \mathrm{~kg}\right)$ & $\begin{array}{c}3.51 \pm 0.105 \\
4.5_{-1.8}^{+2.0}\end{array}$ & $7.8 \pm 0.9$ & -- & -- & $\begin{array}{l}\text { Itokawa: Fujiwara, 2006; Müller, } 2005 \\
\text { Bennu: Chesley, 2014 } \\
\text { 2008 EV5: N/A } \\
\text { Ryugu: N/A }\end{array}$ \\
\hline Porosity & $41 \%$ & $40 \pm 10 \%$ & -- & -- & $\begin{array}{l}\text { Ittokawa: NASA Jet Propulsion Laboratory } \\
\text { Bennu: Chesley, 2014 } \\
2008 \text { EV5: N/A } \\
\text { Ryugu: N/A }\end{array}$ \\
\hline $\begin{array}{l}\text { Average regolith grain } \\
\text { size }(\mathrm{mm})\end{array}$ & -- & $5.6 \pm 3.9$ & $\begin{array}{c}6.6 \pm 1.3 \dagger \\
12.5_{-2.6}^{+2.7}\end{array}$ & -- & $\begin{array}{l}\text { Itokawa: N/A } \\
\text { Bennu: Emery, } 2014 \\
\text { 2008 EV5: Alí-Logoa, } 2013 \\
\text { Ryugu: N/A }\end{array}$ \\
\hline $\begin{array}{l}\text { Standard gravitational } \\
\text { parameter }\left(\mathrm{m}^{3} / \mathrm{s}^{2}\right)\end{array}$ & $2.1 \pm 0.063$ & $5.2 \pm 0.6$ & -- & -- & $\begin{array}{l}\text { Itokawa: NASA Jet Propulsion Laboratory } \\
\text { Bennu: Chesley, 2014 } \\
\text { 2008 EV5: N/A } \\
\text { Ryugu: N/A }\end{array}$ \\
\hline $\begin{array}{l}\text { Key minerals and } \\
\text { compounds }\end{array}$ & $\begin{array}{l}\text { Olivine, low \& high Ca-pyroxene, } \\
\text { feldspar, troilite, chromite, } \\
\text { phosphate, Fe-Ni grains, silicates }\end{array}$ & $\begin{array}{l}\text { Volatiles; hydrous clay minerals; } \\
\text { silicates; pyroxene }\end{array}$ & $\begin{array}{l}\text { Fe-bearing and } \mathrm{Mg} \text {-rich serpentine } \\
\text { and saponite, ferrihydrite with } \\
\text { variable } \mathrm{S} \text { and } \mathrm{Ni}\end{array}$ & Fe-bearing phyllosilicates & $\begin{array}{l}\text { Itokawa: Nakamura, 2011 } \\
\text { Bennu: Chesley, 2014; Emery, 2014; Nolan , } 2013 \\
\text { 2008 EV5: Tomeoka, } 1988 \\
\text { Ryugu: Vilas, } 2008\end{array}$ \\
\hline Internal structure & Rubble-pile & Rubble-pile & Rubble-pile & -- & $\begin{array}{l}\text { Itokawa: Fujwarra, } 2006 \\
\text { Bennu: Chesley, } 2014 \\
\text { 2008 EV5: Busch, } 2013 \\
\text { Ryugu: N/A }\end{array}$ \\
\hline Surface features & $\begin{array}{c}\text { Many large boulders; gravel, } \\
\text { fine dust }\end{array}$ & $\begin{array}{c}\text { Single } 10-20 \mathrm{~m} \text { boulder, } \\
\text { smooth surface, loose } \\
\text { regolith }\end{array}$ & $\begin{array}{c}\text { Single } 150 \text { m concavity; } \\
\text { prominent equatorial ridge, } \\
\text { loose regolith }\end{array}$ & Boulders, bare rocks, gravel & $\begin{array}{l}\text { Ittokawa: Fujiwara, 2006; Nakamura, } 2011 \\
\text { Bennu: Nolan, 2013 } \\
\text { 2008 EV5: Busch, 2013; Busch, } 2011 \\
\text { Ryugu: Hasegawa, 2008 }\end{array}$ \\
\hline
\end{tabular}

LEGEND- $\dagger$ : Low compaction estimate; + : High compaction estimate

spacecraft hovered seven $\mathrm{km}$ from Itokawa's surface to preform additional tests at close proximity. Later that year, the spacecraft briefly touched down on the asteroid surface and collected rocky particles from the surface. Numerous boulders and large rock particles were discovered on Itokawa's surface during the Hayabusa mission. A scanning electron microscope identified 1534 rocky particles from Itokawa's surface, most of them smaller than $10 \mu \mathrm{m}$ (Nakamura, 2011).

\section{Bennu (101955)}

Bennu was first discovered in September, 1999 by the LINEAR asteroid survey. Since its discovery, Bennu has been optically observed over 500 times to obtain astrometric measurements. In addition, radar and radio telescopes have been used to further classify the asteroid (Chesley, 2014). In 2009, the European Space Agency launched a spacecraft 1.5 x $106 \mathrm{~km}$ from Earth to preform spectral photometry measurements of Bennu. During its most recent (and closest) approaches to Earth in 1999 and 2005, radar images taken of Bennu were used to develop the 
first shape models of the body (Müller, 2012).

\section{EV5 (341843)}

The asteroid body 2008 EV5 was discovered on March 4, 2008. Radar imaging was used to observe 2008 EV5 in December of 2008. The first shape models were produced to show the shape of 2008 EV5 to be an oblate spheroid (Busch, 2011). Spectral observations were made using visible and near-infrared wavelengths (Reddy, 2012).

\section{Ryugu (162173)}

The asteroid Ryugu (alternatively known as 1999 JU3) was discovered on May 10, 1999. Visual spectral data was obtained for the original characterization of Ryugu before 2007. In 2007, Ryugu approached its closest point to Earth along its orbit. Mid-infrared observations were performed from space in 2007, while ground-based, mid-infrared observations of Ryugu were performed later that year (Hasegawa, 2008).

\subsubsection{Asteroid Sturcture}

While spectral imaging has been performed extensively to assess the mineralogy of asteroids for classification, the internal structures and material strengths of asteroids are not as well understood and agreed upon.

Internal structures of asteroids depend heavily on asteroid size, collision history, physical processes, spin rates, and mineral grain sizes, with these factors influencing the cohesion and force interactions between mineral grains. The internal structures of asteroids can be broken into two broad categories: monolithic and rubble-pile, though the internal structures of asteroids are speculated to be much more complex.

Monolithic structures are described as solid bodies that have homogeneous internal mass distributions, whereas a rubble-pile is a non-monolithic object resulting from the gravitational coalescence of numerous pieces of rock material. Through collisional events, many asteroid bodies have endured damaging impacts that may have resulted in substantial fractures and disassociations in their main structures 
when impact energy has not been strong enough to permanently disperse asteroid materials. Such affected asteroid bodies have been referred to as rubble-pile asteroids, having internal disorganization and weak gravitational cohesion between fragments (Benavidez et al. 2012).

Before successful autonomous capture of a boulder on the surface of a larger asteroid body, the internal structure and stability of the boulder should be assessed to prevent time loss in the attempted apprehension of a boulder that will not retain its structural integrity during capture. Strength information can provide data on the stability of asteroid structures, since it is related to lack of void space and is dictated by forces between grains.

\subsubsection{Asteroid Strength}

Data on mechanical properties of asteroids is limited in quantity and methods of derivation. Material strengths of asteroids have been inferred through various means of indirect estimations. At this time, in situ asteroid material has been scarcely studied. Asteroid strengths have been speculated based on computer models, experiments of simulated asteroid material, and strength of meteorites.

Computer models and testing of asteroid simulants is accomplished through the incorporation of observable phenomena. Some studies have proposed correlations between ejecta velocity of asteroids and their compressive strengths based on observations of ejecta responses for materials of similar strength. Other studies have focused on the thermal stress influences on modeling asteroid strength.

Most of the currently-accepted strength data originates from mechanical testing and observation of meteorites. Ram-pressure estimates via observations of meteorite fractures are indicative of the bulk strength of the material and ram pressure is calculated for each fragmentation that occurs during a meteorite's descent. Laboratory tests of meteorite samples revealed much greater compressive and tensile strengths than were inferred by ram observations. Table 2.4 summarizes the inferred strength of asteroid from the studies discussed above. The target candidate parent asteroids for ARM (discussed in Section 2.2.1) are of the stony and carbonaceous types. Based on the information in Table 2.4, the strength ranges expected for stony and carbonaceous asteroids range from 0.025 MPa to $207 \mathrm{MPa}$. 
Table 2.4: $\quad$ Collection of Inferred Asteroid Strengths

\begin{tabular}{llcll}
\hline Strength Type & Material Type & Strength (MPa) & Determination Method & Source \\
\hline Cohesive & Asteroid regolith & 0.025 & $\begin{array}{l}\text { Soft sphere DEM of regolith } \\
\text { behavior }\end{array}$ & Sanchez \& Scheeres \\
Ram/First Breakup & Stony meteorite & $0.04-5$ & Fragmentation observation & Popova et al. \\
Compressive & Stony asteroid & $0.1-5.5$ & Impact ejecta modeling & Michikami et al. \\
Ram/First Breakup & Stony meteorite & $0.4-11$ & Fragmentation observation & Popova et al. \\
Compressive & $\begin{array}{l}\text { Bunburra Rockhole } \\
\text { Achondrite }\end{array}$ & 0.9 & N/A & NASA SBAG \\
Compressive & Stony asteroid & $1-5$ & Fragmentation observation & Petrovic \\
Compressive & Tagish Lake CC & 2.2 & N/A & NASA SBAG \\
Tensile & Iron meteorite & 4 & Mechanical test & Petrovic \\
Compressive & Eros (stony asteroid) & 10 & Thermal stress FEA & Dombard \& Freed \\
Tensile & Stony meteorite & $21.83-29.5$ & Mechanical test & Petrovic \\
Tensile & Stony meteorite & $24.7-28.5$ & Mechanical test & Popova et al. \\
Tensile & $\begin{array}{l}\text { Carbonaceous } \\
\text { meteorite }\end{array}$ & 29.5 & Mechanical test & Popova et al. \\
Compressive & Stony meteorite & $188-207$ & Mechanical test & Popova et al \\
Compressive & Stony meteorite & 200 & Mechanical test & Petrovic \\
Compressive & Iron meteorite & 430 & Mechanical test & Petrovic \\
\hline \hline
\end{tabular}

\subsubsection{Low-Temperature Effects}

As the asteroid bodies in our solar system revolve around the sun, their irregular shapes can cause them to tumble erratically in orbit. As asteroids cycle between facing the sun and being turned away from it, their temperatures can change drastically. The average temperature of a typical asteroid is approximately $-100^{\circ} \mathrm{C}$ (NASA Marshall Space Flight Center). Coradini et al. (2011) used visible, InfraRed, and Thermal Imaging Spectrometry (VIRTIS) on board the Rosetta spacecraft to model the surface temperature of the asteroid 21 Lutetia and found a surface temperature range of 170 to $245 \mathrm{~K}$ ( -103 to $-28 \mathrm{C})$. They also found that the surface temperature was highly correlated with topographic features on the surface of 21 Lutetia.

In 1962, Monfore \& Lentz (as cited in Heins \& Friz, 1967) produced some of 
the first studies in mechanical behavior changes of concrete at low-temperature that showed, in general, that compressive strength of concrete mixtures increased with decreasing temperature as samples were brought down to $121^{\circ} \mathrm{C}\left(-250^{\circ} \mathrm{F}\right)$. Various other studies in low-temperature mechanics of concrete summarized by Dahmani et al. (2006) have shown that for concrete samples exposed to low-temperature environments, compressive strength may be as high as two to three times higher than at room temperature for wet concrete, though the strength increase is much less for air-dried concrete. This is related to the formation of ice in the pores of hydrated concrete that contribute to an increase in matrix strength. Concrete studies have also shown that Young's modulus increases with decreasing temperature, with greater increases in stiffness occurring in wetted concrete as opposed to air-dried concrete. The review by Dahmani et al. concludes that the behavior of concrete at low-temperature is governed by its porosity and moisture content.

Heins \& Friz (1967) provided one of the first investigations into changes in rock properties and behaviors due to low-temperatures. Heins \& Friz found that for rock samples frozen with liquid nitrogen, the point load strength increased compared to room temperature values. Similarly, the modulus of rupture (maximum bearing stress) for all specimens increased with decreasing temperature. Analysis of strain of limestone samples during uniaxial point load compression in this study showed an increase in Young's modulus for limestone at liquid nitrogen temperatures. Shortly after this study, Mellor (1971) analyzed the effects of low-temperature on both air-dried and saturated rock samples frozen by liquid nitrogen. Results showed that for all samples at dry and saturated conditions, both compressive and tensile strengths increased with decreasing temperature, with greater changes in strength observed for saturated samples due to ice generation. For nominally dry rocks, Mellor concluded that strength increases by approximately $2 \%$ for each $10^{\circ} \mathrm{C}$ temperature drop. In his study, Mellor included past investigations into changes of compressional and breaking strength of rocks at low-temperature that also indicated increases in strength at decreasing temperatures. In his analysis of deformation effects, Mellor shows that the tangent modulus slightly increases with decreasing temperature for sandstone and limestone samples, but a change in modulus is negligible for granite samples. In 1969, a similar study by Podnieks et al. (as cited in Mellor, 1971) showed increases in Young's modulus with decreasing temperature for basalt, granodiorite, and dacite samples, although a decrease in the elastic modulus of limestone samples with colder temperature was observed. 
Table 2.5: Low-Temperature Rock Mechanics in Literature

\begin{tabular}{llcl}
\hline \hline Material(s) & Property & Effect & Source \\
\hline Concrete & Compressive strength & $\uparrow$ & Summarized in Dahmani et al. (2006) \\
Concrete & Young's modulus & $\uparrow$ & Summarized in Dahmani et al. (2006) \\
Concrete & Compressive strength & $\downarrow$ & Monfore \& Lentz (1962) \\
Concrete & Tensile strength & $\downarrow$ & Monfore \& Lentz (1962) \\
Silica, granite, quartz & Compressive strength & $\uparrow$ & Charles (1959) \\
Limestone, basalt, granite & Point load strength & $\uparrow$ & Heins \& Friz (1967) \\
Limestone & Young's modulus & $\uparrow$ & Heins \& Friz (1967) \\
Basalt & Young's modulus & $\uparrow$ & Podnieks (1969) \\
Limestone & Young's modulus & $\downarrow$ & Podnieks (1969) \\
Limestone, sandstone, granite & Compressive strength & $\uparrow$ & Mellor (1971) \\
Limestone, sandstone & Young's modulus & $\uparrow$ & Mellor (1971) \\
Granite & Young's modulus & -- & Mellor (1971) \\
\hline \hline
\end{tabular}

Issues with the studies from Heins \& Friz (1967) and Mellor (1971) concern their use of liquid nitrogen to freeze rock samples. In both papers, samples were not protected from the liquid nitrogen environments they were submerged in before testing procedures took place, raising issues concerning the validity and applicability of the work. The effect of low-temperature on elastic properties of rock material is still very unclear from past studies, as the trends do not agree for all sample types. From low-temperature rock and concrete mechanics literature, it seems to be generally accepted that rock materials gain strength when exposed to below-freezing environments.

A summary of results from low-temperature studies in literature is presented in Table 2.5. This table includes available information on the effect of low-temperature on mechanical properties of rock and concrete samples. Arrows pointing upwards indicate an increase in that property as a result of low-temperature, and down arrows indicate a decrease in that property as a result of low-temperature.

\subsection{Summary}

This literature review has established several shortcomings associated with 
using NDTs to characterize mechanical properties of low-temperature terrestrial materials for the eventual characterization of asteroid material.

While UCS is one of the most common design criterion for mining engineering design, the UCS test method often underestimates in situ strength of the rock mass. Using NDT correlations to UCS may be unrepresentative of true strength values. Additionally, elastic analysis of stress-strain curves derived from UCS testing is best utilized for simple elasticity analyses.

SH and UPV methods to approximate mechanical properties of rocks are heavily dependent on operational methods and specific properties of the materials tested. Choice of hammer type, rock core support, and $\mathrm{R}$ calculation methods influence the results of SH tests. Meta-analysis of R to UCS correlations showed that these equations are notably influenced by rock type. A variety of different weathering levels for samples used in a study may contribute to an exponential shape for $\mathrm{R}$ to UCS correlations, as failure mechanisms transition from intra-microcrack to intra-granular. The shape of correlation equations may be indicative of the mechanisms causing failure for a collection of samples.

The composition, structure, and strength of asteroids are not well-defined. Mineralogical compositions are estimated for the four target asteroids candidates for ARM. The anticipated minerals must be considered in order to relate results from mechanical tests of terrestrial samples to those of the asteroids targeted for ARM. Asteroids and asteroid boulders may have monolithic or rubble-pile structures. In the case that a boulder for capture has a rubble-pile structure, it may not be able to withstand gripping and lifting mechanisms without crumbling. Strengths of asteroids are also highly unverified and differ in determination methods. Most notably, estimated strengths for stony and carbonaceous asteroids range from 0.025 $\mathrm{MPa}$ to $207 \mathrm{MPa}$.

While rock mechanics at high temperatures are well-understood, there is deficiency in an understanding of how mechanical properties of terrestrial materials are affected by cold temperatures. Development in low-temperature rock mechanics can assist in answering questions regarding the mechanical properties of asteroids if these properties are influenced by temperature.

Altogether, the challenges presented in this literature review establish the 
need for research into low-temperature rock mechanics. A proper method to reduce terrestrial rock samples to low-temperatures (independent of liquid absorption) must be developed. To characterize asteroid material, the influence of low-temperature on NDT responses should also be considered. Based on analyses of NDTs, the correlations of NDT responses to mechanical properties determined through destructive testing are heavily dependent on rock type. Shapes of these curves may be further explained by mineral constituents or crystal and grain arrangements in the rock. Results from low-temperature terrestrial tests will be used alongside the anticipated mineral compositions and strengths of asteroids targeted for ARM. Considerations of the specific asteroid properties will allow for low-temperature influences on the mechanical properties and NDT responses to be estimated for the characterization of asteroid material. 


\section{Chapter 3}

\section{Novel Method to Test Rock Samples at Low-Temperature}

\section{$3.1 \quad$ Theory}

To investigate the influence of low-temperatures on rock mechanics measurements, a method for cooling rock samples was developed. To fulfill project objectives for the characterization asteroid material, the method was selected and designed to reduce rock temperatures to $-75^{\circ} \mathrm{C}$, while being cost effective and safe to conduct in a laboratory setting. This section will include the theory behind generation of dry ice and methanol cooling baths. Materials and requirements for bath generation will be detailed.

\subsubsection{Dry Ice-Methanol Baths}

Prior studies have shown that dry ice (solid $\mathrm{CO}_{2}$ ) slurried with an alcohol solvent may be used to achieve cooling temperatures of $-70^{\circ} \mathrm{C}$ to $0^{\circ} \mathrm{C}$ (Ledgard, 2007). Methanol, being reasonably safe and inexpensive, was chosen as the alcohol solvent for the cooling baths, since the freezing point of methanol is around $-97^{\circ} \mathrm{C}$ (Roper, 1938). Pure methanol diluted with distilled water can raise the effective freezing point, enabling the production of a range of bath temperatures based on dilution ratios of methanol. 


\subsubsection{Materials}

To produce cooling baths from mixtures of dry ice and methanol, thermally- and chemically-resistant supplies were used for testing. Polyurethane ice buckets rated for temperatures down to $-160^{\circ} \mathrm{C}$ were utilized in a 2.5 - $\mathrm{L}$ capacity for crushing dry ice and a 4-L capacity for generation of baths. The buckets included snug-fitting lids that were used when baths were not being generated or mixed to maintain bath temperatures.

A probe thermometer rated for temperatures down to $-99.9^{\circ} \mathrm{C}$ was utilized so that bath temperatures could be monitored throughout the testing process. Sample surface temperatures were recorded with an infrared thermometer rated for down to $-60^{\circ} \mathrm{C}$.

During cooling, rock samples were placed in sealed, $2 \mathrm{~mm}$ thick Teflon bags to prevent specimens from absorbing liquid from the baths. This material was chosen since it is chemically and cryogenically stable and does not greatly affect the modes of heat transfer between the samples and the bath. For safe management of cold materials, a steel spatula for stirring and steel tongs for handling rock samples were utilized. To reduce heat gain to samples after bath removal during the various tests, foil-laminated, metalized bubble cushion material was used to insulate rock samples.

Dry ice in the form of $1-\mathrm{cm}$ cylindrical pellets was obtained in amounts of $10 \mathrm{lb}$ to $20 \mathrm{lb}$ at a time and was used within two days. For storage of dry ice, a $33 \mathrm{lb}$ capacity Styrofoam chest capable of storing dry ice for 2.6 days was obtained.

For the liquid solution portion of baths, $99.9 \%$ pure methanol was utilized. Distilled water was used to dilute the methanol to produce solutions of various methanol concentrations.

\subsubsection{Requirements}

For the current work, the method for cooling samples was developed to be relatively safe to implement. Cost was also a consideration in method selection. Original research on cooling baths revealed that cooling baths can be prepared with liquid nitrogen or dry ice and various alcohol solvents. Bath temperature is dictated by the freezing points of various solvents. Alcohol solvents mixed with either liquid 
nitrogen or dry ice will produce stable bath temperatures based on the solvent properties. In order to standardize the approach, a single solvent was desired. Working on the theory that stable cooling baths could be generated based on the various freezing points of different solvents, the use of a single solvent whose freezing point could be altered by water dilution was considered.

Due to the relative cost efficiency and theoretic capability to produce temperatures down to $-80^{\circ} \mathrm{C}$, methanol was chosen as a solvent to use with dry ice, which was also chosen for its general affordability and availability. Methanol was among one of the safer chemicals investigated, and its disposal was approved. Similarly, dry ice was chosen as a safer cooling medium than liquid nitrogen, which can be dangerous to work with and requires more stringent storage considerations.

\subsection{Method Development}

Crushed dry ice and $99.9 \%$ methanol were used to generating cooling baths capable of stable temperatures down to less than $-70^{\circ} \mathrm{C}$. Experimental results from the generation of cooling baths, theoretical models for sample temperature, and validations of these methods are presented in this section.

\subsubsection{Mixture Development}

In order to produce mixtures of varying methanol concentrations, methanol and distilled water were hand-mixed in a 2,500-mL Erlenmeyer flask. Total bath volumes varied from $250 \mathrm{~mL}$ to $2,000 \mathrm{~mL}$ based on the requirements of a specific test. For example, baths created during the experimental method development were of smaller volumes. When testing several rock samples in a bath at the same time, greater bath volumes were required compared to when only one sample was tested at a time.

Dry ice pellets were crushed by hand in the thermally- and chemically-resistant vessel with a rock hammer until the dry ice was powdery and no intact pieces remained. The crushed dry ice was weighed and recorded as the final step in preparation for bath generation, as exposure to the room temperature air 
caused the ice to evaporate rapidly.

All measurements and subsequent bath generations were performed under a laboratory-approved fume hood. Dry ice and varying dilutions of methanol were combined in a temperature- and chemically-resistant vessel to generate the cooling mixture, and bath temperature was monitored with a thermometer throughout testing.

Approximately half of the mixture contained in the Erlenmeyer flask was poured into the bath vessel. Crushed dry ice was slowly added to the vessel at a rate determined to minimize overflow of the mixture during the reaction, while the mixture was hand-mixed with a stainless steel stirrer. After all of the dry ice had been added, the mixture was continuously stirred until the reaction had ceased to a point that a foam above the liquid surface was no longer visible and the mixture appeared homogenous. Next, the remaining liquid mixture was slowly added to the vessel at a rate that prevented the mixture from reacting and foaming above the wall limits of the vessel. Figure 3.1a shows the reaction occurring in a bath after all ingredients had been added. Once all of the methanol mixture was added, the bath was stirred until all of the dry ice had reacted with the methanol and the mixture

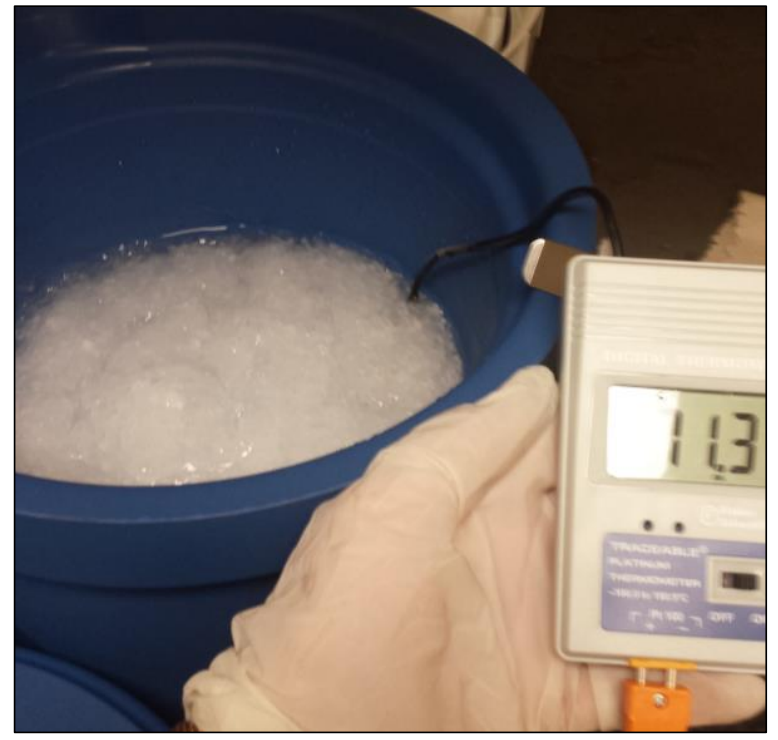

(a)

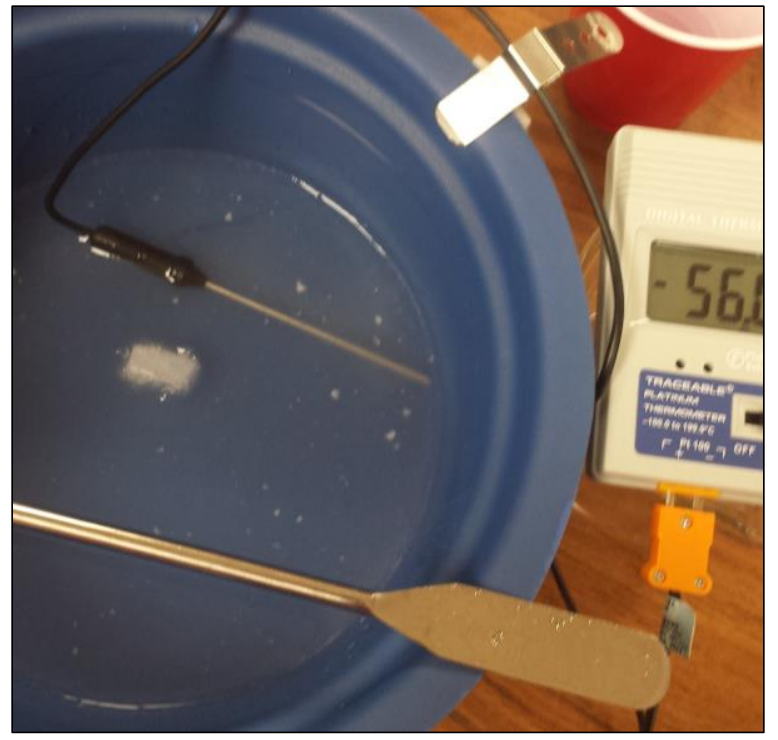

(b)

Figure 3.1: Example Cooling Bath (a) after Dry Ice and Methanol Solution Addition and (b) after Completion of Dry Ice and Methanol Reaction 
appeared to be homogenous (Figure 3.1b). At this point, the temperature was recorded. One to two pellets of dry ice ( 1 in) were added to the mixture and the lid was placed on the vessel to maintain the temperature. The bath was agitated with the steel stirrer and additional dry ice pellets were added when a significant $\left(+2^{\circ} \mathrm{C}\right)$ temperature change was observed. Periods in which the bath required agitation and additional dry ice varied from 15 to 30 minutes.

In order to determine mixture ratios and material requirements needed to produce a desired bath temperature, a series of experiments were run at methanol concentrations ranging from $20 \%$ to $80 \%$ with varying amounts of dry ice based on the total mixture volume.

Figure 3.2 shows stable bath temperatures as a function of experimental dry ice and methanol contents. This plot specifies the precise material ratios required to generate a low-temperature bath of a desired temperature based on the steps highlighted by the red arrows. To utilize Figure 3.2, first the desired bath temperature is chosen. Bath temperature is located on the left axis of the figure, and a horizontal straight line (step 1a in Figure 3.2) is drawn from the desired

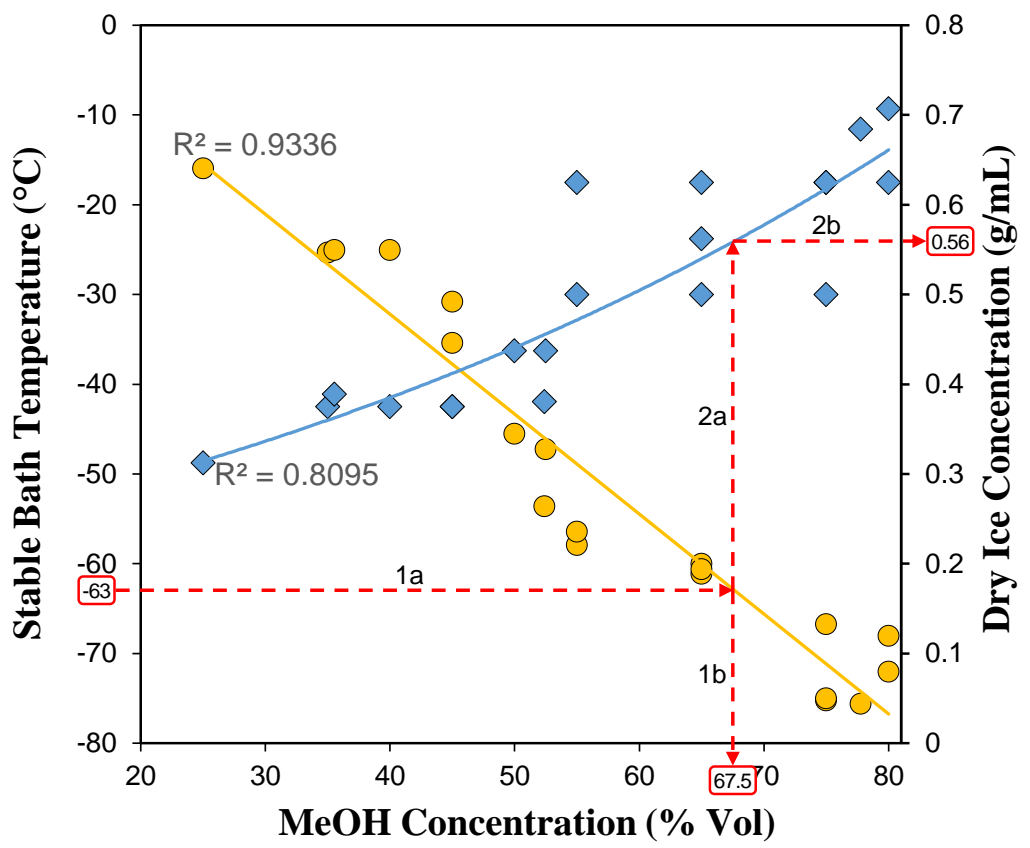

Figure 3.2: Method to Determine Methanol and Dry Ice Concentrations for a Desired Bath Temperature Based on Experimental Data with Example Steps for Use 
temperature to the linear trend representing bath temperature as a function of methanol concentration (yellow curve). The corresponding $\mathrm{x}$-axis value at this point (step $1 \mathrm{~b}$ in Figure 3.2) is the volume percentage of methanol needed to construct a bath of the chosen temperature. A vertical straight line (step $2 \mathrm{a}$ in Figure 3.2) is drawn from the determined methanol concentration on the $\mathrm{x}$-axis to the exponential curve representing dry ice concentration as a function of methanol content (blue curve). The corresponding value on the right axis (step $2 \mathrm{~b}$ in Figure 3.2) of the plot is the concentration of dry ice needed for a specific methanol concentration. The example illustrated in Figure 3.2 is for the generation of a $-63^{\circ} \mathrm{C}$ bath. The steps discussed above are represented by the red arrows in Figure 3.2 and illustrate that for a bath of $-63^{\circ} \mathrm{C}$, the required methanol concentration is $67.5 \%$ and the required concentration of dry ice is $0.56 \mathrm{~g} / \mathrm{mL}$ of total solution. Therefore, generation of a 2,000 $\mathrm{mL}$ bath with a stable temperature of $-62^{\circ} \mathrm{C}$ will require $1,350 \mathrm{~mL}$ of $99.9 \%$ methanol, $650 \mathrm{~mL}$ of distilled water, and $1,120 \mathrm{~g}$ of crushed dry ice.

\subsubsection{Determination of Cooling and Warming Time}

The amount of time required to cool a sample from room temperature to a desired cold temperature was approximated by Newton's law of cooling, which states that the rate of change of an object's temperature is proportional to the difference between the object's temperature and the ambient temperature (Negus \& Bergstedt, 2012):

$$
T(t)=T_{a}+\left(T_{o}-T_{a}\right) \cdot e^{-k t}
$$

where, $\mathrm{T}(\mathrm{t})$ is the object temperature after unit time, $\mathrm{t}, \mathrm{T}_{\mathrm{a}}$ is the ambient fluid temperature, $\mathrm{T}_{\mathrm{o}}$ is the initial object temperature, and $\mathrm{k}$ is a derived cooling constant (in this case the rate of conductive heat transfer) with units 1/unit time for the initial conditions $\mathrm{t}=0$ and $\mathrm{T}(0)=\mathrm{To}$. The law applies to both heating and cooling (Negus \& Bergstedt, 2012), and was also used to approximate warming times of samples upon bath removal. For the purposes of estimating the amount of time that samples needed to be submerged in baths to reach a certain temperature, Equation 3.1 was rearranged to solve for time: 


$$
t=\frac{\ln \left(\frac{T(t)-T_{a}}{T_{o}-T_{a}}\right)}{-k}
$$

For solid object bodies that are analyzed via lumped parameter models (neglecting temperature gradients inside the solid), the rate of heat transfer, (k), may be calculated based on the relationship between Newton's law of cooling and Fourier's transient heat conduction for simply shaped solids (K.C. Cheng):

$$
k=\frac{h_{f} A}{M C_{p}}
$$

where $h_{f}$ is the convective heat transfer coefficient in watts per squared meter-kelvin, $\mathrm{A}$ is the material surface area in square meters, $\mathrm{M}$ is the object mass in kilograms, and $\mathrm{Cp}$ is the specific heat of the object in Joules per kilogram-kelvin.

To assess the accuracy of the lumped thermal capacity model, the rate of conductive heat transfer through the rock was examined using a 2D heat transfer model. The simulation was based on a finite element solution to the heat transfer equation given by:

$$
\rho C_{p} \frac{\partial T}{\partial t}=\nabla \cdot\left(h_{s} \nabla T\right)
$$

where $\rho$ is the density in kilograms per cubic meter, and $h_{s}$ is the conductive heat transfer coefficient for the solid in watts per squared meter-kelvin.

The core cross-section geometry and boundary conditions were input into the model, and mesh analysis approximated the temperature change at different points in the rock. For the minimum temperature used in this study, the rock sample center lagged the rock surface temperature by approximately one minute for cooling models and approximately two minutes for warming models. Figures 3.3a and 3.3b show temperature differentials between external and internal rock samples approximated by the simulation. Based on the model analysis of conductive heat transfer through the solid, it was concluded that the time-scale for conduction through the rock was insignificant compared to the time-scale for convective heat transfer between the fluids and the rock. This conclusion enabled the remaining convective heat transfer 
models to be developed with the assumption of lumped thermal capacity for rock samples.

To address heat transfer between a rock samples and the bath fluid, correlations relating fluid properties to convection were utilized. In heat transfer at a boundary within a fluid, the Nusselt number is the ratio of convective heat transfer to conductive heat transfer across the boundary and is defined as follows (Boetcher, 2014):

$$
N u_{L}=\frac{h_{f} L}{\lambda_{f}}
$$

where $\mathrm{Nu}_{\mathrm{L}}$ is the dimensionless Nusselt number, $\lambda_{\mathrm{f}}$ is the thermal conductivity of the fluid in watts per meter-kelvin, and $\mathrm{L}$ is the characteristic length represented by:

$$
L=\frac{V}{A}
$$

where $\mathrm{V}$ is the object volume in cubic meters.

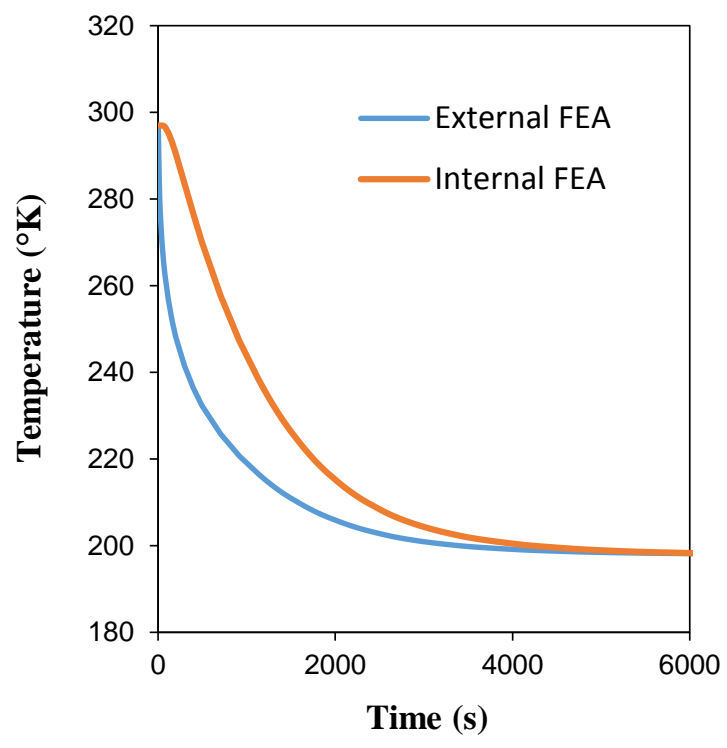

(a)

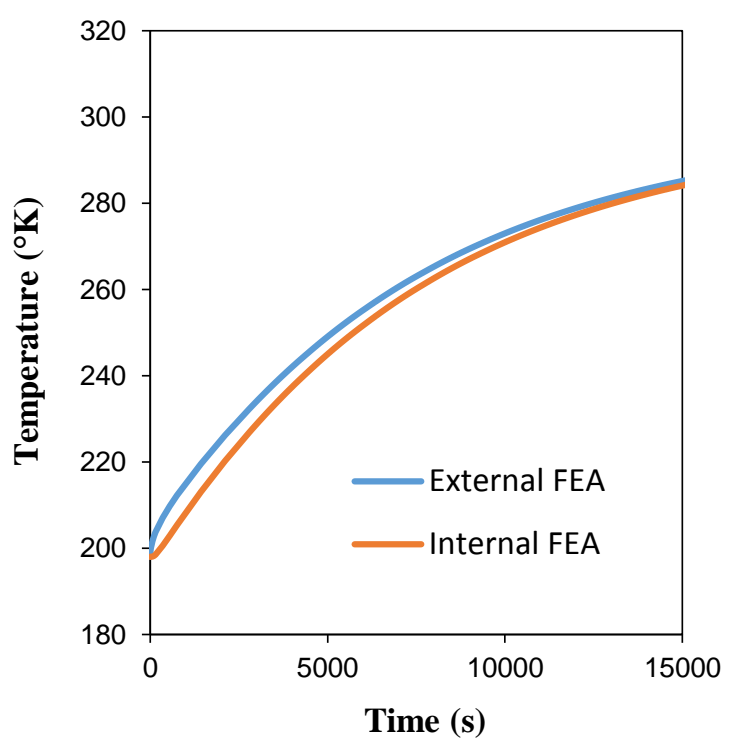

(b)

Figure 3.3: Internal and External Temperature Differentials of Rocks Approximated by Finite Element Analysis (FEA) of 2D Heat Transfer Model for (a) Cooling and (b) Warming 
A correlation between Nusselt number and Grashof and Prandlt numbers (relating to fluid viscosity and convection) developed by Churchill and Chu (as cited in Boetcher, 2014) is shown below, rearranged to solve for $\mathrm{h}_{\mathrm{f}}$ using Equations 3.5 and 3.6:

$$
h_{f}=\left(0.6+0.387 \cdot\left(\frac{G r_{D} P r}{\left(1+(0.559 / P r)^{9 / 16}\right)^{16 / 9}}\right)^{1 / 6}\right)^{2} \cdot \frac{\lambda_{f}}{L}
$$

where $\operatorname{Gr}_{\mathrm{D}}$ is the dimensionless Grashof number for pipes given by:

$$
G r_{D}=\frac{g \beta\left(T_{o}-T_{a}\right) D^{3}}{v^{2}}
$$

where $\mathrm{g}$ is the acceleration due to Earth's gravity in meters per second squared, $B$ is the coefficient of thermal expansion in units per kelvin, and $\mathrm{D}$ is the object diameter in meters, and $\mathrm{v}$ is the kinematic viscosity of the fluid in square meters per second, and $\mathrm{Pr}$ is the dimensionless Prandlt number calculated by:

$$
\operatorname{Pr}=\frac{\mu C_{p}}{\lambda_{f}}
$$

where $\mu$ is the dynamic viscosity of the fluid in kilogram per meter-second.

The convective heat transfer coefficient $\left(\mathrm{h}_{\mathrm{f}}\right)$ was calculated in Equation 3.7 using Equations 3.8 and 3.9, using average values for fluid variables for $75 \%$ methanol and $45 \%$ methanol solutions based off of combinations between methanol and water variables at different temperatures and average values for samples sizes and rock type dependent variables. The cooling rate constant $(\mathrm{k})$ was then calculated with Equation 3.3 based on the convective heat transfer coefficient $\left(h_{f}\right)$ calculated in Equation 3.7. Cooling model plots were constructed by inserting the calculated $\mathrm{k}$ value into Equation 3.1. Warming models were constructed in a similar fashion using properties of room temperature air and properties of a frozen sample to solve for parameters in Equations 3.1-3.9.

From the cooling models, the time required to reduce the internal temperature of a rock sample to a desired value was estimated for a given bath temperature. Due 


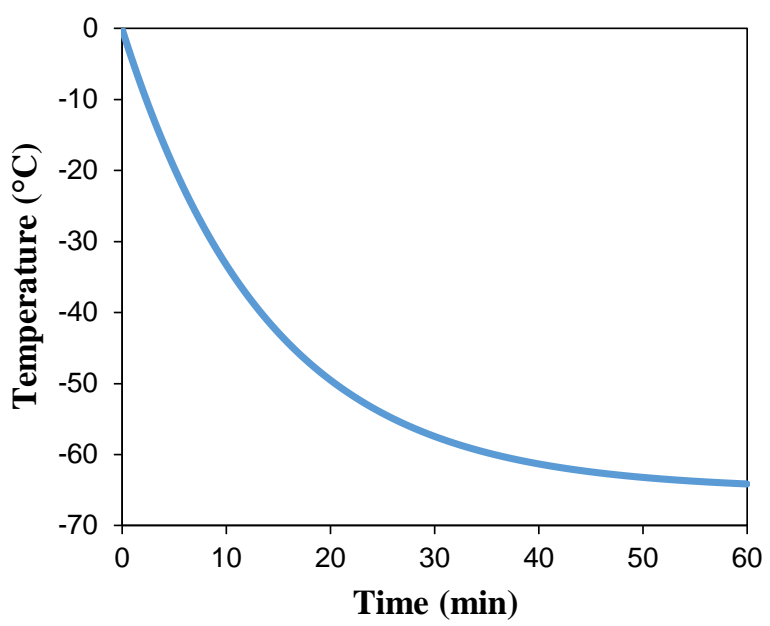

(a)

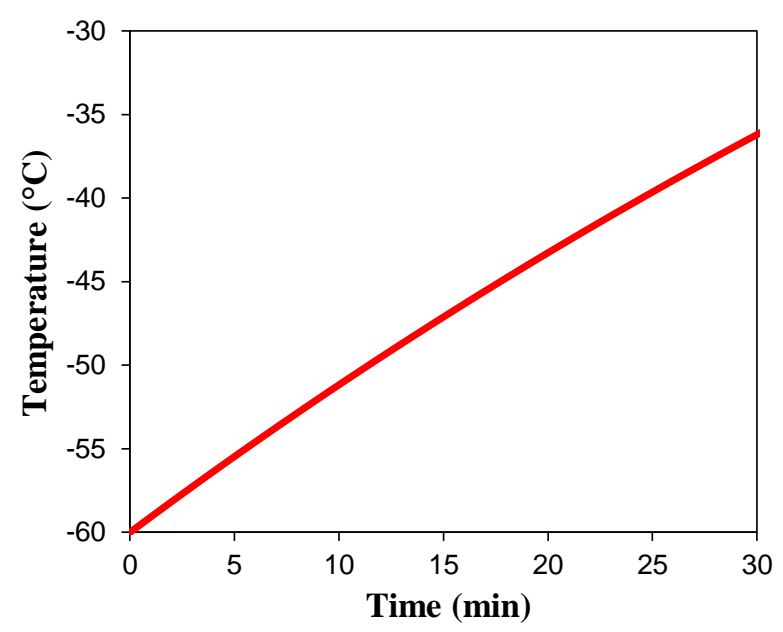

(b)

Figure 3.4: Example (a) Cooling Model to Determine Required Time to Cool Pre-Frozen Rock Sample to $-60^{\circ} \mathrm{C}$ in a $-65^{\circ} \mathrm{C}$ Bath and (b) Warming Model to Asses Temperature Change Over Time for Cooled Sample After Removal to Room Temperature $\left(22^{\circ} \mathrm{C}\right)$

to the exponential nature of heating mechanisms, baths were prepared $5^{\circ} \mathrm{C}$ cooler than desired rock temperatures, as the models begun to plateau as rock temperatures approached bath temperatures. Warming models were constructed to assess how quickly heat transfer to the samples would occur once they were removed from the baths for testing in the room temperature environment. These modeling procedures indicated that a maximum time of approximately two hours would be needed to cool a sample from room temperature to $-75^{\circ} \mathrm{C}$ using a cooling bath of $-80^{\circ} \mathrm{C}$. This time could be decreased by pre-freezing samples in a laboratory freezer $\left(0^{\circ} \mathrm{C}\right)$, and the average time needed for pre-frozen samples to come to temperatures $5^{\circ} \mathrm{C}$ warmer than bath temperatures was approximately 45 minutes. Warming models indicated that frozen samples would remain within $5^{\circ} \mathrm{C}$ to $10^{\circ} \mathrm{C}$ of their temperature upon removal within the first ten minutes in a room temperature environment, with greater temperature change occurring in the first ten minutes after bath removal for cooler samples.

An example cooling model to reduce a pre-frozen sample from $0^{\circ} \mathrm{C}$ to $-60^{\circ} \mathrm{C}$ by soaking in a $-65^{\circ} \mathrm{C}$ bath is shown by Figure $3.4 \mathrm{a}$. This example cooling model shows a required time of about 45 minutes to achieve the desired temperature. Figure $3.3 \mathrm{~b}$ shows an example warming model for a $-60^{\circ} \mathrm{C}$ sample after allowed to sit at room 
temperature. The warming model shows that for a $-60^{\circ} \mathrm{C}$ sample, temperature will remain within $5^{\circ} \mathrm{C}$ of its original temperature for 10 minutes once removed from the bath and allowed to sit in a room temperature environment.

\subsection{Method Validation}

\subsubsection{Bath Generation}

The experimentally-developed curves from Figure 3.2 were later used to develop subsequent cooling baths as testing continued. Table 3.1 summarizes several tests prepared by using the method described in Section 3.2.1 to determine the approximate concentrations of dry ice and methanol to produce a bath of a specific temperature.

The tests from Table 3.1 confirm that the experimentally-developed curves in Figure 3.2 can be used to approximate dry ice and methanol concentrations for generation of a cooling bath of a specific temperature with less than 5\% error and less than $3^{\circ} \mathrm{C}$ difference in resulting bath temperature from the proposed temperature. Error between desired and actual bath temperature does not appear to be affected by the temperature chosen.

The stability of generated baths was tested by allowing baths to sit for various amounts of time while their temperatures were monitored. When a bath's temperature increased by more than $2^{\circ} \mathrm{C}$, one to two pellets of dry ice were added and the mixture was agitated. Maintenance of bath temperature was performed as

Table 3.1: Validation of Cooling Bath Generation Curves

\begin{tabular}{rrrr}
\hline \hline $\begin{array}{r}\text { Desired Bath } \\
\text { Temp. }\left({ }^{\circ} \mathbf{C}\right)\end{array}$ & $\begin{array}{r}\text { Final Bath } \\
\text { Temp. }\left({ }^{\circ} \mathbf{C}\right)\end{array}$ & $\begin{array}{r}\text { Temp. } \\
\text { Difference }\left({ }^{\circ} \mathbf{C}\right)\end{array}$ & $\begin{array}{r}\text { Error } \\
(\%)\end{array}$ \\
\hline-25 & -24.2 & 0.8 & 3.2 \\
-30 & -31.2 & 1.2 & 4.0 \\
-40 & -41.6 & 1.6 & 4.0 \\
-55 & -56.1 & 1.1 & 2.0 \\
-60 & -62.4 & 2.4 & 4.0 \\
-72 & -74.9 & 2.9 & 4.0 \\
-75 & -77.9 & 2.9 & 3.9 \\
-75 & -76.8 & 1.8 & 2.4 \\
\hline \hline
\end{tabular}


needed, and times of up to 80 minutes were tested. Results from bath stability tests are summarized in Table 3.2. The bath durations are not representative of the maximum time a bath of that temperature can remain stable, but rather the amount of time the temperature remained stable for the specific addition of dry ice designated in the table. Continued addition of dry ice in most of the baths would have likely prolonged their stable temperature durations.

Results in Table 3.2 validate that the cooling baths could maintain their original temperature within $\pm 3^{\circ} \mathrm{C}$ in all cases with the addition of dry ice. Increased dry ice additions reduced stable temperature ranges to $\pm 2^{\circ} \mathrm{C}$. The concluding recommendations from the bath stability study are to add one to two pellets of dry ice to the bath every 15 minutes to remediate temperature change. This trial also showed the capabilities of these baths to be maintained for at least 120 minutes, though greater durations may be achieved - but were not attempted - in this study.

\subsubsection{Sample Temperature Models}


Table 3.3: $\quad$ Validation of Cooling Models

\begin{tabular}{rrrrr}
\hline \hline Sample & $\begin{array}{r}\text { Stable Bath } \\
\text { Temp. }\left({ }^{\circ} \mathbf{C}\right)\end{array}$ & $\begin{array}{r}\text { Time in Bath } \\
(\text { min. })\end{array}$ & $\begin{array}{r}\text { Surface } \\
\text { Temp. }\left({ }^{\circ} \mathbf{C}\right)\end{array}$ & $\begin{array}{r}\text { Internal } \\
\text { Temperature }\end{array}$ \\
\hline L-7-01 & -68 & 38 & $<-53$ & -58 \\
L-7-06 & -68 & 60 & $<-55$ & $-48^{*}$ \\
L-3-14 & -68 & 98 & -35 & $-35^{*}$ \\
\hline \hline
\end{tabular}

NOTE- *Low internal sample temperature with increased bath duration is due to leakage of bath fluid into sample bags

$\begin{array}{rrrrr}-45.5 & -43.8 & 1.7 & 15 & 2 \\ -57.9 & -56.4 & 1.5 & 20 & 1 \\ -35.4 & -33.3 & 2.1 & 20 & 2 \\ -9.5 & -10.3 & 0.8 & 20 & 3 \\ -25.0 & -24.3 & 0.7 & 20 & 2 \\ -30.8 & -30.3 & 0.5 & 20 & 2 \\ -25.3 & -23.3 & 2.0 & 25 & 2 \\ -15.9 & -15.4 & 0.5 & 25 & 4 \\ -57.2 & -56.3 & 0.9 & 25 & 4 \\ -61.1 & -60.6 & 0.7 & 40 & 5 \\ -36.0 & -34.9 & 1.1 & 50 & 4 \\ -50.8 & -50.9 & 0.1 & 55 & 8 \\ -74.8 & -73.9 & 0.9 & 60 & 8 \\ -76.0 & -75.1 & 0.9 & 75 & 15 \\ -59.4 & -58.8 & 0.6 & 80 & 120 \\ -56.1 & -54.9 & 1.2 & & \end{array}$

The cooling models discussed in Section 3.2.2 were later validated by testing the temperatures of rock samples that were cooled in the same bath for specific amounts of time and subsequently broken. Table 3.3 displays results from this test in which three limestone core samples were submerged in a stable $-68^{\circ} \mathrm{C}$ bath and removed one at a time, at approximate intervals of 30 minutes.

The minimum surface temperature, tested via infrared thermometer, was recorded for the tops and sides of core specimens, and the two values were averaged to calculate the surface temperature as listed in Table 3.3. Due to the limitations of the IR thermometer, samples temperatures that were indicated as less than $-60^{\circ} \mathrm{C}$ by the thermometer were designated as $-60^{\circ} \mathrm{C}$ to calculate the maximum average surface temperature of that sample.

Core specimens were then placed in an MTS for uniaxial testing, which took place over an average of 1.5 minutes, and the minimum surface temperature near the center of the core was recorded using the IR thermometer.

It was noted during testing that the bags had leaked, causing some solution to 
Table 3.4: Validation of Warming Models

\begin{tabular}{|c|c|c|c|c|c|c|}
\hline Sample & $\begin{array}{l}\text { Stable Bath } \\
\text { Temp. }\left({ }^{\circ} \mathbf{C}\right)\end{array}$ & $\begin{array}{r}\text { Time in Bath } \\
\text { (min.) }\end{array}$ & $\begin{array}{r}\text { Initial Surface } \\
\text { Temp. }\left({ }^{\circ} \mathbf{C}\right) \\
\end{array}$ & $\begin{array}{l}\text { Time out of } \\
\text { Bath (min.) }\end{array}$ & $\begin{array}{r}\text { Final Surface } \\
\text { Temp. }\left({ }^{\circ} \mathbf{C}\right) \\
\end{array}$ & $\begin{array}{r}\text { Internal } \\
\text { Temp. }\left({ }^{\circ} \mathbf{C}\right) \\
\end{array}$ \\
\hline L-3-13 & -46.5 & 85 & -44 & 0 & - & -41 \\
\hline L-2-08 & -46.5 & 85 & -49 & 7 & -30.5 & -27 \\
\hline L-6-04 & -46.5 & 85 & -50 & 13 & -16.0 & -16 \\
\hline
\end{tabular}

surround the samples enclosed in bags. This problem is reflected by the unexpected trends shown in Table 3.3. Though for the first sample the internal was reduced to within $10^{\circ} \mathrm{C}$ of the bath temperature, the samples kept in the bath for longer durations actually had lower internal temperatures than the first sample. While the Teflon bags had been wrapped securely around specimens and taped shut, unknown small tears in the bags had cause some of the bath fluid to seep into the bags. This may have acted as insulation for the samples, which explains why longer durations resulted in lower internal temperatures. The leaking problem was rectified for future tests by ensuring a proper seal and ensuring the bags did not have any holes in which water could seep through.

Warming models were also validated by submerging and removing three limestone samples from a bath at the same time and allowing them to sit at room temperature for increasing intervals of time. Results from this test are summarized in Table 3.4. Specimens were submerged in a $-46.5^{\circ} \mathrm{C}$ bath for 85 minutes. The samples were broken via uniaxial compression after sitting at room temperature for zero, seven, and thirteen minutes. Upon fracture, the core minimum temperatures were recorded. Results from the validation of warming models show that samples gained heat when allowed to sit at room temperature. Compared to expected values based on warming models, samples in this test gained heat at a rate $50 \%$ faster. The sample exposed to room temperature for seven minutes had a change in surface temperature of almost $20^{\circ} \mathrm{C}$. If we assume that L-2-08 was the same approximate temperature as L-3-13 upon removal, the internal temperature would only have been altered by less than $15^{\circ} \mathrm{C}$. For the sample that sat at room temperature for 13 minutes, surface temperature measurements increased by over $30^{\circ} \mathrm{C}$, though models predicted temperature change of approximately $20^{\circ} \mathrm{C}$.

For all samples in the warming validation, internal temperatures taken right before breaking indicate that in these instances, IR thermometer averages of top and 
side core measurements are adequate approximations of the internal temperature. This verified the assumption made in the model development that differences between surface and internal temperatures were insignificant.

The next set of validation tests were performed to test different insulation designs on the ability to inhibit heat transfer to the sample during testing at room temperature. Four limestone samples were placed in baths of slightly different temperatures for different durations, and changes in surface temperatures for samples sitting at room temperature were noted. Table 3.5 shows results for warming tests for samples covered with insulation.

Three different insulation designs were secured to samples as rock cores sat at room temperature and included: (1) full insulation that covered the rounded core surface and core ends; (2) rectangular insulation that wrapped around the core's surface leaving the flat ends of the core exposed; and (3) Schmidt insulation, that was specifically design for SH testing to cover the ends of the specimen, while leaving a one-inch portion in the center of the curved portion of the core exposed to allow for hammer impacts.

Results from Table 3.5 show that insulation helped to slow down the rate of heat gain from the room temperature air. Full insulation provided the best protection, while Schmidt and rectangular versions contributed to an additional $3^{\circ} \mathrm{C}$ temperature change.

\subsubsection{Conclusions}

Results from validation studies confirm that the developed mixture curves can be used to determine methanol and dry ice concentrations required for generation of a cooling bath between $-20^{\circ} \mathrm{C}$ and $-75^{\circ} \mathrm{C}$. The ability to maintain bath temperatures

Table 3.5: $\quad$ Insulation Influence on Warming of Samples

\begin{tabular}{lrrrrrrr}
\hline \hline Sample & $\begin{array}{r}\text { Stable Bath } \\
\text { Temp. }\left({ }^{\circ} \mathbf{C}\right)\end{array}$ & $\begin{array}{r}\text { Time in Bath } \\
(\mathbf{m i n})\end{array}$ & $\begin{array}{r}\text { Initial Surface } \\
\text { Temp. }\left({ }^{\circ} \mathbf{C}\right)\end{array}$ & $\begin{array}{r}\text { Time out of } \\
\text { Bath }(\text { min. })\end{array}$ & $\begin{array}{r}\text { Final Surface } \\
\text { Temp. }\left({ }^{\circ} \mathbf{C}\right)\end{array}$ & $\begin{array}{r}\text { Change in } \\
\text { Temp }\left({ }^{\circ} \mathbf{C}\right)\end{array}$ & $\begin{array}{r}\text { Insulation } \\
\text { Type }\end{array}$ \\
\hline L-2-17 & -43 & 75 & -40.0 & 5 & -30 & -10.0 & $(1)$ \\
L-6-03 & -48 & 45 & -44.5 & 10 & -27 & -17.5 & $(2)$ \\
L-7-02 & -57 & 20 & -49.0 & 5 & -35 & -14.0 & $(2)$ \\
L-7-03 & -46 & 60 & -43.5 & 5 & -29 & -14.5 & $(3)$ \\
\hline \hline
\end{tabular}

LEGEND- (1): Full insulation; (2): Rectangular insulation; (3): Schmidt insulation 
at $\pm 2^{\circ} \mathrm{C}$ of the starting temperature may be achieved by the addition of one to two ( 1 in) pieces of dry ice and bath agitation every 15 minutes.

Experimental studies confirm that differential temperatures between sample surfaces and cores in this study are negligible when calculating cooling and warming times. Cooling validations show that samples may be cooled down to $5^{\circ} \mathrm{C}$ more than bath temperatures. Warming tests indicate that original warming models were not accurate. Poor warming approximations of $\mathrm{k}$ and $\mathrm{h}_{\mathrm{f}}$ led to inaccurate models, although calculated approximations for these values to model cooling were sufficient. A fitted $\mathrm{k}$ value can be back-calculated based on validation data to approximate the true $h_{f}$ value. This method would allow for a more accurate cooling and warming models to be built. Convective heat transfer rates for samples sitting at room temperature were greater than predicted by approximately 50\%; however, applying insulation to rock samples after bath removal significantly reduced the rate of heat transfer to samples. 


\section{Chapter 4}

\section{Materials and Test Methods}

\subsection{Experimental Objectives}

The experimental testing portion of this study was performed to address the uncertain influence of low-temperature on the fundamental elastic and strength properties of rocks. For the purposes of assessing SH and UPV for asteroid characterization, the responses of these tools at low-temperatures and how they indicate changes in mechanical properties must also be investigated.

\subsection{Sample Selection}

Terrestrial rocks for this study were chosen to represent rocks with different properties; this allowed a proper analysis of how materials of different strength dictate the influences of low-temperature. Due to inconsistencies in and the unreliability of strength estimates for asteroids (as found in the relevant literature),

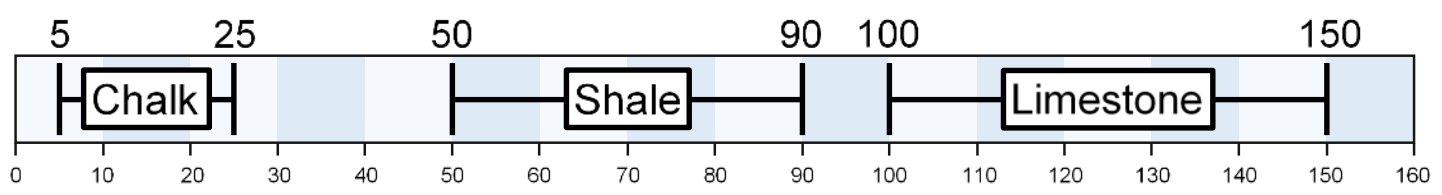

Figure 4.1: $\quad$ Expected Ranges of Sample UCSs 
"low," "medium," and "high" strength terrestrial samples were acquired to address a broad range of material properties, rather than a single asteroid simulant. Selected samples included limestone, shale, and chalk to provide high, medium, and low strengths, respectively. The average strengths of these rock types are displayed in Figure 4.1. The range of strengths provided by the selected samples allowed for the findings in this study to relate to stony and carbonaceous asteroid samples, the strengths of which lie within these bounds.

\subsubsection{Sample Petrology}

Limestone cores from the Elbrook and Conococheague formations in northern Virginia were provided for this study to constitute the "high" strength portion of samples. Barnett shale ("medium" strength) and Austin chalk ("low" strength) were purchased from a stone supplier based in Texas. The samples chosen for testing are classified as sedimentary rocks. Properties of rock formations from which samples in this study originated are detailed with specific focuses on their textures and mineralogies.

\section{Elbrook and Conococheague Limestone}

Limestone is a carbonate sedimentary rock that is largely dominated by calcite carbonate minerals that have rhombohedral crystal systems. The atoms in calcite minerals are arranged such that layers containing $\mathrm{Ca}, \mathrm{Mg}, \mathrm{Mn}, \mathrm{Fe}$, or $\mathrm{Zn}$ atoms alternate with layers of carbonate atoms along a vertical axis. Substitution of magnesium ions for calcite ions of carbonate minerals is common, and high molar ratios of $\mathrm{MgCO}_{3}$ to $\mathrm{CaCO}_{3}$ in calcite minerals are characteristic of magnesian calcites.

Carbonite rocks usually contain less than $5 \%$ of noncarbonated minerals and commonly include quartz, feldspars, micas, clays, and heavy minerals, and most noncarbonated minerals in limestone are of detrital origin.

Though limestone mineralogy differs greatly from that of sandstone, from a textural standpoint, limestones resemble sandstones in that limestone rocks consist of sand and silt-sized carbonate grains with various amounts of fine carbonate cements. Unlike sandstone grains, individual carbonate grains in limestone are comprised of large numbers of fine calcite crystals as opposed to single crystals. 
Spherical or rod-shaped carbonate grains that lack definite internal structure, called peloids, are common in some limestone formations. Coated grains in MGcalcites are often radially structured and result from concentric cementation around a nucleus. Aggregate grains in carbonates are described at two or more carbonate fragments that have been accumulated by a lime-mud matrix.

The Elbrook limestone formation contains blue-gray limestones that are somewhat shaly and thin-bedded in the exposed outcrop, but appear massive elsewhere. The mid portion of the formation is richer in magnesium and siliceous beds than the upper and lower portions of the rock mass. While several beds of the Elbrook are suitable for lime and cement production, most beds of the Elbrook have high levels of magnesium-bearing minerals. The Elbrook formation, located in the western Maryland and northern Virginia, is met with the Conococheague formation to its west (Mathews \& Grasty, 1910).

The Conococheague formation consists primarily of siliceous and argillaceous limestones suitable for cement manufacture at various bedding horizons that are associated with white or dark beds of magnesium-rich materials. Material at the base of this formation consists of limestone conglomerates accompanied by siliceous bedding. These conglomerates contain 1 in limestone pebbles imbedded in a calcite matrix. The occurrence of "edgewise beds" composed on tilting, thin limestone fragments held together by calcareous cement have been observed in the Conococheague formation. Other unreliable contacts result from the observations of oolites (sedimentary rocks formed by spherical grains composed of concentric layers) and limestones with uneven clay planes (Mathews \& Grasty, 1910).

\section{Austin Chalk}

Chalk is an unusually pure variety of limestone composed largely of $\mathrm{CaCO}_{3}$ in the form of micritic lime-mud and low MG-calcite. Chalk has a fine texture, is usually white or light in color, and is often very porous (Hancock, 1975). The fine texture in chalks is caused by the shedding of micro-organisms that are overtime compacted to form the rock. During compaction, the release of water from the small spaces between shell remains creates a porous structure in the rock (Boggs, 2009).

Up to $90 \%$ of white chalk is made up of particles between $0.5 \mu \mathrm{m}$ to $4 \mu \mathrm{m}$ and $10 \mu \mathrm{m}$ to $100 \mu \mathrm{m}$, with the finer fraction making up most of the structure for average 
white chalks. Shelly chalks are those in which much of the finer-grained matrix has been weathered away (Hancock, 1975). Approximately 10\% of the total mineral composition of chalk are noncarbonites that include mostly clay and quartz (Phillips et al., 1998). While chalks are reported to have extremely high porosities and void spaces, those with increased clay contents and those subject to extreme compaction can lead to decreases in overall porosity. Chalk materials have remained soft after formation due to the stability of the low-Mg calcites that were deposited to form chalk (Hancock, 1975).

The Austin chalk formation contains few clay minerals (Hunt \& McNichol, IDK). In situ Austin chalk has vertically oriented fractures (Phillips et al., 1998). A study by Corbett et al., (1987) analyzed the influence of porosity, calcite, smectite, and clay percentages on the strength of Austin chalk samples from various locations in the formation, and found that total clay content has the highest simple correlation to strength. Smectite concentrations and porosity also provide strong singular correlations with strength of various Austin chalks. High clay content, porosity, and smectite concentration were correlated with weaker samples for Austin chalk.

\section{Barnett Shale}

Shale is a type of fine-grained, siliclastic sedimentary rock that is comprised mostly of particles smaller than approximately 62 microns. Other nomenclature for such fine-grained silicates include: siltstone, mudstone, mudrock, and claystone, though in Tourtelot's (1960) review of historic detail of fine-grained sedimentary terminology (as cited in Boggs, 2009), restricted use of the term "shale" has been used to describe a laminated clay rock. The shapes of small particles that comprise shales reflect the shapes of their detrital particle origins. These particles see little transport abrasion, and as such, most particles in shales tend to be angular. Electron microscopy observations of clay minerals by Sudo et al., (1981), (as cited in Boggs, 2009) reveal the platy, flaky shape of most clay minerals.

The platy structure of clay minerals in shale is responsible for the formation of microfabrics that are resultant of preferred mineral orientations. The organization of these angular minerals contributes to the different parting tendencies of microfabrics in shale. Shale particle associations when suspended can take several forms that dictate the final parting tendencies of the assembled rock. Particles may 
be dispersed or aggregated as parallel layers, and clay minerals may be grouped edgeto-edge, edge-to-face, or randomly suspended.

Fissility is a term used to describe the tendency and frequency for shale beds to be easily broken into thin layers, though the cause of this phenomenon is not completely understood. Moon and Hurst (1984) (as cited in Boggs, 2009) have suggested that fissility may be caused by processes of the geochemical environment that cause dispersion and then settling of clay particles into single plates, while Curtis et al. (1980) (as cited in Boggs, 2009) proposed that compaction strain is the cause of preferred orientation of clay sediments and further suggests that orientation of clay minerals are often limited by the existence of nonplaty minerals which prevent development of continuous microfabrics.

The most abundant minerals in shale rocks are clay minerals (phylosilicates), fine micas, quartz, and feldspars, though a variety of other minerals may be present and percentages of major minerals are not consistent for different shales.

The Barnett shale formation of the Fort Worth Basin in Texas is dominated by fine-grained clay and silt particles, though three main facies are recognized. These facies include: (1) laminated siliceous mudstone; (2) laminated argillaceous lime mudstone; and (3) skeletal, argillaceous packstone (Loucks \& Ruppel, 2007). All facies of Barnett shale are abundant in phosphate and pyrite, and concentrated carbonates are not uncommon in some locations.

Contrary to many average shales, quartz in the form of fine-grained crystals is by far the most abundant mineral in Barnett shale, and clay minerals (dominantly illite with some smecite) make up less than one-third of the minerals in Barnett. Flocculations of phylosilicates are common for assemblages in the Barnett formation (Loucks \& Ruppel, 2007) and may contribute to a random assortments of particles as these flocculations sink to the bottom when suspended (Boggs, 2009). Carbonate finegrained calcite and dolomite minerals are also locally common in the Barnett formation (Loucks \& Ruppel, 2007).

\subsubsection{Sample Preparation}

Barnett shale and Austin chalk were purchased as prepared 2 in diameter, 4.5 in length samples. Unprepared limestone cores, drilled from 2 in bits, were cut and 


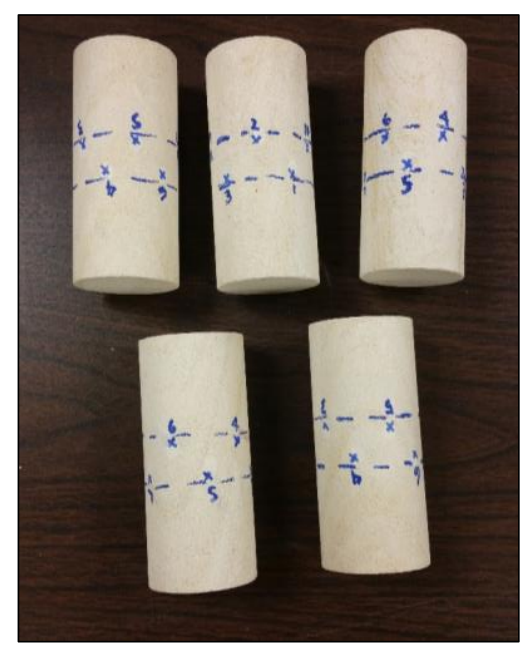

(a)

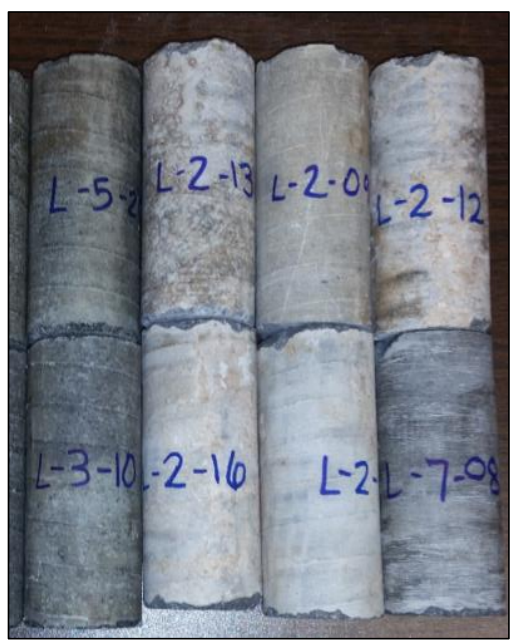

(b)

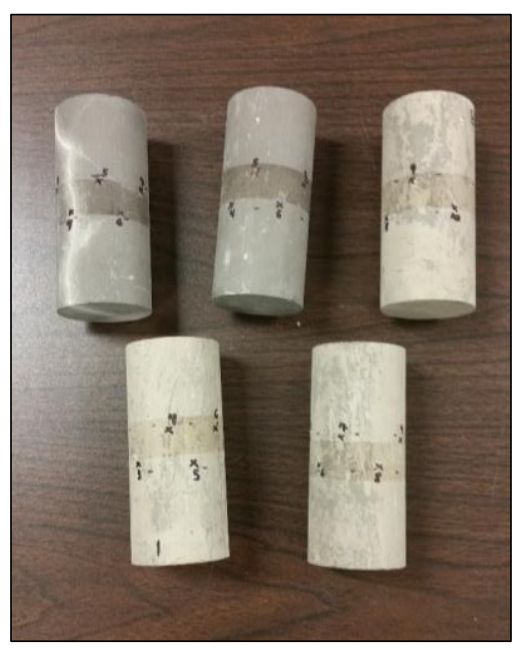

(c)

Figure 4.2: $\quad$ Prepared 2 in diameter, 4.5 in core samples of (a) Austin Chalk, (b) Elbrook and Conococheague Limestone, and (c) Barnett Shale

ground to approximate 4.5 in lengths to match the lengths of other provided samples. Prepared core samples for chalk, limestone, and shale samples are shown in Figures $4.2 \mathrm{a}, 4.2 \mathrm{~b}$, and $4.2 \mathrm{c}$, respectively.

For limestone samples, several core boxes containing NX-sized cores of approximately 2 in diameter were acquired. Several samples were isolated for PL testing. Based on the sample sizes required for diametral and axial loading, smaller core pieces that could not be cut for full testing were used in PL tests and most did not require additional preparation, though some samples were cut due to limitations of the test device's loading frame. Other samples were cut to approximate 4.5 in lengths with a diamond rock cutting saw. A grinding machine was used to produce level, perpendicular surfaces for core samples. Perpendicular core ends ensure proper loading for UCS tests and can improve transmission of UPV signals if the saw caused sample roughness.

Based on the review of standard operations for $\mathrm{SH}$ data collection, a core length of 4.5 in for a 2 in diameter core was deemed sufficient to provide one piston diameter between ten points located at least one core diameter away from the core ends. The chosen length enabled a one-inch area in the center of the core to be tested for SH testing; this area also lies within the suggested and common lengths for both UPV and UCS testing discussed in Chapter 2. 
All rock core samples were inspected for any visible discontinuities. Anomalies were recorded, and significant discontinuities resulted in discarding of those samples. Approximate densities of samples were determined by weighing the samples and measuring the core sample dimensions to calculate volume.

\subsection{Test Methods}

\subsubsection{Equipment}

Several apparatuses were used to conduct the various characterization tests for this study. PL tests were performed with a model PLT-10 point load test meter that was manually operated by a hydraulic pump. For UCS tests, an MTS loading machine was used to apply a constant, unconfined load to core samples. SH tests were performed with the RockSchmidt test hammer by Proceq, which is an L-type hammer specifically made for rock characterization. UPV tests were performed with Proceq's PL-200, fitted with the standard $54 \mathrm{kHz}$ transducers.

In addition to testing apparatuses, a core holder was used to secure samples for SH testing. The core holder secures samples so that any vibration from hammer impact will not be lost through the ground, but rather will only be representative of the reaction under the plunger tip. Based on ASTM standards and considering low cost options, a $60^{\circ} \mathrm{V}$-notch cradle cut from a block of steel was welded to a steel base. The entire device weighs about $16 \mathrm{~kg}$ and has steel plates that can be screwed to the base to secure samples. An image of the core holder is displayed in Figure 4.3

\subsubsection{Destructive Test Procedures}

\section{Point Load Tests}

An initial series of shakedown tests were performed to validate the cooling procedure and investigate any changes in UCS due to temperature. PL tests were chosen as a quick indicator of UCS for these tests. PL testing requires little sample preparation, the data are produced very rapidly, and the results are suitable for comparison between rocks of similar types. For the PL testing in this study, 2 in limestone core samples of varying lengths were cooled to temperatures ranging from 


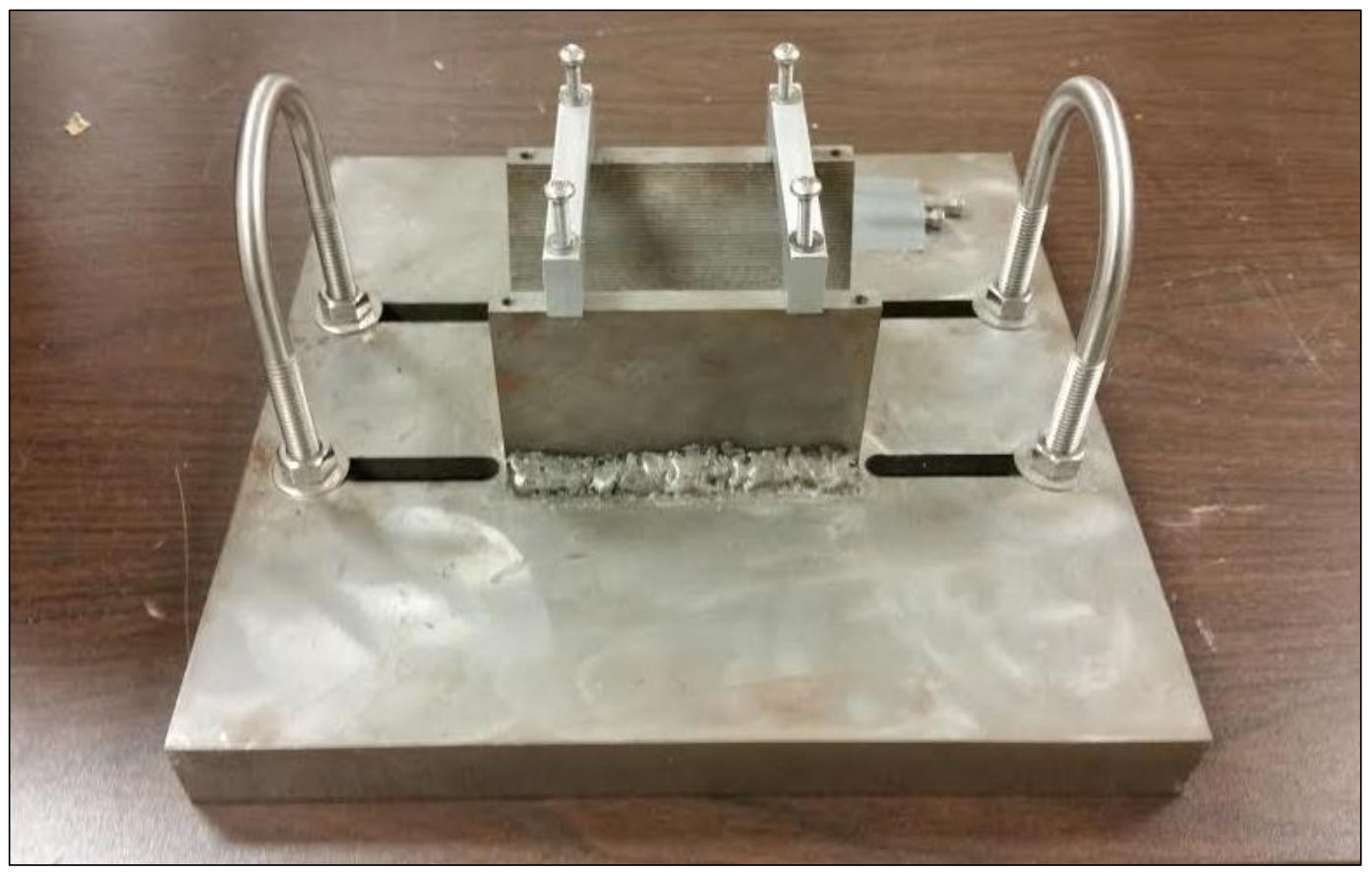

Figure 4.3: $\quad$ Machined Steel SH V-Notch Core Cradle

$22^{\circ} \mathrm{C}$ to $-50^{\circ} \mathrm{C}$ via the cooling procedures described in Section 3.2.

The PL testing procedure was conducted in accordance with ASTM standard D5731-08. The PL test meter used in this study is shown in Figure 4.4a, and test specimens were loaded diametrally between the conical platens of the device (Figure 4.4b). Pressure was applied to the platens by pumping the hydraulic lever until sample failure. For the model used in this study, the failure load was calculated by

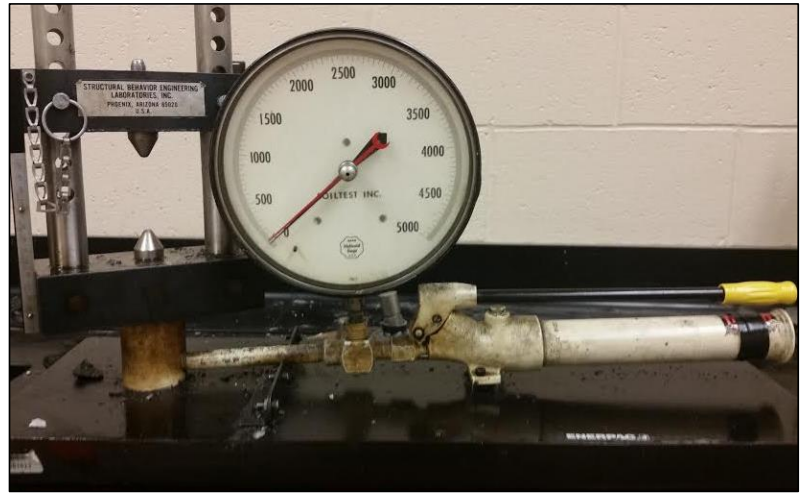

(a)

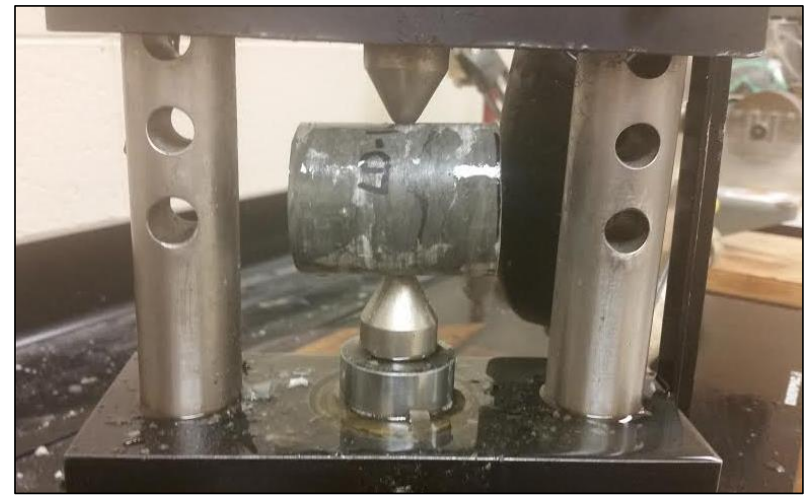

(b)

Figure 4.4: (a) PL Test Device to Estimate UCS and (b) Diametrically Loaded Sample 
multiplying the gauge pressure reading at failure by the effective area of the conical platens, $2.236 \mathrm{in}^{2}$ and was divided by the squared equivalent core diameter, as specified in Section 2.1.1, to determine $\mathrm{I}_{\mathrm{s}}$.

The UCS of samples was estimated by multiplying $\mathrm{I}_{\mathrm{s}}$ by an index-to-strength conversion factor. Generalized conversion factors for specific core diameters are provided by ASTM Standard D5731 (2008), and a value of 22 was chosen for this study based on the NX size of cores used.

\section{Uniaxial Compressive Tests}

UCS tests were performed on room temperature and frozen samples to establish if strength and elasticity of the samples changed with exposure to low-temperature. Procedures for UCS were consistent with ASTM Standard D7012 (2014). Core samples were placed between platens of the MTS used for testing (Figure 4.5a), and a light pressure was applied to secure the sample between machine platens. The MTS was operated at a constant strain rate of $0.0002 \mathrm{in} / \mathrm{sec}$ for all samples to limit the time required for testing so that frozen samples would not undergo significant temperature changes during testing. Testing stopped once samples had failed between the platens (Figure 4.5b).

UCS was calculated by dividing the maximum load before failure by the

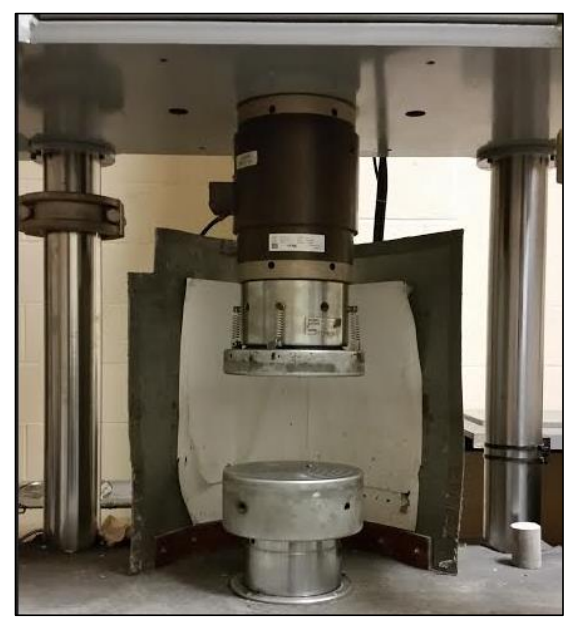

(a)

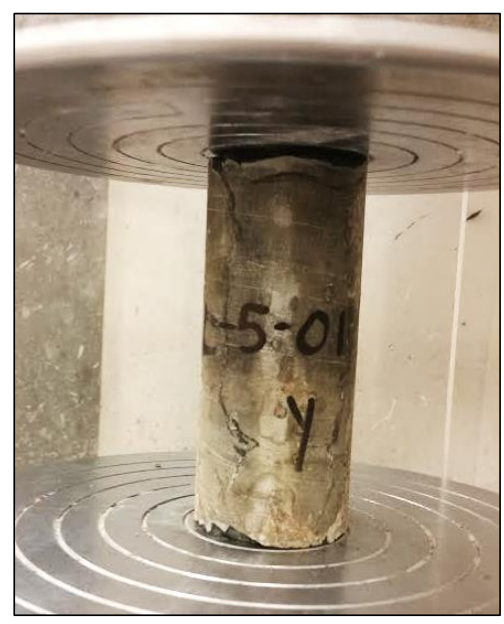

(b)

Figure 4.5: (a) MTS Machine for UCS Testing and (b) Sample after Failure 
surface area of the core sample in contact with the machine platens as described in Section 2.1.1. Stress-strain plots were developed for all samples using the axial-load plots recorded by the MTS during testing.

\subsubsection{Nondestructive Test Procedures}

\section{Schmidt Hammer Tests}

An L-type Schmidt hammer (Figure 4.6a) was used to record $\mathrm{R}$ values of samples. SH tests were performed in accordance with a developed set of standards (based on a combination of ASTM and ISRM standards) that is summarized in Table 4.1. Rock samples were secured to the core holder during testing. Figure $4.6 \mathrm{~b}$ shows an example of Schmidt hammer operation for a core sample. A total of 10 impacts, separated by at least one piston diameter, were taken over an area that was one core diameter away from the core ends. In accordance with ASTM Standard D5873 (2014), the average $R$ value for a specimen was calculated by averaging all $10 R$ values obtained and omitting any value that differed from the average by $\pm 7 \mathrm{R}$ units to calculate the final average.

\section{Ultrasonic Pulse Velocity Tests}

Initial $V_{P}$ of samples were obtained for all samples at room temperature through UPV testing with standard $54 \mathrm{kHz}$ compressional wave transducers. Figure

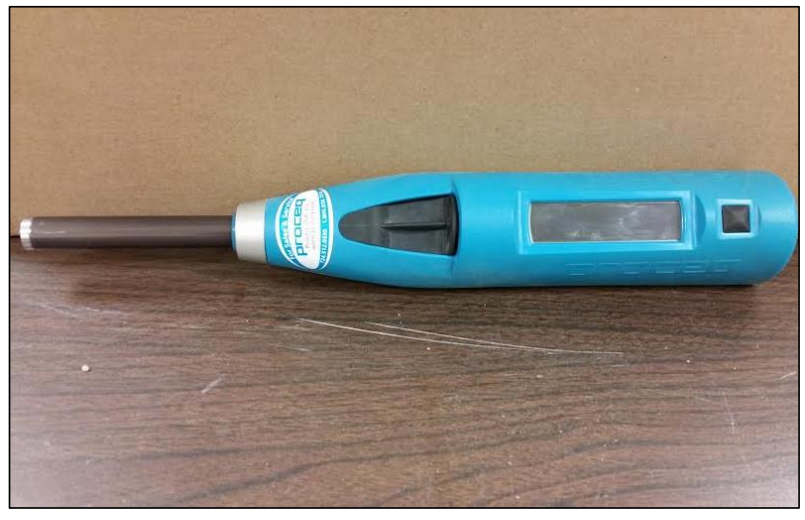

(a)
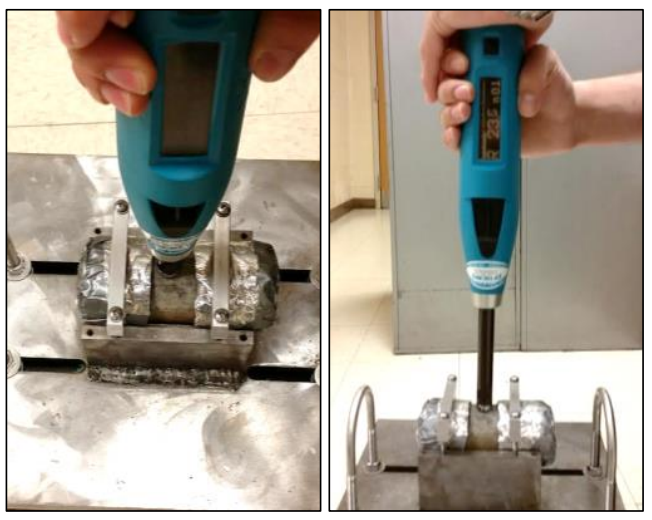

(b)

Figure 4.6: (a) L-Type SH Test Device and (b) SH Testing of Sample 
Table 4.1 Standards for L-Type SH Testing of Rock Core Samples

\begin{tabular}{l|l}
\hline \hline Description & \multicolumn{1}{c}{ Developed Standard } \\
\hline Specimen Quality & $\begin{array}{l}\text { Core samples shall be free of visible cracks and shall be representative of the rock being } \\
\text { characterized. }\end{array}$ \\
Surface Quality & $\begin{array}{l}\text { Test surfaces of specimens shall be smooth and free of dust. Fine to medium grained sand paper } \\
\text { will be used to smooth core surfaces. }\end{array}$ \\
Moisture & $\begin{array}{l}\text { Core samples will either be air dried for a minimum of 24 hours after they are prepared, or will } \\
\text { be partially saturated by submersion in water for a minimum of 24 hours. }\end{array}$
\end{tabular}

Specimen Diameter

Core specimens shall be 1.85 inches or larger in diameter. ${ }^{1}$

Specimen Length $\quad$ Core specimens shall be at least $15 \mathrm{~cm}$ in length. ${ }^{2}$

Core Holder Specimens shall be securely clamped to a steel V-block. Steel core holder will be welded to a steel block to produce an overall weight of at least $15 \mathrm{~kg} .^{3}$

Core Holder Placement The steel base will be placed on the same firm, flat ground in one of the mining labs for all tests.

Testing Area The hammer will be positioned not less than one core diameter from the edge of the specimen.

Test Locations Test locations shall be separated by at least one plunger diameter, and only one test may be taken at any one point.

Measurement Precision Hardness values shall be recorded to the nearest whole number.

Number of Readings Ten values will be recorded at representative locations on the specimen.

Data Reduction Calculate the average of the ten readings to the nearest whole number. Discard readings differing from the average by more than seven units. Recalculate the average from the remaining readings.

NOTE- 1: based on the samples that we have; 2 : additional length may be added for cores less than $54.7 \mathrm{~mm}$ ( 2.15 in) in diameter; 3 : based on machined core holder

4.7a shows an image of the display screen from the UPV device used in this study, and Figure $4.7 \mathrm{~b}$ shows an example of a rock sample being tested. UPV tests were performed on all samples for the detailed low-temperature tests as well. UPV measurements were conducted in accordance with ISRM-suggested methods for

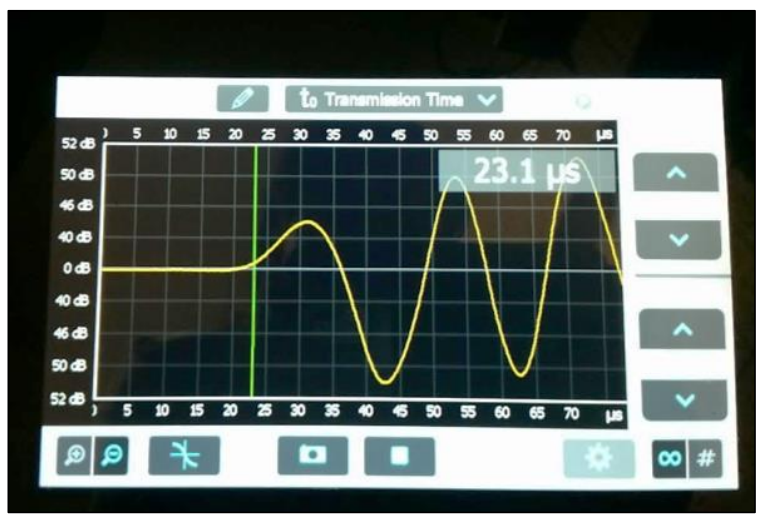

(a)

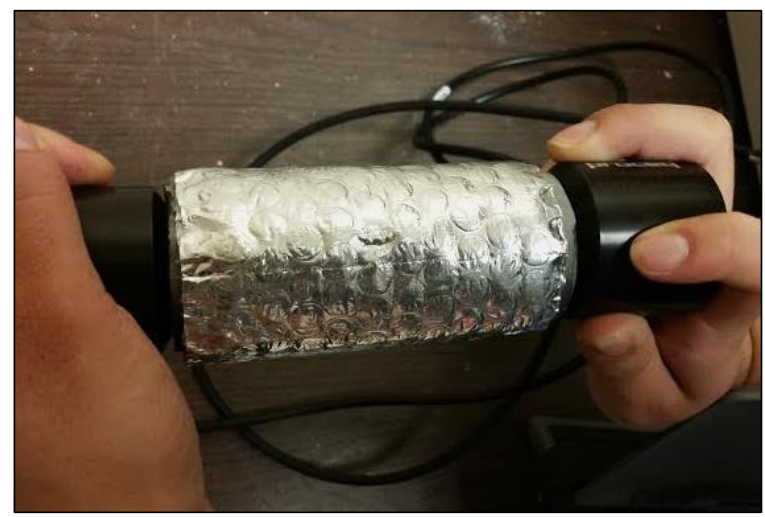

(b)

Figure 4.7: (a) UPV Test Device Display Screen and (b) UPV Testing of Sample 
determination of sound velocity by UPV (Aydin, 2013). The couplant provided in the PL-200 package was applied to the end of cores to be tested, and the transducers were placed on core samples for direct UPV measurement while pressure was applied.

Three readings were taken for the P-wave travel time to calculate three values for $V_{P}$ by dividing the sample length by travel time. The three velocities were averaged to provide a single $V_{P}$ value for each sample.

\subsubsection{Detailed Low-Temperature Tests}

Rock samples were pre-frozen in a laboratory freezer for 24 hours prior to testing to reduce soaking durations and fractures due to thermal shock. Figure 3.2 was consulted to determine the amounts of water, methanol, and dry ice needed to produce a cooling bath of a specific temperature, while total bath volumes varied depending on the number of samples being tested. As mentioned in Section 3.2.2, baths were prepared to $5^{\circ} \mathrm{C}$ cooler than desired sample temperatures due to the exponential nature of convectional cooling and reduction in bath temperature observed upon sample addition. Samples were placed in sealed Teflon bags to prevent contact and absorption of the bath liquid before being placed in the baths, prepared as described in Section 3.2.1, and cooling models were consulted to estimate approximate soak durations for the samples. Rock samples were removed from the baths, after their surface temperatures were within $\pm 5^{\circ} \mathrm{C}$ of the desired temperatures.

Upon removal from the cooling bath, samples were wrapped with aluminum insulation to prepare for SH testing, leaving the central part of the core side exposed. Following SH testing, samples were re-submerged in the cooling baths to chill the cores to their desired low-temperatures. The samples were removed, wrapped in insulations, and tested once again for UPV at the low-temperature. Lastly, the sample insulation was removed and UCS testing was conducted. Following the uniaxial tests, the final internal temperatures of the broken sample were recorded, and fracture patterns were evaluated. Tests were repeated for multiple samples at multiple temperatures to fully evaluate the effects of data scatter and potential asteroid surface temperatures.

Figure 4.8 illustrates the step-by-step process discussed above for the detailed test regime. Methods for the detailed low temperature tests of rock cores are summarized by the following numbered steps: 


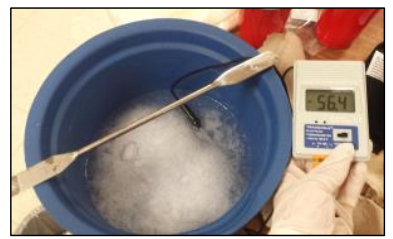

Step 1: Generate chemical mixture to produce bath of desired temperature

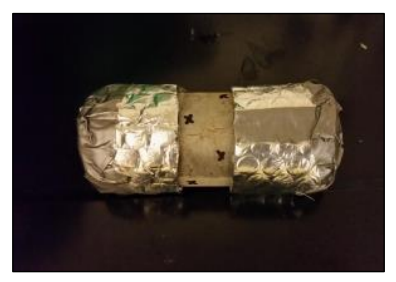

Step 4: Apply insulation to prepare for Schmidt testing

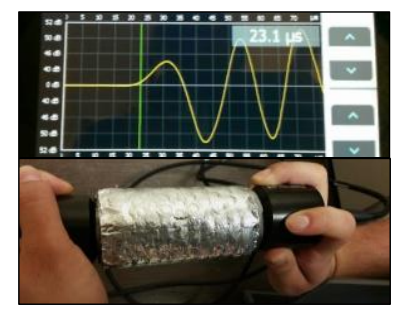

Step 7: Perform UPV test on insulated sample

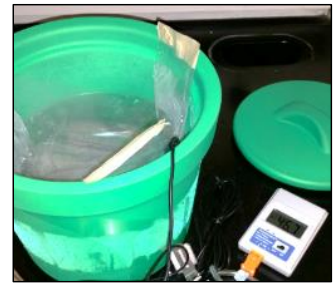

Step 2: Add rock samples to cooling bath

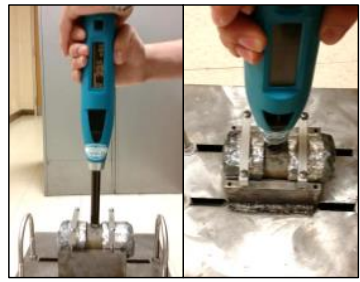

Step 5: Perform Schmidt Hammer test

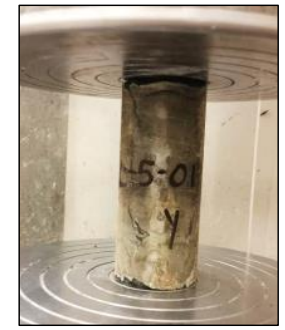

Step 8: Perform UCS test

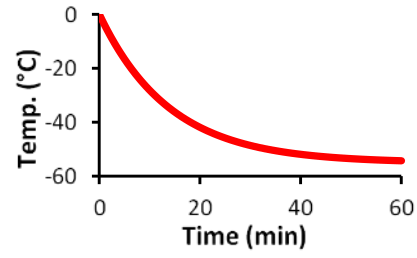

Step 3: Cool for specified amount of time and record sample surface temperature

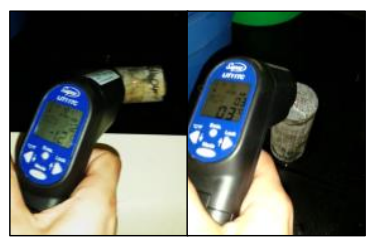

Step 6: Re-chill sample to match original surface temperature

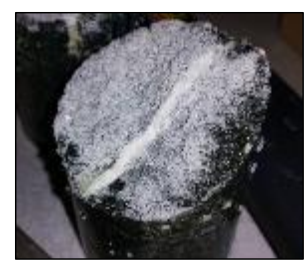

Step 9: Record internal temperature and evaluate fracture pattern

Figure 4.8: Detailed Steps with Images for Low-Temperature Testing

1. Generate chemical mixture to produce bath of desired temperature.

a. Choose a bath temperature $5^{\circ} \mathrm{C}$ cooler than desired sample temperature.

b. Consult Figure 3.2 in Section 3.2.1 to determine methanol and dry ice concentrations for desired bath temperature.

c. Use equipment and instructions described in Sections 3.1 and 3.2.

2. Add rock samples to prepared cooling baths.

a. Place samples in sealed Teflon bags as described in Section 3.1.2.

b. Maintain bath temperature as described in Section 3.1.1.

3. Cool samples for specified amounts of time and record sample surface temperature.

a. Consult methods in Section 3.2.2 to develop cooling models for specific bath temperature and sample type.

b. At the time designated by the cooling model, record the minimum 
surface temperature on the top and sides of core samples with an IR thermometer.

c. Average the top and side temperature values of the specimen and ensure this value matches the desired sample temperature before sample removal.

4. Apply insulation to prepare for SH testing.

a. Use insulation type (3) as described in Section 3.3.2

5. Perform SH test as described in Section 4.2.3.

a. Complete SH test within three minutes of sample removal from bath.

6. Re-submerge sample in bath (in sealed Teflon bag) until average surface temperature matches the sample temperature recorded in step 3.

a. Remove sample and apply insulation type (2) as described in Section 3.3.2.

7. Perform UPV test as described in Section 4.2.3.

a. Complete UPV test within one minute of sample removal from bath.

8. Perform UCS test as described in Section 4.2.2.

a. Remove insulation used for UPV test before conducting UCS testing.

b. Complete UCS test within two minutes after UPV test.

9. Record minimum internal temperature of sample with IR thermometer. 


\section{Chapter 5}

\section{Results and Discussion}

\subsection{Baseline Results}

Chalk, shale, and limestone samples were assessed at room temperature to establish their baseline properties. The values were later compared for the low-temperature tests. Table 5.1 details the baseline properties measured for the samples at room temperature which included $\rho, V_{P}, R$, and UCS. Sample UCS values determined by destructive tests verified that the selected samples provided "high," "medium," and "low" ranges of strengths, while ranges for $\rho, V_{P}$, and $R$ vary in similar and expected fashions. The limestone was slightly weaker and more variable than expected, while chalk strength was the most consistent, and shale strength was moderately variable.

Table 5.1: $\quad$ Baseline Sample Properties at Room Temperature

\begin{tabular}{lc|ccc}
\hline Property & Unit & Chalk & Shale & Limestone \\
\hline Number of Specimens & $(--)$ & 24 & 12 & 18 \\
Density $(\boldsymbol{\rho})$ & $\left(\mathrm{g} / \mathrm{cm}^{3}\right)$ & $1.86-2.02$ & $2.47-2.62$ & $2.60-2.77$ \\
P-wave Velocity $\left(\mathbf{V}_{\mathbf{P}}\right)$ & $(\mathrm{m} / \mathrm{s})$ & $2,713-4,099$ & $4,080-5,582$ & $5,071-7,049$ \\
Schmidt Hardness $(\mathbf{R})$ & $(-)$ & $19.0-26.0^{*}$ & $40.5-53.0$ & $57.5-69.5^{*}$ \\
Uniaxial Compressive Strength $(\mathbf{U C S})$ & $(\mathrm{MPa})$ & $10.6-15.5^{*}$ & $71.5-127.0^{*}$ & $102.6-115.2^{*}$ \\
\hline
\end{tabular}

NOTE- *indicates parameters that were not tested for entire group of specimens 
As indicated by the note in Table 5.1, SH tests and UCS tests were only performed on several samples of the groups and could not be repeated on the same samples, unlike UPV tests. Due to the slight deformation that occurs under the tip of the hammer during SH testing and the total destruction that occurs during UCS testing, these tests are not repeatable for NX cores.

\subsection{Low-Temperature Results and Discussion}

PL tests were performed on limestone samples as a shakedown experiment to quickly determine if low-temperature influences relative strength. Detailed low-temperature tests were performed on chalk, shale, and limestone samples to analyze the effects of low-temperature on mechanical properties derived from destructive methods (i.e. UCS and E) and NDT responses (i.e. VP and R) for these samples.

\subsubsection{Destructive Testing}

Figure 5.1 displays the effects of internal temperature on UCS estimated from $I_{s}$. This test series was performed as a "quick-result" test to determine preliminary

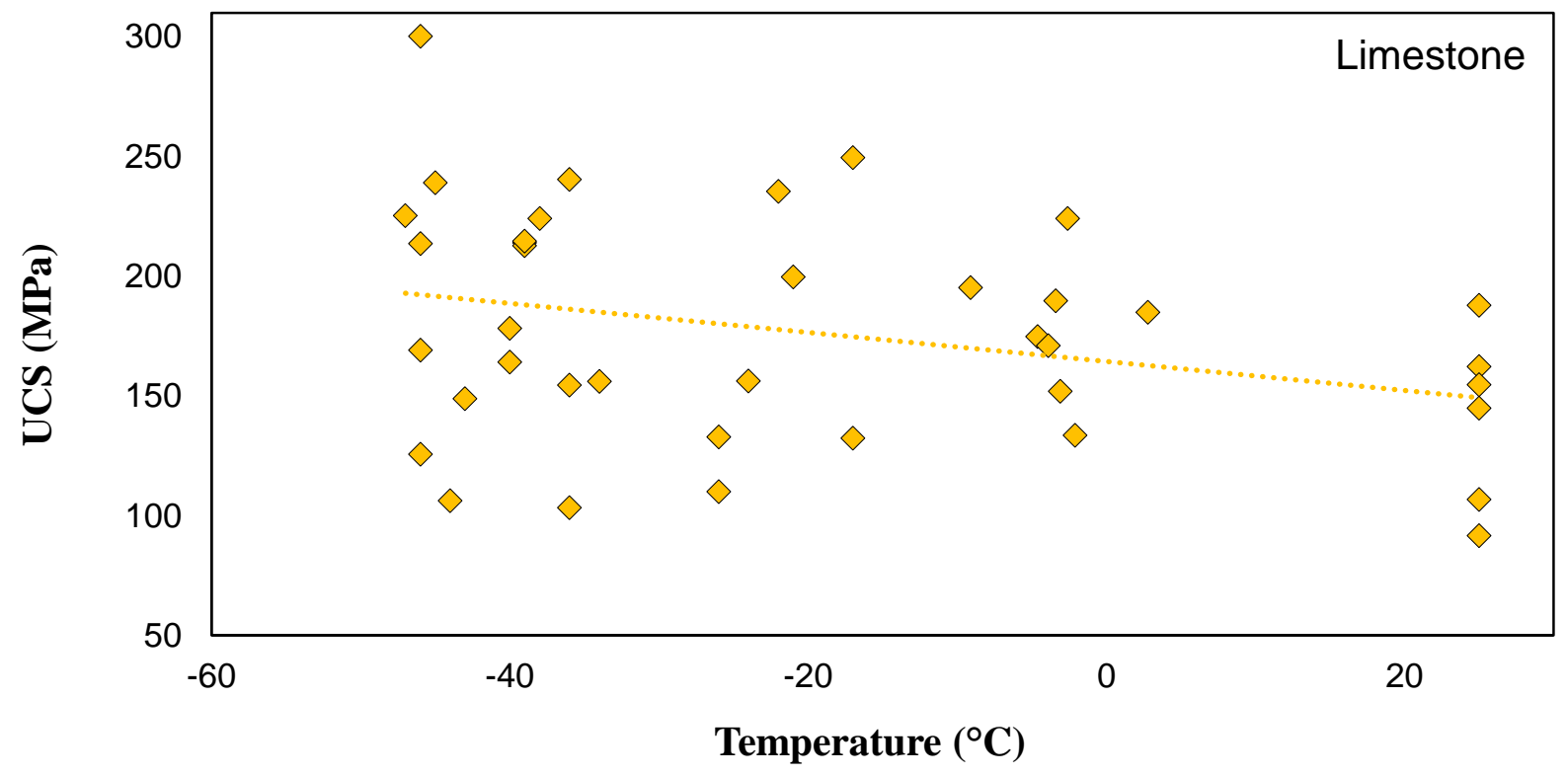

Figure 5.1: PL Estimated UCS as a Function of Temperature for Limestone 
relationships between rock strength and temperature for below-freezing temperatures.

PL estimated UCS at room temperature is slightly greater and exhibits a larger strength range than the baseline measured strengths for limestone from Table 5.1. This result indicates that the strength-to-conversation factor used to estimate UCS from $I_{s}$ was too high. However, based on the purpose of shakedown testing to evaluate if low-temperature affects strength, relative strength comparisons over temperature changes is sufficient

While results from the PL test exhibit significant scatter, the variation in PL estimated UCS appears to increase with decreasing temperature; however, PL analysis does not show erratic behavior. Since samples for PL tests were loaded diametrally and were of the same diameter, correction of PL calculated $\mathrm{I}_{\mathrm{s}}$ was not necessary. As a result, the PL method is advantageous for relative strength analysis of similar samples. Analyzing the overall trend of the data, low-temperature may contribute to escalated compressive strength as indicated by the slightly negative slope in PL estimated UCS as temperature increases from below-freezing to room temperature.

Due to the imprecise nature of estimating UCS from PL tests and the original variability in the baseline limestone strengths, a significant low-temperature influence on limestone strength cannot be discerned from PL tests alone. Overall, the PL shakedown test results show that for limestone samples, low-temperature may influence strength properties, and may contribute to an increase in resistance to failure under applied loads.

Since Pl tests showed low-temperature may influence rock strength, detailed low-temperature testing was planned. For destructive tests, E derived from stress-strain curves and measured UCS were compared for the different samples over a range of low-temperatures. Figure 5.2 displays results from the low-temperature UCS tests for chalk, limestone, and shale. Results from these tests show insignificant changes in UCS as a function of temperature for chalk and shale, but significant increases in UCS with decreasing temperature were observed for limestone.

As indicated by the trendline in Figure 5.2b, low-temperature tests reveal that 


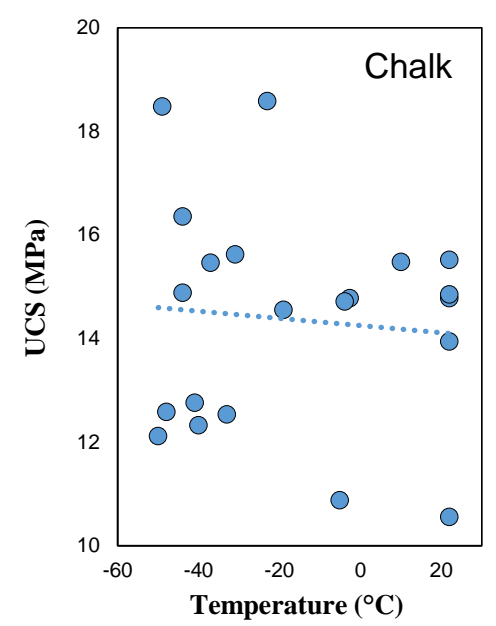

(a)

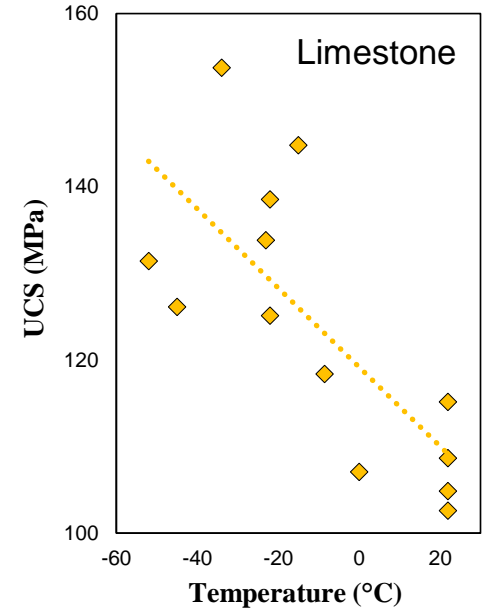

(b)

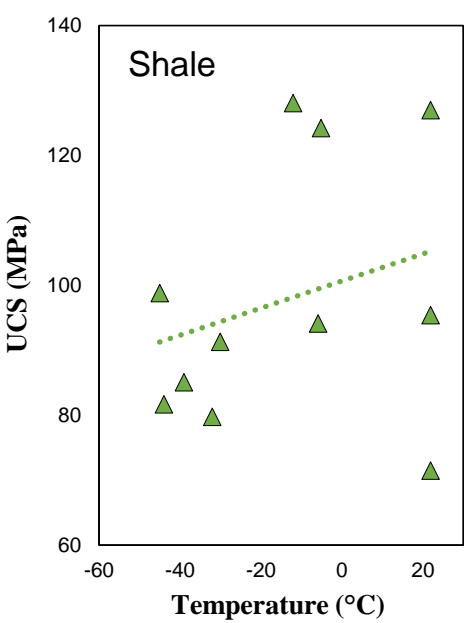

(c)

Figure 5.2: UCS as a Function of Temperature for (a) Chalk, (b) Limestone, and (c) Shale

strength increases for limestone samples in this study as temperature decreases. Strengths of limestone samples at temperatures less than $-20^{\circ} \mathrm{C}$ were greater than the maximum strength of samples at room temperature. The range of UCS for limestone samples at temperatures below $-20^{\circ} \mathrm{C}$ are between $120 \mathrm{MPa}$ and $160 \mathrm{MPa}$; however, PL approximations of UCS at similar temperatures for limestone were in the range of $100 \mathrm{MPa}$ to $300 \mathrm{MPa}$. These results reiterate the notion that the index-to-strength conversion factor to estimate UCS from $\mathrm{I}_{\mathrm{s}}$ did not accurately represent how $\mathrm{I}_{\mathrm{s}}$ relates to UCS for these samples. A correction factor may instead be back-calculated using known UCS is the relationship between $\mathrm{I}_{\mathrm{s}}$ and UCS is in fact linear.

As shown in Figure 5.2a and 5.2c, the UCS of chalk samples increases with decreasing temperature, while shale samples show a slight decrease in UCS with decreasing temperature, based on the trendlines shown on the respective graphs. Chalk and shale samples at room temperature show greater variation in UCS than limestone samples. With increased sample consistencies, trendlines showing the change in UCS with decreasing temperature may become more apparent for chalk and shale.

E values, calculated from UCS tests, are represented as a ratio to UCS, since slight variations in UCS between samples were observed. Results are summarized in Figure 5.3 and show that for chalk and limestone, E decreases with decreasing 


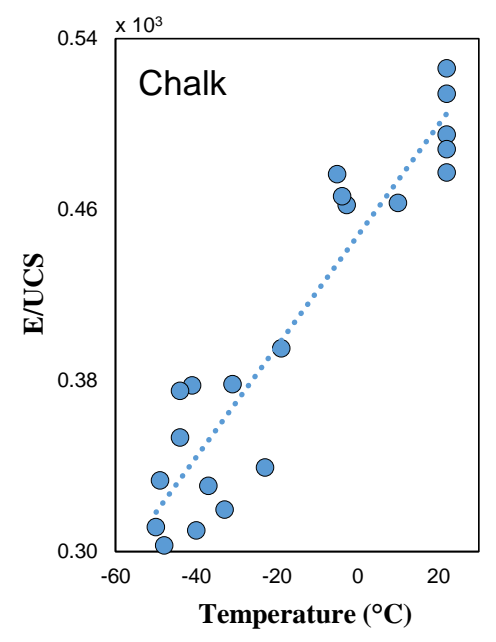

(a)

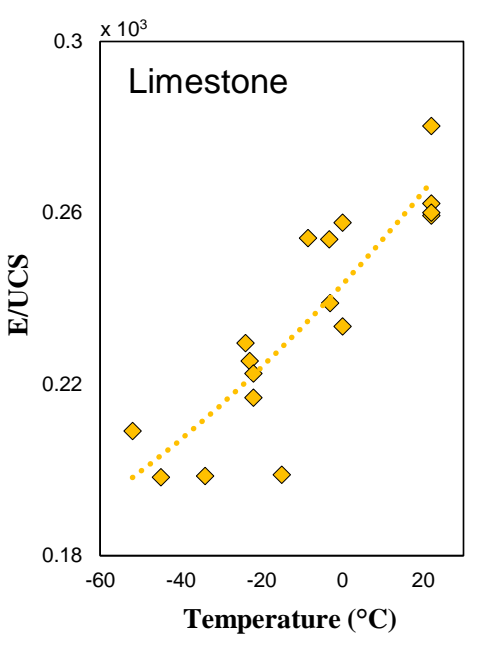

(b)

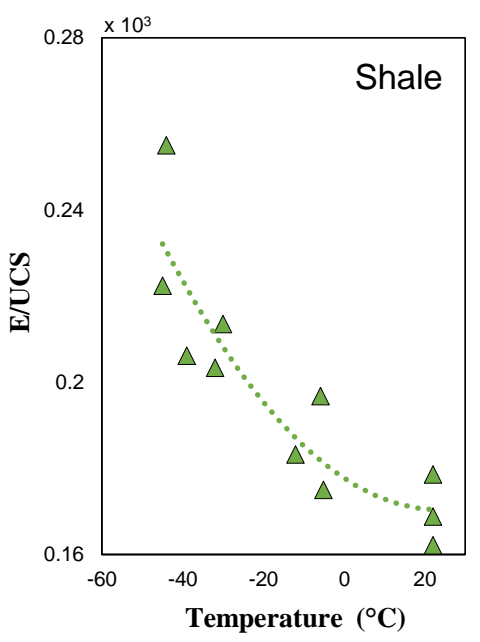

(c)

Figure 5.3: $\quad$ E/UCS as a Function of Temperature for (a) Chalk, (b) Limestone, and (c) Shale

temperatures (elasticity increases as temperature decreases). Shale results show an increase in $\mathrm{E}$ with decreasing temperature (stiffness increases as temperature decreases). For chalk, the trend of data for the temperatures tested is linear, while for limestone and shale, data trends of $\mathrm{E}$ at the same range of low-temperatures show increased curvature.

These trends are significant and coincide with changes in UCS with decreasing temperature. For chalk and limestone, as temperature decreases, slight increases in UCS and decreases in E (increases in elasticity) are observed. For shale, as temperature decreases, slight decreases in UCS and increases in E (increases in brittleness) are observed. Changes in elastic properties may explain potential and observed changes in UCS with decreasing temperature. For chalk and limestone, samples become more elastic with decreasing temperature, allowing them to flex and deform elastically and potentially bear greater loads as a result of this elastic deformation. For shale, samples became more plastic and brittle with decreasing temperature, leading to brittle failure and the potential inability to bear greater loads due to reduction in elastic deformation.

\subsubsection{Nondestructive Testing}

$\mathrm{V}_{\mathrm{P}}$ values were recorded for all samples at room temperature and again once samples were frozen to their desired temperatures. Initial $V_{P}$ values (room 


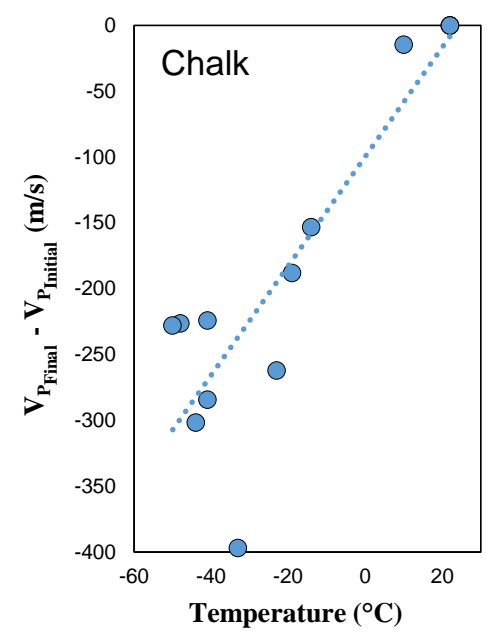

(a)

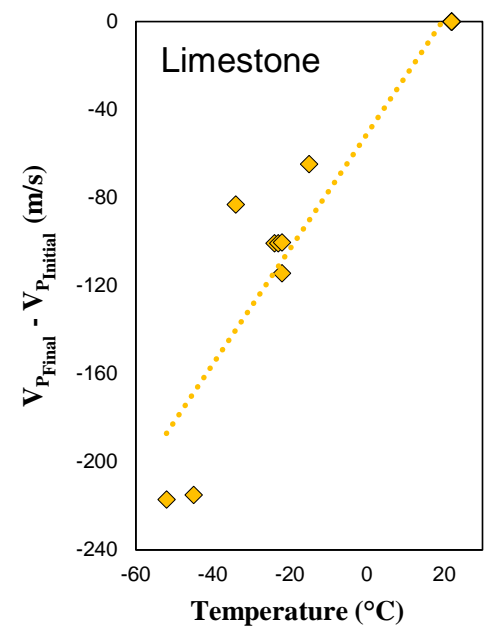

(b)

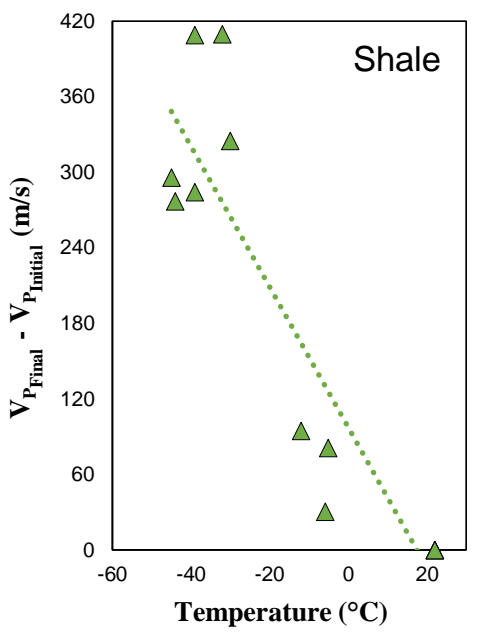

(c)

Figure 5.4: $\quad V_{P}$ Change as a Function of Temperature for (a) Chalk, (b) Limestone, and (c) Shale

temperature) were subtracted from final $V_{P}$ values (cold temperatures) to display change in $V_{P}$ as a function of temperature. $V_{P}$ differentials as a function of temperatures are shown for chalk, limestone, and shale in Figure 5.5a, Figure 5.45b, and Figure 5.4c, respectfully.

For chalk and limestone, $V_{P}$ significantly decreases as temperature decreases. For chalk, maximum $\mathrm{V}_{\mathrm{P}}$ change is nearly $25 \%$ of the average $\mathrm{V}_{\mathrm{P}}$, whereas less significant $\mathrm{V}_{\mathrm{P}}$ changes occur in limestone (less than $10 \%$ for the maximum value). Opposing trends are observed for shale samples: as temperature decreases, $\mathrm{V}_{\mathrm{P}}$ for shale samples increases. The experimental trends in $V_{P}$ change agree with the observed changes in $\mathrm{E}$ with decreasing temperature. For chalk and limestone, $\mathrm{E}$ decreases as temperature also decreases. Similarly, $V_{P}$ for chalk and limestone samples decrease with decreasing temperature. As chalk and limestone samples begin to lose their brittleness, $V_{P}$ decreases as a result of increased void space. For shale, results show an increase in $\mathrm{E}$ with decreasing temperature. In a similar fashion, changes in $V_{P}$ for shale increase with decreasing temperature. As shale samples becomes more brittle, $\mathrm{V}_{\mathrm{P}}$ increases as a result of decreased void space.

As previously stated, changes in $\mathrm{R}$ with decreasing temperature were only recorded for chalk and limestone samples, and respective plots are displayed in respective Figures 5.5a and 5.5b. Results show that as temperature decreases, $\mathrm{R}$ for chalk and limestone also decreases. For chalk, the decrease in $\mathrm{R}$ with decreasing 


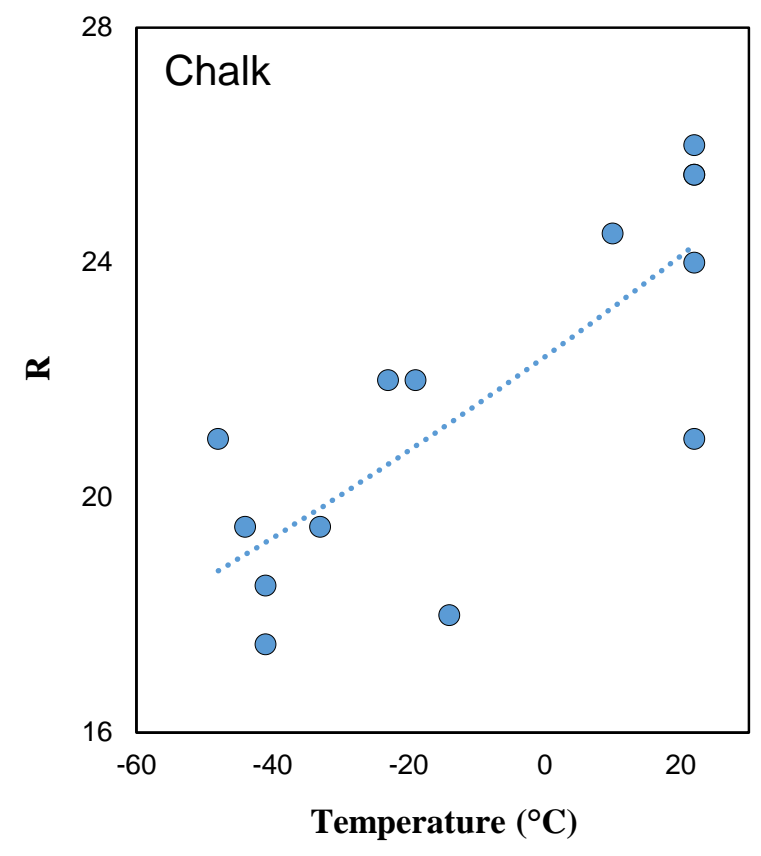

(a)

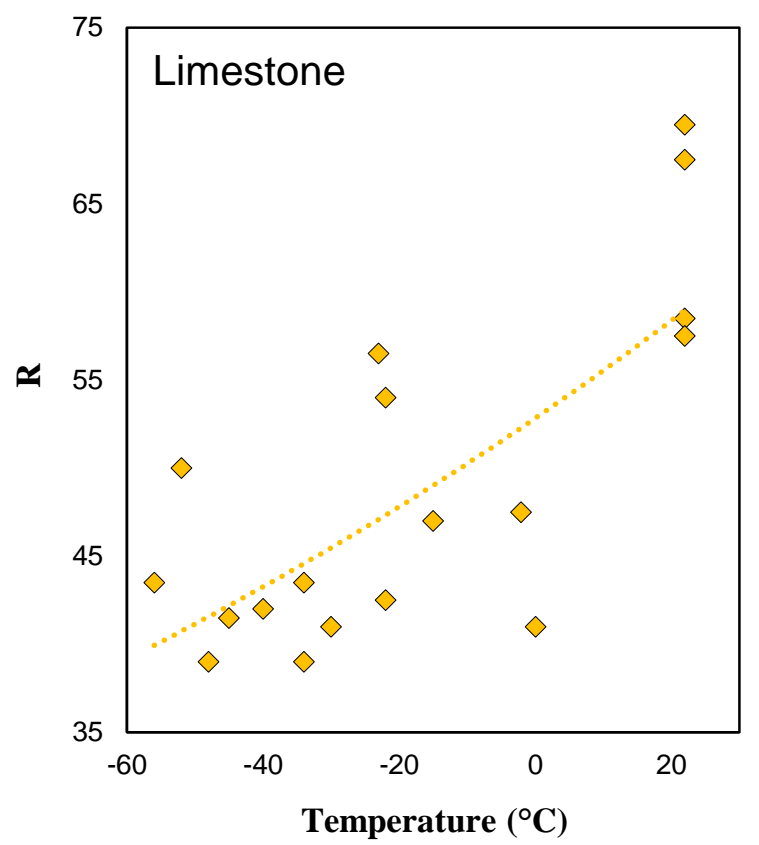

(b)

Figure 5.5: $\quad \mathrm{R}$ as a Function of Temperature for (a) Chalk, and (b) Limestone

temperature is less drastic. These results correspond to the observed changes in elasticity for chalk and limestone with decreasing temperature.

For both chalk and limestone, the elasticity of samples increases (E decreased) as temperatures decreases. As elasticity increases, plasticity decreases. Since R is a mechanism of plastic failure occurring on the surface struck by the hammer, reductions in Schmidt response with decreasing temperature observed for chalk and limestone may be explained by a similar decline in plastic deformation revealed by the reduction in $\mathrm{E}$ with decreasing temperature observed for chalk and limestone.

Although SH tests were not conducted on shale samples at low-temperature, the potential trend of $\mathrm{R}$ as a function of temperature may be estimated through analysis of elastic changes in shale samples at low-temperatures. $\mathrm{E}$ and $\mathrm{V}_{\mathrm{P}}$ change results for shale show increases in plasticity as temperature decreases. Given the correlations between changes in elastic properties and changes in $\mathrm{R}$ displayed by chalk and limestone samples, it is estimated that for shale samples, $R$ should increase as temperature decreases since shale samples became more brittle with decreasing temperatures.

Low-temperature effects for UCS, E, $\mathrm{V}_{\mathrm{P}}$, and R are summarized for chalk, limestone, 
Table 5.2: $\quad$ Property Effects for Rocks at Low-Temperature

\begin{tabular}{c|cc}
\hline \hline Rock Type & Property & Effect \\
\hline \multirow{4}{*}{ Chalk } & UCS & $\uparrow$ \\
& $\mathrm{E}$ & $\downarrow$ \\
& $\mathrm{V}_{\mathrm{P}}$ & $\downarrow$ \\
$\mathrm{R}$ & $\downarrow$ \\
\hline \multirow{3}{*}{ Limestone } & $\mathrm{UCS}$ & $\uparrow$ \\
& $\mathrm{E}$ & $\downarrow$ \\
& $\mathrm{V}_{\mathrm{P}}$ & $\downarrow$ \\
& $\mathrm{R}$ & $\downarrow$ \\
\hline \multirow{3}{*}{ Shale } & $\mathrm{UCS}$ & $\downarrow$ \\
& $\mathrm{E}$ & $\uparrow$ \\
& $\mathrm{V}_{\mathrm{P}}$ & $\uparrow$ \\
& $\mathrm{R}^{*}$ & $\uparrow$ \\
\hline \hline
\end{tabular}

NOTE- *inferred from changes in UCS and E

and shale samples in Table 5.2. Property effects for chalk and limestone are impacted in the same directions; however, property effects are reversed for shale when compared to those for chalk and limestone samples.

\subsection{Implications of Results}

\subsubsection{Relationship between Test Results}

Final $\mathrm{V}_{\mathrm{P}}$ (taken at cold temperatures) as a ratio to $\mathrm{R}$ is displayed in Figures $5.6 \mathrm{a}$ and $5.6 \mathrm{~b}$ for chalk and limestone, respectively. While the slopes in these plots appear to indicate that chalk and limestone exhibit similar changes in $V_{P}$ and $R$ with decreasing temperature, results from individual tests summarized in Figures 5.4 and 5.5 show that $V_{P}$ change is more significant in chalk, while change in $R$ is more significant in limestone as sample temperatures decrease.

To increase the understanding of how the responses of NDTs correspond to mechanical properties measured through uniaxial compression, the responses (e.g. $\mathrm{V}_{\mathrm{P}}$ and $\mathrm{R}$ ) are represented as ratios to the mechanical properties (e.g. E and UCS). These ratios were plotted as a function of temperature to see how the NDT responses change with temperature as they relate to mechanical changes with temperature. 


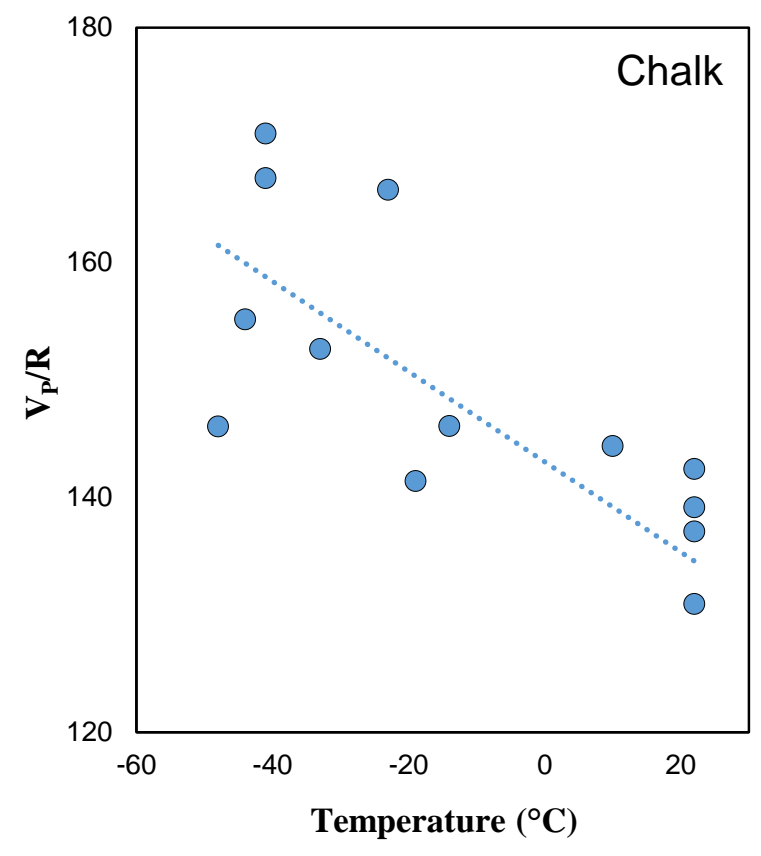

(a)

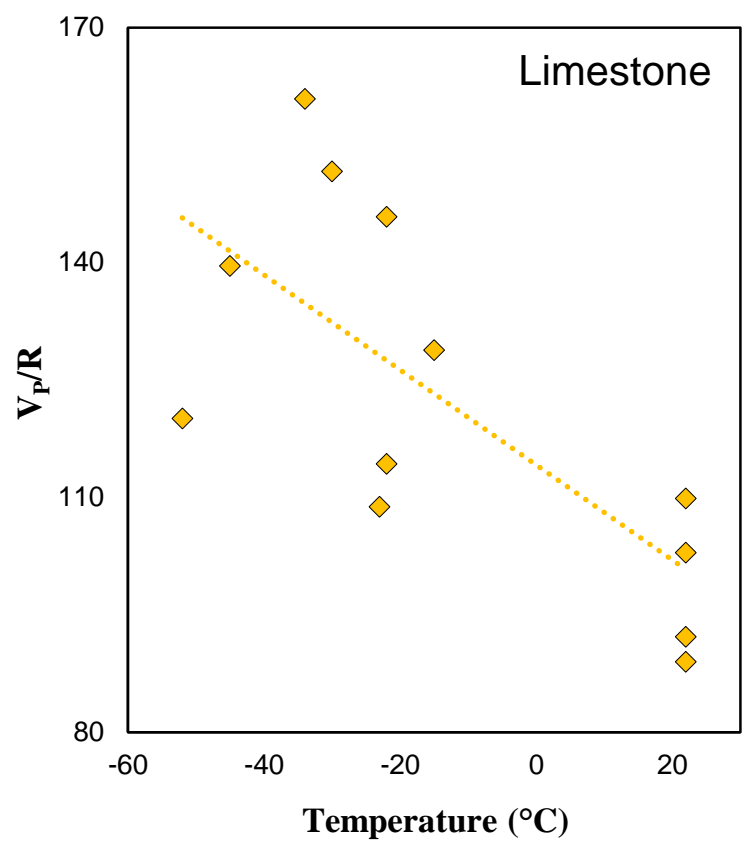

(b)

Figure 5.6: $\quad \mathrm{V}_{\mathrm{P}} / \mathrm{R}$ as a Function of Temperature for (a) Chalk, and (b) Limestone

This simple comparison method will indicate how the relationships between NDT responses and mechanical properties change linearly with temperature, though these relationships may change nonlinearly with temperature.

The correlations of final $\mathrm{V}_{\mathrm{P}}$ to UCS for the three sample types at various temperatures are displayed in Figure 5.7. As indicated in Figure 5.7b, the velocity correlations to UCS for limestone are not strong at low temperatures, whereas Figure $5.7 \mathrm{a}$ and $5.7 \mathrm{c}$ respectively show that these correlations are stronger for chalk and shale.

Figures 5.8a, 5.8b, and 5.8c display the ratios of $\mathrm{V}_{\mathrm{P}}$ to UCS for chalk, limestone, and shale, respectively. The negative slope with decreasing temperature in Figure 5.8b indicates that for limestone, UCS is more significantly influenced by temperature than $V_{P}$. Figure 5.8a also shows a negative slope with decreasing temperature for chalk, though the slope of this line is not as significant as the slope for limestone. This indicates that, like limestone, UCS is influenced more by temperature than $V_{P}$ for chalk. The ratio of $V_{P}$ to UCS for shale in Figure 5.8c shows slight increases with decreasing temperature. This shows that for shale samples, $V_{P}$ is slightly more significantly influenced by temperature than UCS. 


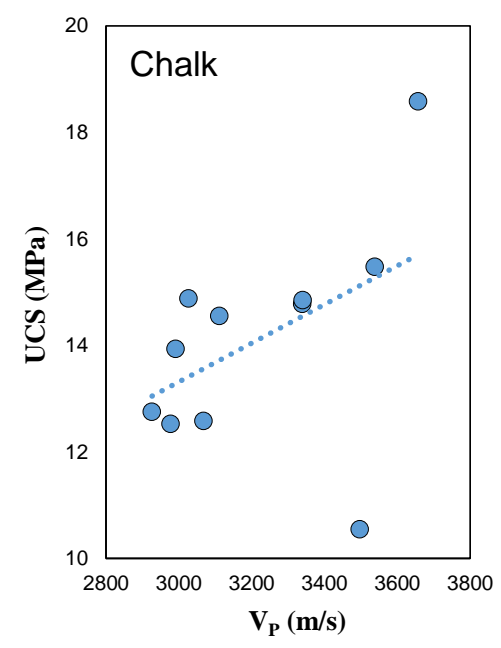

(a)

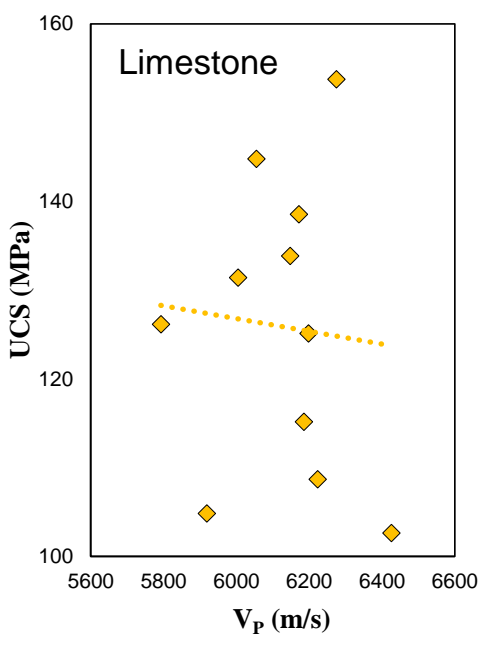

(b)

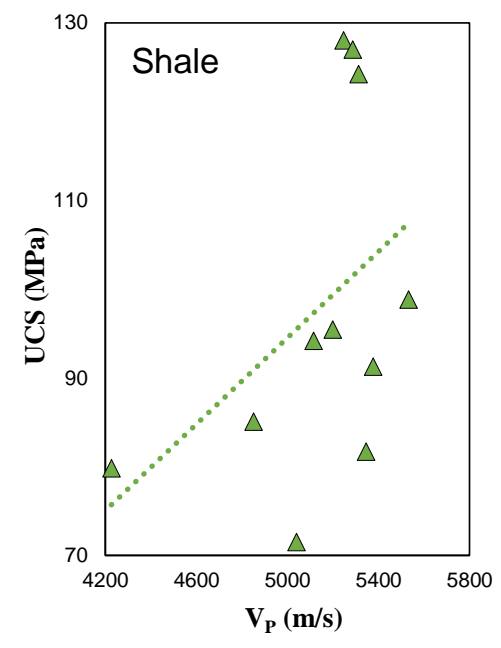

(c)

Figure 5.7: Correlation of Final VP to UCS for (a) Chalk, (b) Limestone, and (c) Shale

Figure 5.9 displays how the ratio of $\mathrm{V}_{\mathrm{P}}$ to $\mathrm{E}$ changes with decreasing temperature. Figure 5.9b indicates that for limestone samples, this relationship is not significantly impacted by temperature. Although Figure 5.3b indicates a significant reduction in $\mathrm{E}$ for limestone with decreasing temperature, the $\mathrm{V}_{\mathrm{P}}$ change was not as significant (Figure 5.4b), weakening the overall impact of temperature on the relationship between $V_{P}$ and $E$. This indicates that $V_{P}$ and $E$ change relatively proportionally to each other as temperature decreases, though the slightly positive

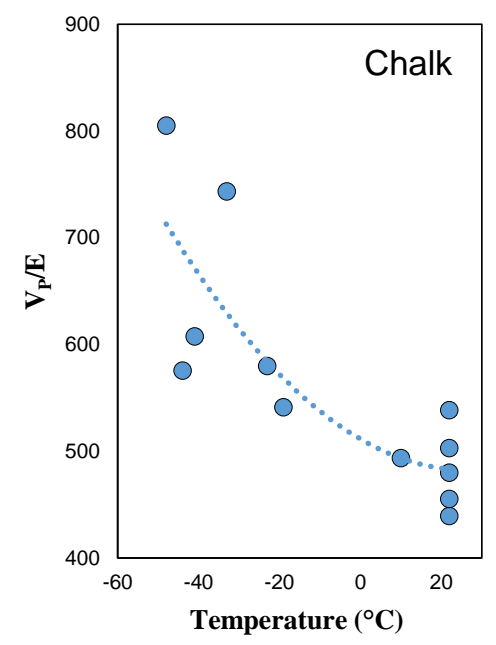

(a)

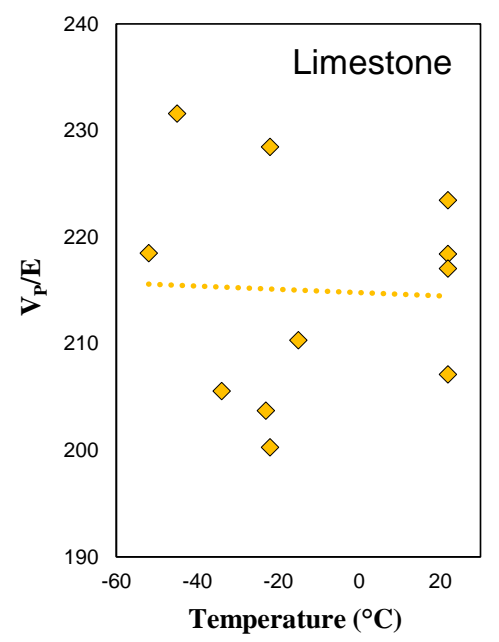

(b)

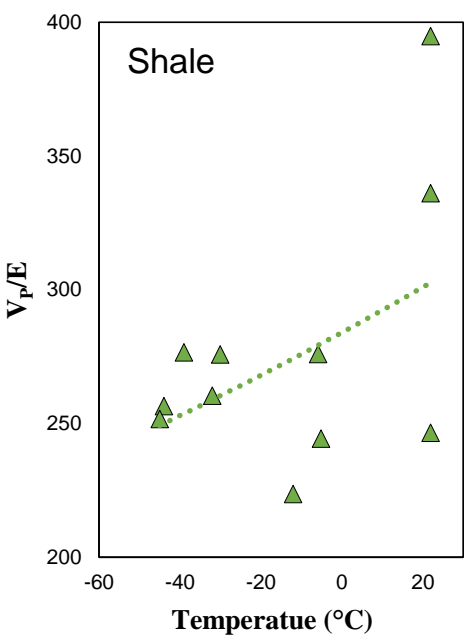

(c)

Figure 5.8: $\quad \mathrm{V}_{\mathrm{P}} / \mathrm{E}$ as a Function of Temperature for (a) Chalk, (b) Limestone, and (c) Shale 


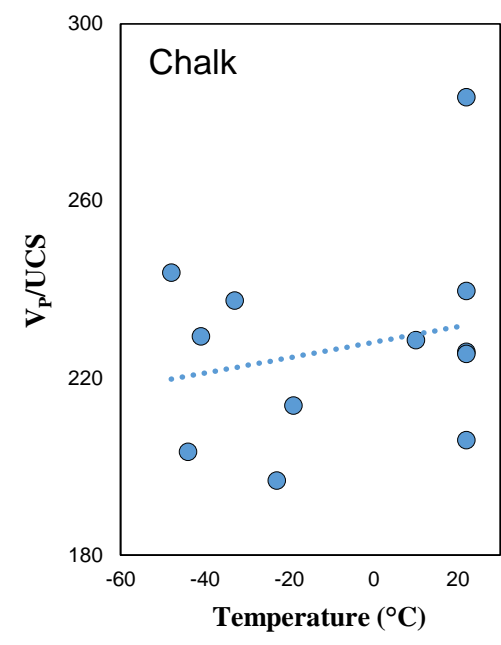

(a)

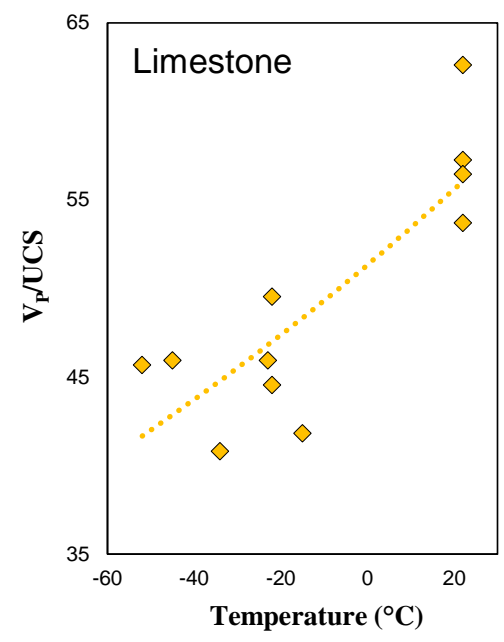

(b)

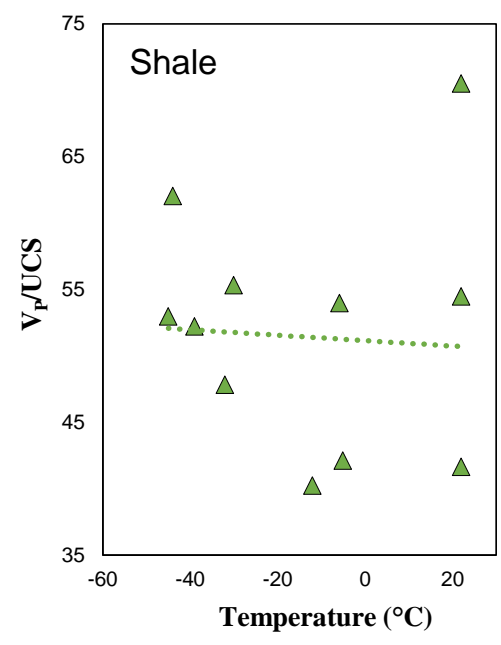

(c)

Figure 5.9: $\quad \mathrm{V}_{\mathrm{P}} / \mathrm{UCS}$ as a Function of Temperature for (a) Chalk, (b) Limestone, and (c) Shale

slope of this ratio as temperature decreases indicates that low-temperatures may have a slightly greater influence on $\mathrm{V}_{\mathrm{P}}$ than $\mathrm{E}$ for limestone.

For chalk and shale, on the other hand, Figures 5.9a and 5.9c respectively indicate that $\mathrm{V}_{\mathrm{P}}$ and $\mathrm{E}$ change less proportionally to each other with low-temperature, than they do for limestone. For shale, low-temperature influences on E (Figure 5.3c) and $V_{P}$ (Figure 5.4c), exhibit similar curvature; however, the relationship expressed in Figure 5.9c shows that $V_{P}$ and $\mathrm{E}$ do not change proportionally for shale. The negative trend of the data as temperature decreases indicates that $\mathrm{E}$ is more significantly influenced by low-temperature than $V_{P}$ for shale samples. Similarly, low-temperature influences on E (Figure 5.3a) and $V_{P}$ (Figure 5.4a) for chalk samples exhibit comparable curvature; however, the slope of data in Figure 5.9a indicates that $\mathrm{V}_{\mathrm{P}}$ and $\mathrm{E}$ do not change proportionally with low-temperature for chalk. The positive slope of the $V_{P}$ to $\mathrm{E}$ ratio as temperature decrease indicates that $\mathrm{V}_{\mathrm{P}}$ is more significantly influenced than E as chalk sample temperatures decrease.

The correlations between R and UCS for chalk and limestone samples at various temperatures are summarized in Figure 5.10. Expectations of these correlations from literature are that low $\mathrm{R}$ corresponds to low UCS, and high $\mathrm{R}$ corresponds to high UCS. While the chalk material exhibited this expected trend (Figure 5.10a), the data trend for limestone in Figure 5.10b opposes the expectation, 


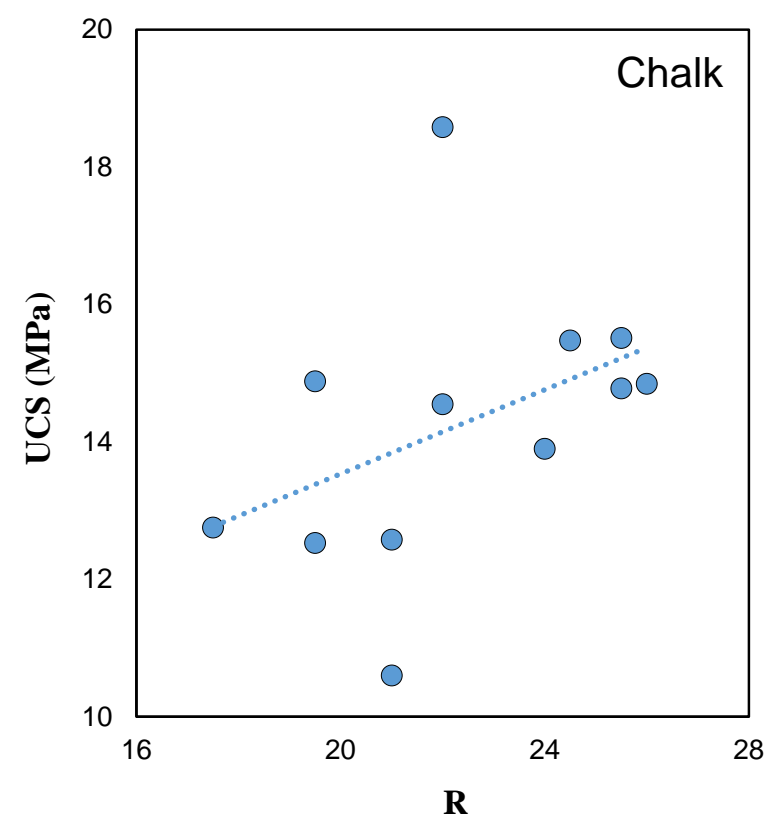

(a)

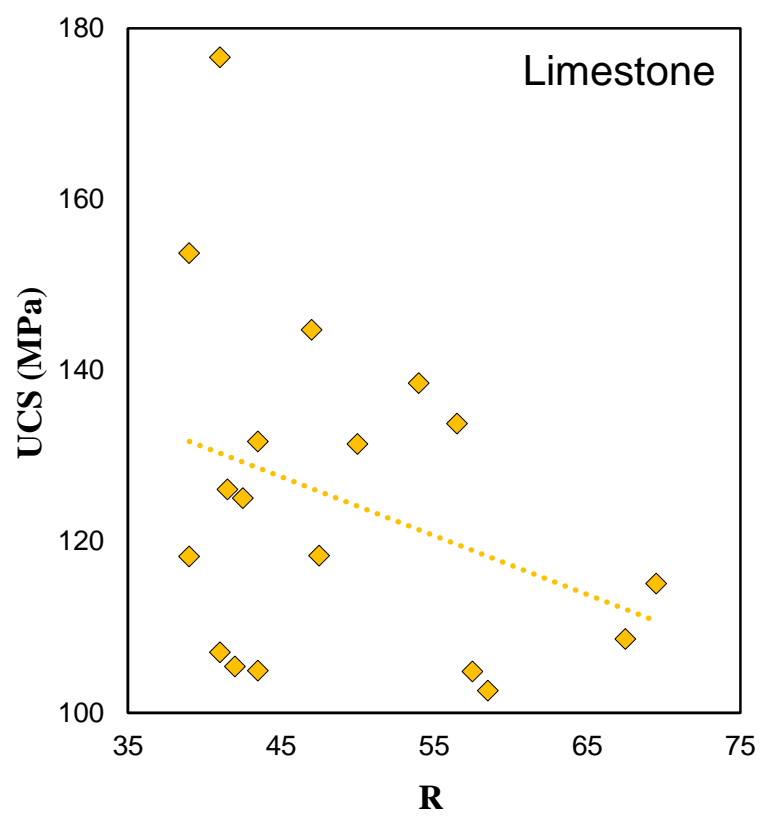

(b)

Figure 5.10: Correlation of R to UCS for (a) Chalk and (b) Limestone

as $\mathrm{R}$ was lower for the highest strength limestone material.

While the plots in Figure 5.10 are not differentiated by sample temperature, analysis of UCS change with temperature for limestone (Figure 5.2b) and R change with temperature for limestone (Figure 5.5b) leads to a possible explanation for the unexpected trend observed in Figure 5.10b. For decreasing temperature of limestone, UCS increases and R decreases. These phenomenon explain the reverse correlation between R and UCS than what is expected from previous investigations.

For chalk, however, the correlation between R and UCS (Figure 5.10a) trends in the expected direction, though the correlation is not strong. The weakness in this relationship may be explained by the slight possible increases in UCS with decreasing temperature, as shown in Figure 5.2a, and the less drastic reduction in $\mathrm{R}$ with decreasing temperature (Figure 5.5a) when compared to these values for limestone.

The relationships between changes in $\mathrm{R}$ with temperature are better illustrated when represented as a ratio to UCS, as shown in Figures 5.11a and 5.11b for chalk and limestone, respectively. This figure represents the reduction in $R$ values for the tested samples as temperature decreases. The relationship is stronger for limestone due to the stronger correlation between increased strength (Figure 5.2b) 


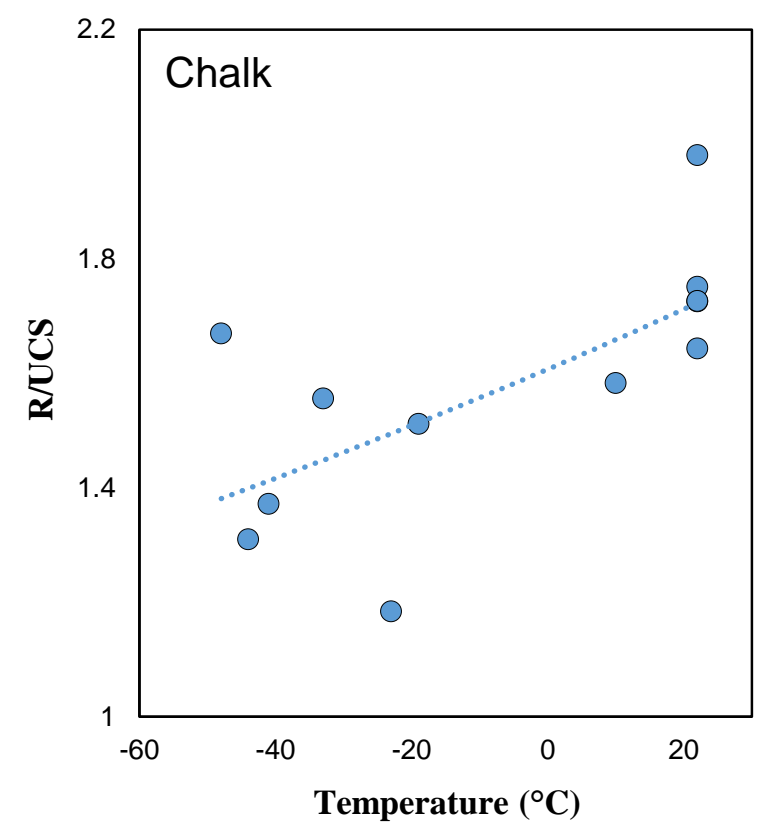

(a)

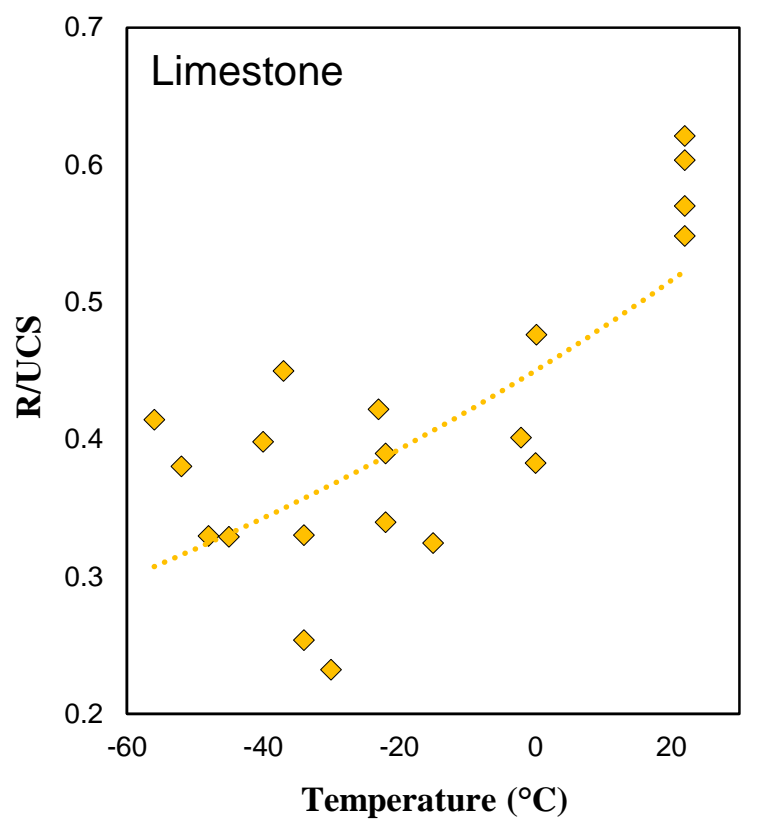

(b)

Figure 5.11: R/UCS as a function of Temperature for (a) Chalk and (b) Limestone

and $\mathrm{R}$ reduction at low-temperatures. The negative trends in Figure 5.11 as temperature decreases indicate that for chalk and limestone, low-temperature influences are more significant for UCS than for R.

The relationships between $\mathrm{R}$ and $\mathrm{E}$ for chalk and limestone with decreasing temperatures are summarized in Figure 5.12. The results from this analysis for chalk show that the ratio of $\mathrm{R}$ to $\mathrm{E}$ increases as temperature drops, as indicated by the data in Figure 5.12a. This signifies that for chalk, the change in $\mathrm{R}$ with temperature is more significant than this change in $\mathrm{E}$ as sample temperatures decrease.

For limestone, the trend in Figure 5.12b shows a significant decrease in the ratio of $\mathrm{R}$ to $\mathrm{E}$ as temperature decreases. Based on analysis of the trends of E/UCS and $\mathrm{R}$ with decreasing temperature for limestone (Figures $5.3 \mathrm{~b}$ and $5.5 \mathrm{~b}$, respectively), both $\mathrm{R}$ and E/UCS decrease as temperature decreases. The negative trend in the ratio of $\mathrm{R}$ to $\mathrm{E}$ for limestone as temperature decreases (Figure 5.12b) indicates that $\mathrm{E}$ is more heavily influenced by temperature than $\mathrm{R}$ for limestone.

The significance of UCS, E, VP, and R properties are summarized in Table 5.3 for chalk, limestone, and shale samples. The table shows measured property changes with low-temperature ordered by significance. These levels of significance were 


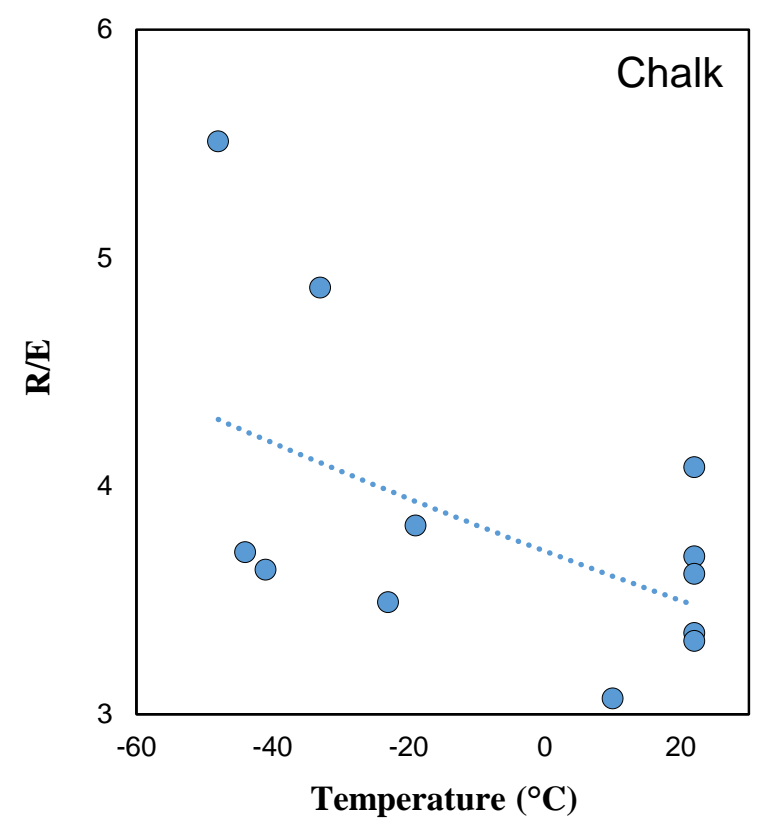

(a)

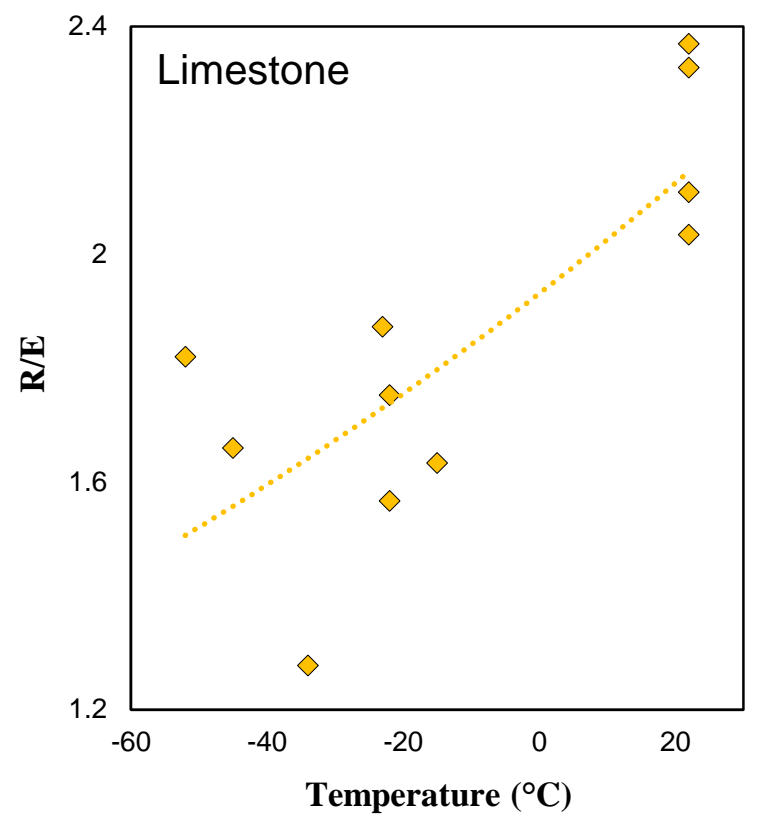

(b)

Figure 5.12: R/E as a function of Temperature for (a) Chalk and (b) Limestone

determined by the analyses in this section by analyzing how the ratios of these properties were influenced by low-temperature. A significance level of (1) implies the property is most-significantly affected by low-temperature, whereas a significance level of (4) implies the property is least affected by low-temperature.

Altogether, this analysis shows that for chalk and limestone, UCS is most-significantly influenced by low temperature. For chalk, E is the property influenced least by low-temperature, signifying that $R$ and $V_{P}$ changes are a result of UCS changes. For limestone, the order of significance for properties affected by low-temperature implies that $V_{P}$ changes are a result of changes in UCS, and R changes depend on changes in E. For shale, $\mathrm{E}$ is the property most affected by

Table 5.3: $\quad$ Significance for Property Changes due to Low-Temperatures

\begin{tabular}{|c|cccc}
\hline \hline \multirow{2}{*}{ Rock Type } & \multicolumn{4}{|c}{ Significance Level } \\
& $(4)$ & $(3)$ & $(2)$ & $(1)$ \\
\hline Chalk & $\mathrm{E}$ & $\mathrm{R}$ & $\mathrm{V}_{\mathrm{P}}$ & $\mathrm{UCS}$ \\
Limestone & $\mathrm{R}$ & $\mathrm{E}$ & $\mathrm{V}_{\mathrm{P}}$ & UCS \\
Shale & & $\mathrm{UCS}$ & $\mathrm{V}_{\mathrm{P}}$ & $\mathrm{E}$ \\
\hline
\end{tabular}

NOTE- (1): most significant; (4): least significant 
low-temperature, whereas UCS is the least significant. The order of significance for properties of shale samples as they change with temperature implies that $V_{P}$ changes with decreased temperatures are a result of changes in E.

\subsubsection{Influences of Rock Type}

Dissimilar trends in the influence of low-temperature on the mechanical and elastic properties of samples may be explained by sample mineralogy. Figure 5.13 displays how final $V_{P}$ (at various temperatures) correlates to UCS for the different rock types tested. Figure 5.14 shows the relationship between R and UCS for chalk and limestone at various temperature.

Chalk and limestone have similar mineral compositions and are primarily comprised of calcite minerals. Calcite minerals possess crystalline structures that are uniformly dispersed, leading to relatively evenly distributed pores in the rocks that they make up. As chalk and limestone samples are frozen, $V_{P}$ decreased, leading to the conclusion that pore space increases since the travel time of the ultrasonic signal increases. Understanding how freezing mechanisms influence calcite minerals

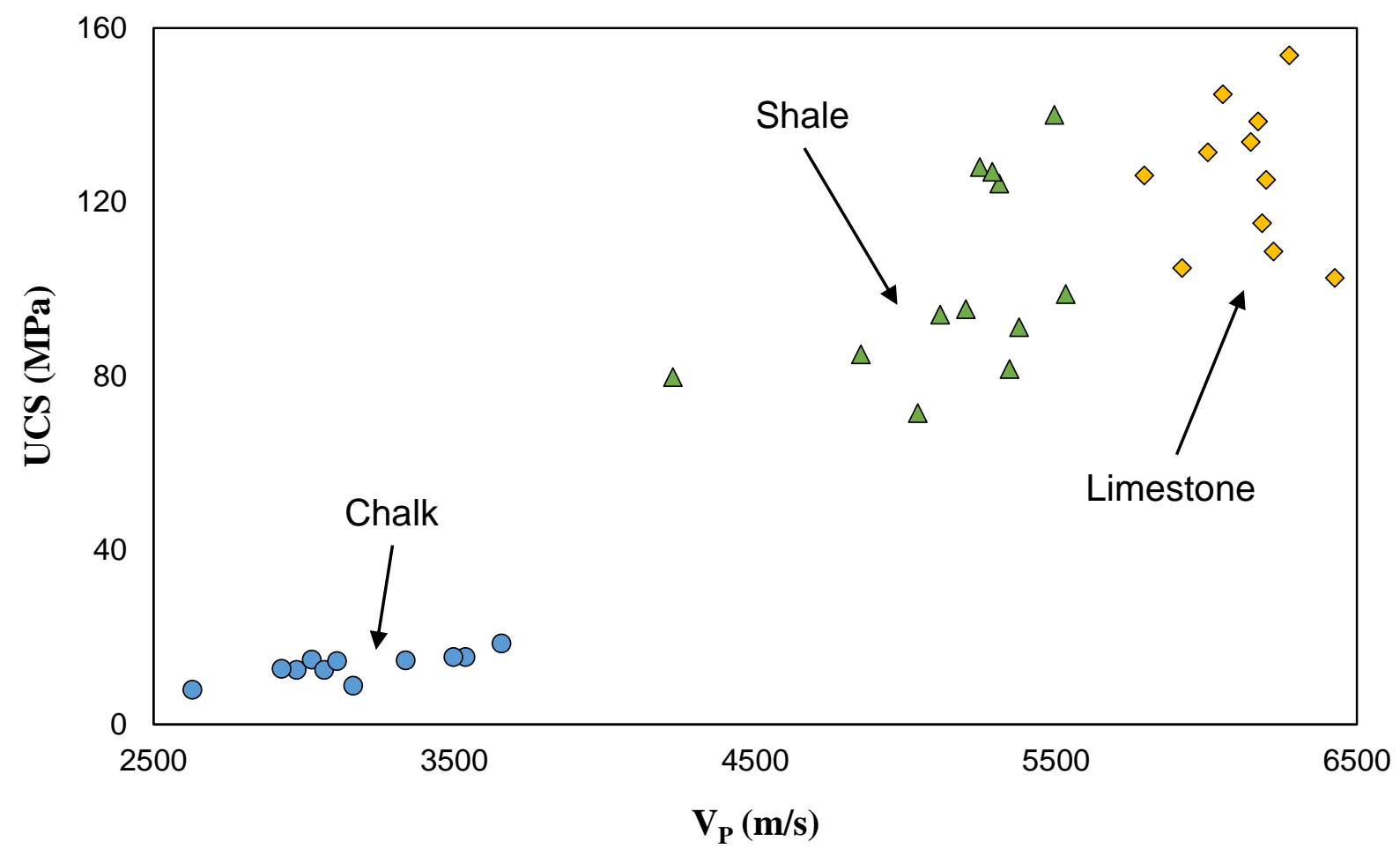

Figure 5.13: Correlation of Initial VP to UCS for Chalk, Limestone, and Shale 


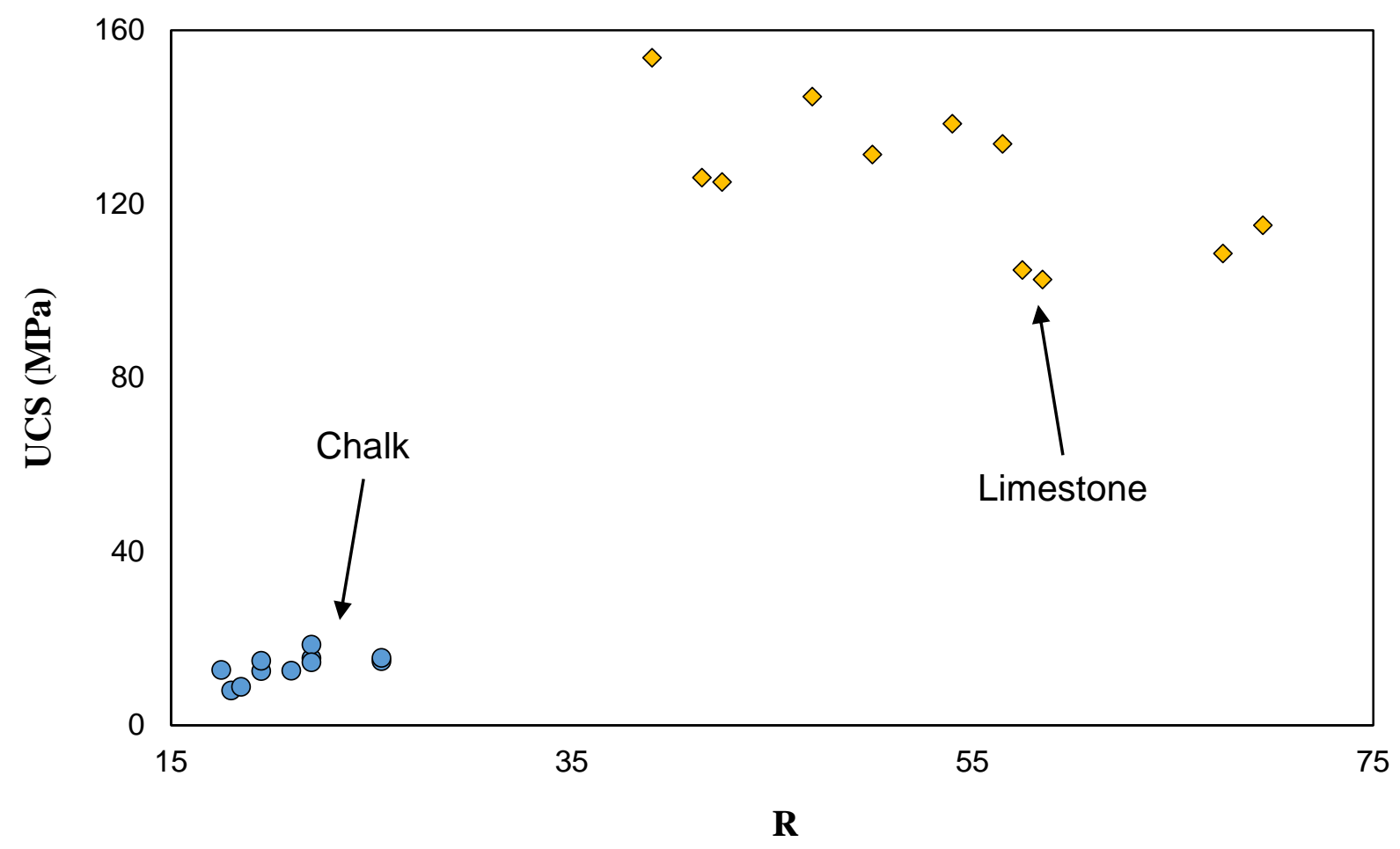

Figure 5.14: Correlation of R to UCS for Chalk and Limestone

or pores between the crystalline structures of calcite minerals may enable predictions to be made about how similarly-arranged minerals might behave under below-freezing conditions.

Shale, on the other hand, consists primarily of clay minerals. These minerals in shale tend to be laminated and create laminated or angular voids in the rock. The water content contained in the clay minerals of shale may serve as a possible explanation for the low-temperature affects witnessed. As shale samples are frozen, $V_{P}$ increases, leading to the conclusion that pore space must decrease to result in a faster signal travel time. The water content in the clay minerals may have caused expansion of the mineral clays upon freezing, leading to a reduction in the laminated voids within the sample. Freezing of angular voids may also contribute to the increase in brittle failure (reduction in E) and slightly reduced UCS as the partitioned layers in the shale become more angular and lead to shearing of layers.

One mechanisms behind the separation of correlations may be attributed to differences in elasticity of the rock samples. The Schmidt hammer rebound number is correspondingly dependent on Young's modulus of elasticity (Kidybinsky, 1967). 
The $R$ value represents the amount of impact energy not absorbed by plastic deformation that occurs under the piston tip of the hammer. For materials that are stiff and resistant to deformation (high $\mathrm{E}$ ), the material may resist plastic failure due to hammer impact, resulting in a high $R$ value, as a majority of the initial impact energy will be transmitted back through the hammer. Materials prone to deformation have low $\mathrm{E}$ values and are not likely to resist a hammer impact to a great degree, resulting in a low $R$ value as a majority of the initial impact is absorbed through the triggered deformation. 


\section{Chapter 6}

\section{Conclusions and Recommendations}

This paper has introduced the challenges associated with characterizing mechanical behavior of asteroid bodies by noting the influences of specific rock types on the destructive and nondestructive response properties of terrestrial tools. This study has also presented a procedure to analyze the effect of temperatures below $0^{\circ} \mathrm{C}$ on rock mechanical properties, as well as responses from SH and UPV testing. This procedure will help in technology development for extraterrestrial rock mechanics studies, particularly NASA's Asteroid Redirect Mission. While the current work is ongoing, four key conclusions are drawn:

1. A low-cost, safe laboratory procedure for cooling rock samples to specific temperatures was successfully developed. Data in this report confirm that cooling mixtures of specific temperatures can be generated from controlled mixtures of crushed dry ice slurried with varying concentrations of methanol solution. This procedure was capable of producing low-temperature rock samples $\left(-60^{\circ} \mathrm{C}\right.$ to $\left.0^{\circ} \mathrm{C}\right)$ in a reasonable time and at a fraction of the cost of similar procedures. Instructions for this procedure provide methods to maintain baths at low-temperature for at least 1.5 hours.

Theoretical cooling and warming models were prepared using conventional convection cooling principles and were verified experimentally to show that rock samples could effectively be cooled to temperatures down to $-60^{\circ} \mathrm{C}$, and could be tested 
for a short time ( 10 minutes $)$ without significant heat gain. Validation of these models confirmed that temperature differentials between the inside and surface of rock cores were negligible in the determination of bath soak time. Cooling models allowed for accurate prediction of soak times, while warming models under-predicted heat transfer rates. Insulation applied to the rock cores after removal from the baths allowed for testing to be completed within 10 minutes after bath removal without significant heat gain.

2. PL and UCS tests confirm that rock mechanical properties (i.e. PL estimated UCS, mechanically determined UCS, and E) do vary for temperatures lower than $0^{\circ} \mathrm{C}$. Generally, UCS increases slightly as temperature decreases for chalk and limestone. Significant increases in UCS with decreasing temperature were observed for limestone. UCS of chalk samples increased slightly with decreasing temperature, whereas those of shale samples decreased slightly as temperature decreased. While the causal mechanisms of this relationship have not been completely explored, the current data does indicate that a predictive correlation is possible. Investigation into prior studies of concrete and rock behavior at low-temperatures have shown increasing strength for samples at below-freezing temperatures, verifying that this relationship likely exists for samples used in this study, although testing and sample inconsistencies did not show these correlations as significantly as expected.

E was also found to be affected by exposure to low-temperature. For chalk and limestone samples, elasticity increased (E decreased) with decreasing temperature. For shale, material stiffness increased (E increased) as temperatures decreased.

Opposing trends for low-temperature effects on the mechanical properties (i.e. UCS and E) of chalk, limestone, and shale samples suggest that mineralogical or structural properties of samples may influence these properties are affected by low-temperature. This conclusion coincides with the disagreements revealed in low-temperature rock mechanics studies from literature.

3. Analysis of SH and UPV techniques and results from detailed low-temperature tests confirm that these NDTs are influenced by changes in temperature. Comparisons of the significances of property changes with temperature revealed that changes in NDT responses are a result of changes in UCS and E that occur during sample freezing. For samples whose E value increased with decreasing 
temperature (i.e. shale), $V_{P}$ also increased. For those samples that exhibited a reduction in $\mathrm{E}$ with decreasing temperature (i.e. chalk and limestone), both $\mathrm{V}_{\mathrm{P}}$ and $\mathrm{R}$ also decreased. Utilization of these techniques at different temperatures or conditions may allow for comparisons of elastic properties to be made

4. The samples used in this study cover a range of strengths expected for asteroids. The significance of changes in mechanical properties and NDT responses differed for each rock type. This result leads to the conclusion that in order to use the low-temperature influences revealed in this study to predict properties of low-temperature asteroid material, considerations of the asteroid's mineralogical and textural characteristics must be considered.

Recommendations for future work include expansion of the low-temperature method; continued research into low-temperature rock mechanics for materials of different strengths, textures, and mineralogy; and testing asteroid simulants that incorporate some of the pertinent, expected physical properties (e.g. grain size, cohesion, mineralogy) at low-temperature.

The low-temperature method may be expanded to include a theoretical development of mixtures based on chemical balances of the materials used. This would verify the methods to determine mixtures concentrations for methanol and dry ice developed in this study. Future low-temperature testing might incorporate testing in a controlled low-temperature environment so that no heat transfer can take place throughout testing. Testing in a cold environment would also ensure that NDTs were of the same temperature as rock samples during testing.

Rock mechanics and NDT studies at low-temperature should include various rock types with special attention to mineral contents, grain sizes, porosity and other factors that might influence how mechanical properties and responses to NDTs behave when exposed to low-temperatures. Additionally, more data beyond $-60^{\circ} \mathrm{C}$ and in-between room temperature and $0^{\circ} \mathrm{C}$ could enhance the results of this study.

Finally, since extreme low-strength terrestrial materials could not be obtained for this study, it is recommended that low-temperature tests be performed on simulated materials that are extremely low-strength and exhibit some of the mineralogical and textural properties speculated for asteroid bodies.

Altogether, this proposed work will allow for a deeper analysis of the factors 
influencing changes in mechanical properties and NDT responses for rock samples exposed to low-temperatures. Results from the proposed work will enable predictions to be made for the mechanical characterization of asteroid material from NDTs used in a low-temperature space environment. With these improvements, conclusions may be used to assist in the design of technology for the mechanical characterization of asteroid material. Low-temperature correction factors may be applied to NDTs to provide accurate mechanical characterization for asteroid materials. 


\section{Bibliography}

Abu Bakar, M.Z., Akram, M.; Khan, M.S., and Khan, M.U. (2013). A Study to Correlate Uniaxial Compressive Strength and Schmidt Hammer Rebound Number for Selected Rocks of Pakistan. Journal of the Pakistan Institute of Chemical Engineers, 41(1), 55-66.

Aggistalis, G., Alivizatos, A., Stamoulis, D., \& Stournaras, G. (1980). Correlating uniaxial compressive strength with Schmidt hardness, point load index, Young's modulus, and mineralogy of gabbros and basalts (Northern Greece). Bulletin of the International Association of Engineering Geology-Bulletin de l'Association Internationale de Géologie de l'Ingénieur, 22(1), 3-11.

Alí-Lagoa, V., Lionni, L., Delbo, M., Gundlach, B., Blum, J., \& Licandro, J. (2014). Thermophysical properties of near-Earth asteroid (341843) 2008 EV5 from WISE data. Astronomy \& Astrophysics, 561, A45.

ASTM Standard D2845. (2008). Standard test method for laboratory determination of pulse velocities and ultrasonic elastic constants of rock. ASTM International, West Conshohocken, PA, doi: 10.1520/D2845-08, www.astm.org.

ASTM Standard D5731. (2008). Standard test method for determination of point load strength index of rock and application to rock strength classifications. ASTM International, West Conshohocken, PA, doi: 10.1520/D5731873-08, www.astm.org.

ASTM Standard D5873. (2014). Standard test method for determination of rock hardness by rebound hammer method. ASTM International, West Conshohocken, PA, doi: 10.1520/D5873-14, www.astm.org. 
ASTM Standard D5873. (2000). Standard test method for determination of rock hardness by rebound hammer method. ASTM International, West Conshohocken, PA, doi: 10.1520/D5873-00, www.astm.org.

ASTM Standard D7012. (2014). Standard test method for compressive strength and elastic moduli of intact rock core specimens under varying states of stress and temperatures. ASTM International, West Conshohocken, PA, doi: 10.1520/D7012-14, www.astm.org.

Aydin, A. (2013). Upgraded ISRM Suggested Method for Determining Sound Velocity by Ultrasonic Pulse Transmission Technique. In The ISRM Suggested Methods for Rock Characterization, Testing and Monitoring: 2007-2014, (pp. 95-99). Springer International Publishing.

Aydin, A. (2008). ISRM suggested method for determination of the Schmidt hammer rebound hardness: revised version. In The ISRM Suggested Methods for Rock Characterization, Testing and Monitoring: 2007-2014, (pp. 25-33). Springer International Publishing.

Aydin, A., \& Basu, A. (2005). The Schmidt hammer in rock material characterization. Engineering Geology, 81(1), 1-14.

Boetcher, S. K. (2014). Natural convection from circular cylinders (SpringerBriefs in Applied Sciences and Technology) [PDF]. Springer. doi: 10.1007/978-3-31908132-8

Buddhue, J. D. (1942). The compressive strength of meteorites. Contributions of the Society for Research on Meteorites, 3(8), 39-40.

Busch, M. W., Barucci, M. A., Benner, L. A. M., Scheeres, D. J., \& Giorgini, J. D. (2013). Near-Earth asteroid 341841 (2008 EV5), target of ESA's Marcopolo-R mission. In $64^{\text {th }}$ International Astronautical Congress. International Astronautical Federation.

Busch, M. W., Ostro, S. J., Benner, L. A., Brozovic, M., Giorgini, J. D., Jao, J. S., ... \& Taylor, P. A. (2011). Radar observations and the shape of near-Earth asteroid 2008 EV5. Icarus, 212(2), 649-660.

Cargill, J. S., \& Shakoor, A. (1990, December). Evaluation of empirical methods for measuring the uniaxial compressive strength of rock. In International Journal of Rock Mechanics and Mining Sciences \& Geomechanics Abstracts (Vol. 27, No. 6, pp. 495-503). Pergamon. 
Cheng, K. C. (2009). Some observations on the origins of newton's law of cooling and its influences on thermofluid science [Review of the book Newtonian Mechanics (1971) by A. P. French]. Applied Mechanics Reviews, 62(6): 060803-060803-17.

Chesley, S. R., Farnocchia, D., Nolan, M. C., Vokrouhlický, D., Chodas, P. W., Milani, A., ... \& Busch, M. W. (2014). Orbit and bulk density of the OSIRIS-REx target Asteroid (101955) Bennu. Icarus, 235, 5-22.

Choi, C. Q. (2014, November 21). Asteroids: fun facts and information about asteroids. Space.com

Clark, B. E., Ziffer, J., Nesvorny, D., Campins, H., Rivkin, A. S., Hiroi, T., ... \& DeMeo, F. (2010). Spectroscopy of B-type asteroids: Subgroups and meteorite analogs. Journal of Geophysical Research: Planets, 115(E6).

Çobanoğlu, İ. \& Çelik, S.B. (2008). Estimation of uniaxial compressive strength from point load strength, Schmidt hardness and P-wave velocity. Bulletin of Engineering Geology and the Environment, 674), 491-498.

Coradini, A., Capaccioni, F., Erard, S., Arnold, G., De Sanctis, M. C., Filacchione, G., ... \& Grassi, D. (2011). The surface composition and temperature of asteroid 21 Lutetia as observed by Rosetta/VIRTIS. Science, 334(6055), 492-494.

Dahmani, L., Khenane, A., \& Kaci, S. (2007). Behavior of the reinforced concrete at cryogenic temperatures. Cryogenics, 479), 517-525.

Deere, D.U. \& Miller, R.P. (1966). Engineering classification and index properties for intact rock. (Technical Report No. AFWL-TR-65-116). New Mexico: Air Force Weapons Laboratory.

Dinçer, I., Acar, A., Çobanoğlu, I., \& Uras, Y. (2004).Correlation between Schmidt hardness, uniaxial compressive strength and Young's modulus for andesites, basalts and tuffs. Bulletin of Engineering Geology and the Environment, 63(2), 141-148.

Egydio-Silva, M., Vauchez, A., Bascou, J., \& Hippertt, J. (2002). High-temperature deformation in the Neoproterozoic transpressional Ribeira belt, southeast Brazil. Tectonophysics, 352(1), 203-224.

Emery, J. P., Fernández, Y. R., Kelley, M. S. P., Warden, K. T., Hergenrother, C., Lauretta, D. S., ... \& Ziffer, J. (2014). Thermal infrared observations and thermophysical characterization of OSIRIS-REx target asteroid (101955) 
Bennu. Icarus, 234, 17-35.

Eppelbaum, L., Kutasov, I., \& Pilchin, A. (2014). Thermal properties of rocks and density of fluids (pp. 99-149). Springer Berlin Heidelberg.

Fener, M., Kahraman, S., Bilgil, A., \& Gunaydin, O. (2005). A comparative evaluation of indirect methods to estimate the compressive strength of rocks. Rock Mechanics and Rock Engineering, 38(4), 329-343.

Fujiwara, A., Kawaguchi, J., Yeomans, D. K., Abe, M., Mukai, T., Okada, T., ... \& Barnouin-Jha, O. (2006). The rubble-pile asteroid Itokawa as observed by Hayabusa. Science, 312(5778), 1330-1334.

Gaffey, M. J., Bell, J. F., Brown, R. H., Burbine, T. H., Piatek, J. L., Reed, K. L., \& Chaky, D. A. (1993). Mineralogical variations within the S-type asteroid class. Icarus, 106(2), 573-602.

Gebhardt, C. (2016, March 16). NASA into deep planning for Asteroid Redirect Mission. NASA SpaceFlight. Retrieved from https://www.nasaspaceflight.com/2016/03/nasa-deep-planning-asteroidredirect-mission/

Ghose, A.K., \& Chakraborti, S. (1986, January). Empirical strength indices of Indian coals- an investigation. In The 27th US Symposium on Rock Mechanics (USRMS). American Rock Mechanics Association.

Gordon, R. B. (1970). Mechanical properties of iron meteorites and the structure of their parent planets. Journal of Geophysical Research, 75(2), 439-447.

Hall, K., Thorn, C. E., Matsuoka, N., \& Prick, A. (2002). Weathering in cold regions: some thoughts and perspectives. Progress in Physical Geography, 26(4), 577-603.

Hand, E. (2015, March 25). NASA opts for boulder-snatch concept in its asteroid redirect mission. Science. doi: 10.1126/science.aab0376.

Haramy, K.Y., \& DeMarco, M.J. (1985, January). Use of the Schmidt hammer for rock and coal testing. In The 26th US Symposium on Rock Mechanics (USRMS). American Rock Mechanics Association.

Hasegawa, S., MüLler, T. G., Kawakami, K., Kasuga, T., Wada, T., Ita, Y., ... \& Abe, M. (2008). Albedo, size, and surface characteristics of Hayabusa-2 sample- 
return target $162173 \quad 1999$ JU3 from AKARI and Subaru observations. Publications of the Astronomical Society of Japan, 60(sp2), S399S405.

Heins, R. W., \& Friz, T. O. (1967, January). The effect of low-temperature on some physical properties of rock. In Drilling and Rock Mechanics Conference. Society of Petroleum Engineers.

Holsapple, Keith A. (2009). On the "strength" of the small bodies of the solar system: A review of strength theories and their implementation for analyses of impact disruptions. Planetary and Space Science, 57(2), 127-141.

Housen, K. R., \& Holsapple, K. A. (1990). On the fragmentation of asteroids and planetary satellites. Icarus, 84(1), 226-253.

Huš, M., Žakelj, G., \& Urbič, T. (2015). Properties of Methanol-Water Mixtures in a Coarse-Grained Model. Acta Chimica Slovenica, 62(3), 524-530.

Kahraman, S. (2001). Evaluation of simple methods for assessing the uniaxial compressive strength of rock. International Journal of Rock Mechanics and Mining Sciences, 38(7), 981-994.

Kahraman, S., \& Gunaydin, O. (2009). The effect of rock classes on the relation between uniaxial compressive strength and point load index. Bulletin of engineering geology and the environment, 68(3), 345-353.

Karakul, H., \& Ulusay, R. (2013). Empirical correlations for predicting strength properties of rocks from P-wave velocity under different degrees of saturation. Rock mechanics and rock engineering, 46(5), 981-999.

Karaman, K., \& Kesimal, A. (2015). A comparative study of Schmidt hammer test methods for estimating the uniaxial compressive strength of rocks. Bulletin of Engineering Geology and the Environment, 74(2), 507-520.

Katz, O., Reches, Z., \& Roegiers, J. C. (2000). Evaluation of mechanical rock properties using a Schmidt Hammer. International Journal of Rock Mechanics and Mining Sciences, 374), 723-728.

Kılıç, A., \& Teymen, A. (2008). Determination of mechanical properties of rocks using simple methods. Bulletin of Engineering Geology and the Environment, 67(2), 237-244. 
Ledgard, J. B. (2007) Familiarization with laboratory techniques. In The preparatory manual of explosives, third edition (pp. 16-36). Jared B. Ledgard.

Mathews, E. B., \& Grasty, J. S. (1910). The limestones of Maryland: with special reference to their use in the manufacture of lime and cement (Vol. 8). Johns Hopkins Press.

Mellor, M. (1971). Strength and deformability of rocks at low-temperatures, Hanover, $\mathrm{NH}$, Cold Regions Research and Engineering Laboratory (CRREL). US Army Corps of Engineers, Research Report, 294.

Minaeian, B. \& Ahangari, K. (2013). Estimation of uniaxial compressive strength based on P-wave and Schmidt hammer rebound using statistical method. Arabian Journal of Geosciences, 6(6), 1925-1931.

Müller, T. G., Ďurech, J., Hasegawa, S., Abe, M., Kawakami, K., Kasuga, T., ... \& Sarugaku, Y. (2011). Thermo-physical properties of 162173 (1999 JU3), a potential flyby and rendezvous target for interplanetary missions. Astronomy \& Astrophysics, 525, A145.

Müller, T. G., O’Rourke, L., Barucci, A. M., Pál, A., Kiss, C., Zeidler, P., ... \& Küppers, M. (2012). Physical properties of OSIRIS-REx target asteroid (101955) 1999 RQ36-Derived from Herschel, VLT/VISIR, and Spitzer observations. Astronomy \& Astrophysics, 548, A36.

Müller, T. G., Sekiguchi, T., Kaasalainen, M., Abe, M., \& Hasegawa, S. (2005). Thermal infrared observations of the Hayabusa spacecraft target asteroid 25143 Itokawa. Astronomy \& Astrophysics, 443(1), 347-355.

Nakamura, T., Noguchi, T., Tanaka, M., Zolensky, M. E., Kimura, M., Tsuchiyama, A., ... \& Yada, T. (2011). Itokawa dust particles: a direct link between S-type asteroids and ordinary chondrites. Science, 333(6046), 1113-1116.

NASA Jet Propulsion Laboratory. JPL Small-Body Database Browser. Retrieved from http://ssd.jpl.nasa.gov/sbdb.cgi

NASA - Marshall Space Flight Center. Small Worlds - The Neighborhood. Retrieved from http://discovery.nasa.gov/SmallWorlds/mars2.cfml

Nazir, R., Momeni, E., Jahed Armaghani, D., \& Mohd Amin, M.F. (2013). Prediction of unconfined compressive strength of limestone rock samples using L-type Schmidt hammer. Electronic Journal of Geotechnical Engineering, 18, 
1767-1775.

Negus, M. T., \& Bergstedt, R. A. (2012). Rates of intraperitoneal temperature change in lake trout implanted with archival tags. Transactions of the American Fisheries Society, 141(2), 383-391.

Nolan, M. C., Magri, C., Howell, E. S., Benner, L. A., Giorgini, J. D., Hergenrother, C. W., ... \& Scheeres, D. J. (2013). Shape model and surface properties of the OSIRIS-REx target Asteroid (101955) Bennu from radar and lightcurve observations. Icarus, 226(1), 629-640.

O'Rourke, J.E. (1989). Rock index properties for geoengineering in underground development. Min. Eng. (Littleton, Colo.); (United States), 41(2).

Park, C., Synn, J. H., Shin, H. S., Cheon, D. S., Lim, H. D., \& Jeon, S. W. (2004). An experimental study on the thermal characteristics of rock at low-temperatures. International Journal of Rock Mechanics and Mining Sciences, 41(3), 367-368.

Paterson, M. S. (1970, September). A high-pressure, high-temperature apparatus for rock deformation. In International Journal of Rock Mechanics and Mining Sciences \& Geomechanics Abstracts (Vol. 7, No. 5, pp. 517-526). Pergamon.

Peng, S., \& Zhang, J. (2007). Rock properties and mechanical behaviors. Engineering Geology for Underground Rocks, 1-26.

Petrovic, J. J. (2001). Review mechanical properties of meteorites and their constituents. Journal of Materials Science, 36(7), 1579-1583.

Popova, O., Borovicka, J., Hartmann, W. K., Spurný, P., Gnos, E., Nemtchinov, I., \& Trigo-Rodríguez, J. M. (2011). Very low strengths of interplanetary meteoroids and small asteroids. Meteoritics and Planetary Science, 46, 1525-1550.

Reddy, V., Le Corre, L., Hicks, M., Lawrence, K., Buratti, B. J., Abell, P. A., ... \& Hardersen, P. S. (2012). Composition of near-Earth Asteroid 2008 EV5: Potential target for robotic and human exploration. Icarus, 221(2), 678-681.

Roper, E. E. (1938). The freezing point of methanol; A simple type of cryostat applicable to freezing point Ddterminations. Journal of the American Chemical Society, 60(7), 1693-1695.

Sachpazis, C.I. (1990). Correlating Schmidt hardness with compressive strength and 
Young's modulus of carbonate rocks. Bulletin of the International Association of Engineering Geology-Bulletin de l'Association Internationale de Géologie de l'ingénieur, 42(1), 75-83.

Shalabi, F.I., Cording, E.J., \& Al-Hattamleh, O.H. (2007). Estimation of rock engineering properties using hardness tests. Engineering Geology, 90(3), 138-147.

Sheorey, P.R., Barat, D., Das, M.N., Mukherjee, K.P., \& Singh, B. (1984, February). Schmidt hammer rebound data for estimation of large scale in situ coal strength. In International Journal of Rock Mechanics and Mining Sciences \& Geomechanics Abstracts (Vol. 21, No. 1, pp. 39-42). Pergamon.

Singh, R.N., Hassani, F.P., \& Elkington, P.A.S. (1983, January). The application of strength and deformation index testing to the stability assessment of coal measures excavations. In The 24th US Symposium on Rock Mechanics (USRMS). American Rock Mechanics Association.

Tedesco, E. F., Noah, P. V., Noah, M., \& Price, S. D. (2002). The supplemental IRAS minor planet survey. The Astronomical Journal, 123(2), 1056.

Tian, H., Kempka, T., Yu, S., \& Ziegler, M. (2016). Mechanical Properties of Sandstones Exposed to High Temperature. Rock Mechanics and Rock Engineering, 49(1), 321-327.

Torabi, S.R., Ataei, M., \& Javanshir, M. (2011). Application of Schmidt rebound number for estimating rock strength under specific geological conditions. Journal of Mining and Environment.

Tuğrul, A., \& Zarif, I.H. (1999). Correlation of mineralogical and textural characteristics with engineering properties of selected granitic rocks from Turkey. Engineering Geology, 51(4), 303-317.

Tullis, J. A. (1979). High temperature deformation of rocks and minerals.Reviews of Geophysics, 17(6), 1137-1154.

Xu, S., Grasso, P., \& Mahtab, A. (1990, August). Use of Schmidt hammer for estimating mechanical properties of weak rock. In 6th international IAEG congress. Balkema, Rotterdam, (pp. 511-519).

Ulusay, R. (2015). The Present and Future of Rock Testing: Highlighting the ISRM Suggested Methods. In The ISRM Suggested Methods for Rock 
Characterization, Testing and Monitoring: 2007-2014 (pp. 1-22). Springer International Publishing

Vasconcelos, G., Lourenço, P.B., Alves, C.A., \& Pamplona, J. (2007). Prediction of the mechanical properties of granites by ultrasonic pulse velocity and Schmidt hammer hardness. In Tenth North American Masonry Conference.

Vilas, F. (2008). Spectral characteristics of Hayabusa 2 near-Earth asteroid targets 1621731999 JU3 and 2001 QC34. The Astronomical Journal, 135(4), 1101.

Warren, P. H. (2001). Porosities of lunar meteorites: Strength, porosity, and petrologic screening during the meteorite delivery process. Journal of Geophysical Research, 106, 10101-10112.

Wittke, W. (2014). Rock mechanics based on an anisotropic jointed rock model (AJRM). John Wiley \& Sons.

Yagiz, S. (2009). Predicting uniaxial compressive strength, modulus of elasticity and index properties of rocks using the Schmidt hammer. Bulletin of Engineering Geology and the Environment, 68(1), 55-63.

Yaşar, E., \& Erdoğan, Y. (2004). Estimation of rock physicomechanical properties using hardness methods. Engineering Geology, 71(3), 281-288.

Yılmaz, I., \& Sendır, H. (2002). Correlation of Schmidt hardness with unconfined compressive strength and Young's modulus in gypsum from Sivas (Turkey). Engineering Geology, 66(3), 211-219.

Yurdakul, M., Ceylan, H., \& Akdas, H. (2011). A predictive model for uniaxial compressive strength of carbonate rocks from Schmidt hardness. In Civil Construction and Environmental Engineering Conference presentations and Proceedings. 